\title{
WestVirginiaUniversity
}

THE RESEARCH REPOSITORY @ WVU

Graduate Theses, Dissertations, and Problem Reports

2000

\section{Prognostic factors for treatment outcome in young children with autism}

Susannah Grimm Poe

West Virginia University

Follow this and additional works at: https://researchrepository.wvu.edu/etd

\section{Recommended Citation}

Poe, Susannah Grimm, "Prognostic factors for treatment outcome in young children with autism" (2000). Graduate Theses, Dissertations, and Problem Reports. 2327.

https://researchrepository.wvu.edu/etd/2327

This Dissertation is protected by copyright and/or related rights. It has been brought to you by the The Research Repository @ WVU with permission from the rights-holder(s). You are free to use this Dissertation in any way that is permitted by the copyright and related rights legislation that applies to your use. For other uses you must obtain permission from the rights-holder(s) directly, unless additional rights are indicated by a Creative Commons license in the record and/ or on the work itself. This Dissertation has been accepted for inclusion in WVU Graduate Theses, Dissertations, and Problem Reports collection by an authorized administrator of The Research Repository @ WVU.

For more information, please contact researchrepository@mail.wvu.edu. 


\title{
Prognostic Factors for Treatment Outcome In Young Children with Autism
}

\author{
Susannah Grimm Poe \\ Dissertation submitted to the \\ College of Human Resources and Education \\ West Virginia University \\ in partial fulfillment of the requirements for the \\ degree of \\ Doctor of Education \\ in \\ Educational Psychology \\ Dan Hursh, Ph.D., chair \\ Anne Nardi, Ph.D. \\ Julie Vargas, Ph.D. \\ Kevin Larkin, Ph.D. \\ Don Kincaid, Ed.D. \\ Carol Parke, Ph.D. \\ Department of Advanced Educational Studies \\ Morgantown, West Virginia \\ 2000
}

Keywords: Autism, Autism Treatment, Prognosis in Autism, Applied Behavior Analysis 


\section{Abstract \\ Prognostic Factors for Treatment Outcome \\ In Young Children with Autism}

\section{Susannah Grimm Poe}

Over the past decade, systematic applications of Applied Behavior Analysis (ABA) have proven an effective means of improving the prognosis for many young children with autism. But in every study indicating that a number of participants have experienced good outcomes from these interventions, there remain a sizeable number of participants who have not had the same success. This study was undertaken to examine the differences between the parental rankings for each of eight characteristics across three points in time for children with autism to determine who succeeds with this kind of treatment and who does not. These parental reports were also examined to determine which rankings, if any, of these characteristics at the time of diagnosis might predict a positive outcome. Participants were recruited through four different Internet listserves dedicated to the use of ABA interventions with young children with autism. Eighty five respondents, all parents of young children with autism, answered a 50 question survey that included, among other questions, a ranking of their child's ability in speech, social attachment, toy play, sensory problems, peer play, tantruming, self-stimulation, and toilet training, across three points in time: at diagnosis, when treatment ended, and when the survey was completed. The results of this study showed, like many before it, that most young children with autism will improve in their functioning, at least in these characteristics, after at least one year of discrete trial training, a method of ABA. In this study, the children not only improved overall based on the comparison of characteristics ranks across time, but they also showed increases in the sums of all eight of the characteristic variables. These results also indicated that, of the eight variables, the ranking for speech increased the most for most children, followed by toilet training and toy play. For the larger group, those that had not yet completed discrete trial training, no one variable, or groups of variables within the eight characteristics, were found to significantly contribute to the outcome (recovery score) more than the others. For the group that had completed treatment $(n=29)$, one variable, toy play, was negatively correlated with a positive outcome from treatment. 


\section{Acknowledgements}

Thanks to...

the many parents who took the time to complete this survey and whose support and good wishes made this research a labor of love,

the families who have invited me into their lives and trusted me as a partner in their attempts to improve their child's outcome from autism, and

the children, who remain my most challenging teachers.

With gratitude to Don Kincaid, who gave me an opportunity to practice in the field of autism treatment and who encouraged me to broaden my understanding of appropriate intervention.

I am especially grateful to Dan Hursh for his calm and confident encouragement and for his quick responses to my endless questions--no matter where he was in the world. It has been a pleasure.

\section{Dedication}

For Steven, who always holds the ladder steady. 


\section{Table of Contents}

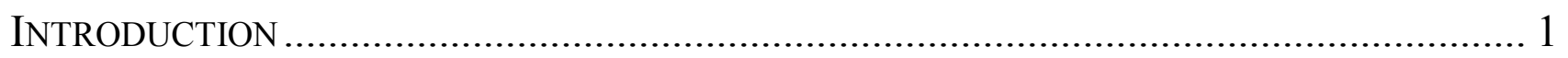

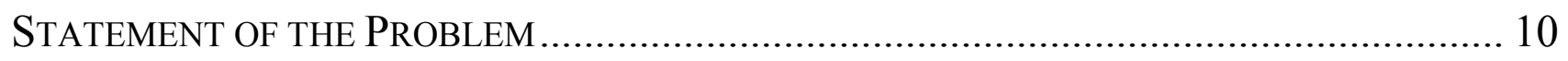

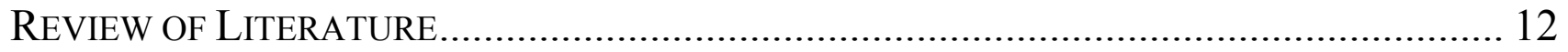

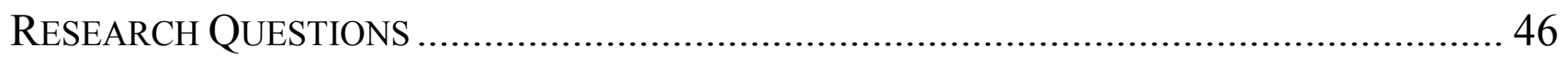

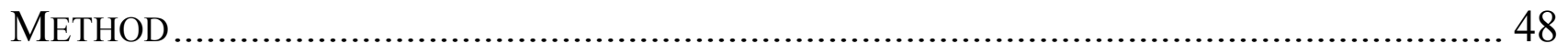

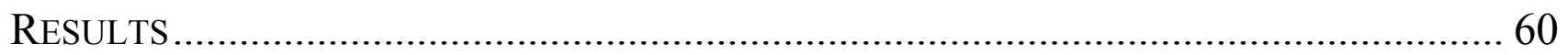

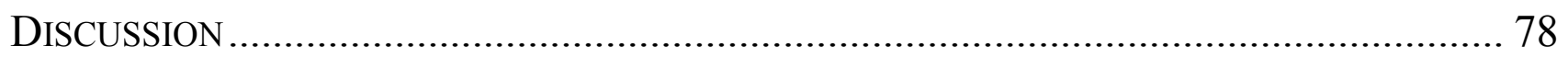

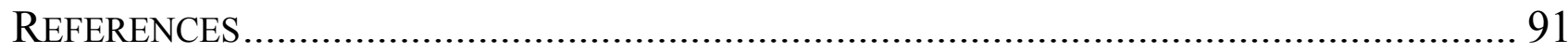

APPENDIX A:

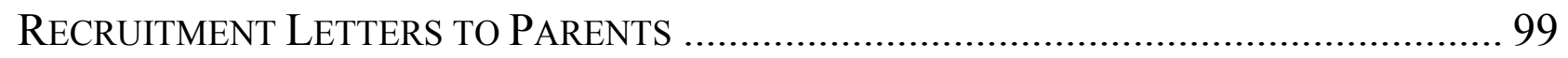

APPENDIX B:

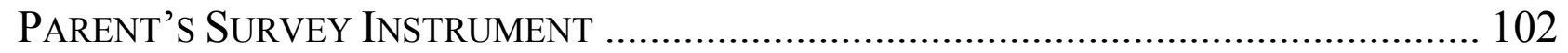

APPENDIX C:

RESEARCH/ REPORTS On PROGNOSIS OF OUtCOME FROM AutiSM........................... 120

APPENDIX D:

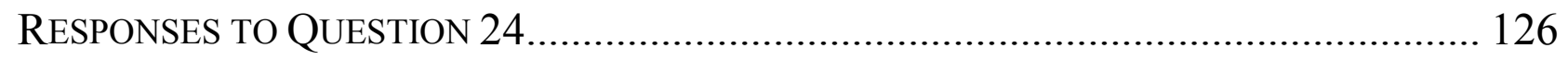

APPENDIX E:

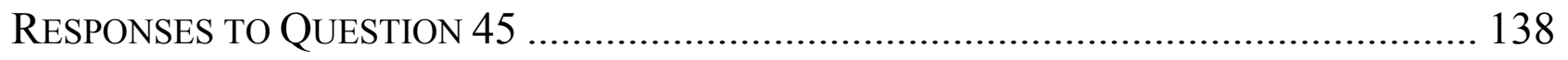

APPENDIX F:

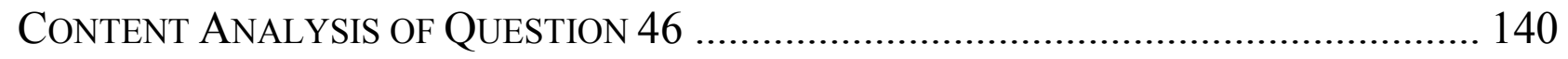




\section{List of Tables}

TABLE 1:

VARIABLES USED IN EACH RESEARCH QUESTION

TABLE 2:

Median Characteristics Scores Across Two PoInTs In TIME

FOR THE Group Who HAD Not Yet COMPLETED TREATMENT

TABLE 3:

BOXPLOT ILLUSTRATION OF VARIABILITY AMONG CHARACTERISTICS

AT TIME OF DIAGNOSIS 64

TABLE 4:

Correlation BetweEn EIght CHARACTERISTICS BeFore

TREATMENT AND THE RECOVERY SCORE 66

TABLE 5:

Median Characteristics Scores ACROSS Three PoInTs In Time FOR THE GROUP WHO HAD COMPLETED TREATMENT 67

TABLE 6:

MEANS FOR ANOVA FOR EACH GROUP FOR SUB QUESTION C 69

TABLE 7:

MEANS FOR ANOVA FOR EACH GROUP FOR SUB QUESTION D 70

TABLE 8:

LiSTING OF ADDITIONAL TREATMENTS, PARENT's IMPRESSION OF OUTCOME. 72

TABLE 9:

DiffERENCES IN IQ/Functional Skills Before AND AfTER TREATMENT. 75

TABLE 10:

COMPARISON AMONG SOME CHARACTERISTICS OF RECOVERED AND LOWEST SCORING CHILDREN 76 


\section{Introduction}

In 1938, child psychiatrist Leo Kanner observed a number of children whose unusual characteristics and clinical presentation appeared to comprise a psychotic illness not yet described in any literature (Kanner \& Lesser, 1958). For the next five years, Kanner, who was the director of the Child Psychiatry clinic at Johns Hopkins, studied eleven such children in detail, and his findings were published in 1943 under the title of "Autistic Disturbances of Affective Contact." In this seminal account he noted a variety of behavioral features that both characterized all eleven children but that also differentiated them from those with other psychiatric illnesses. Those behavioral features included an inability to develop relationships; a delay in acquiring speech and, if speech did develop, continuing problems with echolalia, pronoun reversal, and fluency; repetitive and stereotyped play activities; an obsessive insistence on sameness; a seeming unawareness of other people; an inability to play imaginatively with toys or with other children; a lack of imagination; good rote memory; and a normal physical appearance (Kanner, 1943; Rutter, 1979; Wing, 1976). What made the disorder different from all previously described varieties of childhood psychosis was that these abnormalities were evident in infancy.

The term "autism" had already been introduced to the mental health community in 1906 by Swiss psychiatrist Eugene Bleuler to describe the thought processes of patients diagnosed as having dementia praecox, a diagnosis he later relabeled schizophrenia. For Bleuler, "autism" was an active withdrawal from reality in order to live in an inner world of fantasy (Wing, 1976). Kanner, though, who singled out the characteristic of aloneness and used the term "autistic" to describe this group of children, meant this word in the opposite way from Bleuler. To Kanner, a child with autism could not imagine a fantasy world and experienced no withdrawal--he believed 
the autistic child had failed to make a relationship in the first place. However, the result of the use of the same word to describe two different conditions was that, for years, autism was thought to be an early manifestation of schizophrenia.

The confusion continued over the next several decades. Different clinicians and researchers diagnosed these children according to the specific aspects of the disease that they thought were most important (Ritvo, 1976). In addition to those who believed that autism was an early manifestation of schizophrenia, there were some who felt that it was a symbiotic psychosis, a result of mother-child pathology; and others who believed these children had atypical ego development based on the psychoanalytic approach. During the 1940's and 1950's, clinical centers were set up by advocates of each of these positions, and children were diagnosed and treated from that clinic's particular point of view. Treatments varied from individual psychoanalysis of the patient to concurrent treatment of the mother and child, institutionalization of the patient with no family contact allowed, electroshock treatments, psychotropic drugs, special education approaches, megavitamin therapies, and sensory deprivation (Ritvo, 1976).

None of the treatments from any of these approaches passed the test of time; none were found to alter the course of the syndrome or offer solid evidence to support the theoretical positions from which it evolved (Ritvo, 1976).

By 1964, Bernard Rimland, psychologist and father of a child with autism, lamented that "two decades had passed since Kanner published his classic paper describing the paradoxical and bewildering disturbance of behavior in children which he called 'early infantile autism'...Despite the voluminous literature that has developed, the origin of this disease is as much a mystery today as it was twenty years ago. There is no known cause, and no known cure." Still today, there is no known cause and no known cure for autism. As it was more than 
half a century ago, autism is still behaviorally defined. There are no physical tests that can confirm the diagnosis, only observation and assessments based on the patterns of behavior Kanner outlined in 1943.

Those patterns of behaviors are detailed in the DSM-IV (American Psychiatric Association, 1994) criteria for the diagnosis of autism. Generally speaking, a child must have delays in speech and language, abnormal ways of relating to people or objects, ritualistic or repetitive behaviors, and a history of developmental delay before age three to be considered autistic.

What has changed over the years, specifically since the publication of Rimland's Infantile Autism in 1964, was the understanding that autism is the result of a neurological disorder that affects functioning of the brain. It is not, as once considered by Kanner and other well-known mental health professionals of the mid twentieth century, to be a child's response to inadequate parenting, to "refrigerator parents... who defrost long enough to produce a child" (p. 26). Current studies show evidence of functional and structural abnormalities in several brain regions in persons with autism, including the amygdala, hippocampus, septum, mammillary bodies, and the cerebellum, according to Marie Bristol, Ph.D., of the National Institute of Mental Health (Contemporary Forms, 1996).

While researchers now know autism is a disorder of the brain, just how these abnormalities occur is not yet known. Researchers are making use of today's sophisticated medical and technological advancements to uncover autism's genetic, metabolic, and molecular pathways. The disorder is thought to run in families, and gene mapping has pinpointed several likely sites for autism genes - as many as a dozen--and some researchers believe different genes may be responsible for different manifestations within the autism spectrum. (Shute, 2000). 
Comparisons between autism and the birth defects caused by the drug thalidomide suggest the possibility that a brain insult may lead to autism as early as 20 days in utero. Other researchers believe the disturbance in brain development happens in the third trimester of pregnancy or even after birth, when a normally developing brain is wiring new connections and getting rid of those that are not needed. In early May of 2000, researchers at the National Institute of Mental Health reported that they had found elevated levels of key brain proteins in newborns who later developed autism, raising hopes that there would soon be a biological marker for autism making identification and treatment possible earlier than the three years that is now the average age of diagnosis (Shute, 2000).

The autistic spectrum disorders are not now considered rare, as once thought. Rimland (1964) wrote in the general introduction to Infantile Autism that Kanner, who was reported to have seen over 20,000 disturbed children in his career, had seen only 150 cases of autism. Today, autism is more prevalent in the pediatric population than childhood cancer, diabetes, spina bifida, and Down Syndrome. Autism and its behavioral symptoms occur in approximately one in every 500 births (Filipek, Accardo, Baranek, Cook, Dawson, Gordon, Gravel, Johnson, Kallen, Levy, Minshew, Prizant, Rapin, Rogers, Stone, Teplin, Tuchman, \& Volkmar, 1999) in the U.S. and is estimated to affect at least 400,000 people in this country alone (Shute, 2000). And there is evidence that the incidence of autism may be increasing. Canada and Japan report rates of 1 in 1,000--an increase of more than $40 \%$ since the 1980s. Recently California reported a $273 \%$ increase in the number of children diagnosed with autism from 1987 to 1998 (Shute, 2000).

Autism is 3 to 1 to 4 to 1 more common in boys than in girls, but the ratio seems to vary with IQ, ranging from 2:1 with severe dysfunction to more than 4:1 in those with average IQ (Bryson, 1996; Wing \& Gould, 1979). Some professionals who have expertise in working with 
children with autism believe that fewer females with normal IQ are diagnosed with autism because they may be more socially adept than males with similar IQ (McLennan, Lord, \& Shopler, 1993; Volkmar, Szatmari, \& Sparrow, 1993). Autism has been has been found in families of all racial, ethnic, and social backgrounds. (Filipek et al., 1999).

Although autism has been studied for more than half a century, its diagnosis still results in controversy, misinformation, and great confusion for parents attempting to make treatment and education decisions for their children. Difficulties obtaining an accurate differential diagnosis, and assessing their child's particular needs are still problems faced by parents (Anderson \& Romanczyk, 1999).

Over the years, the treatment of autism has been strongly associated with many fads and movements that have promised much but consistently have failed to deliver when tested using scientific evidence for efficacy (Anderson \& Romanczyk, 1999). Autism has remained, since its identification in 1943, a usually severe, incapacitating, and lifelong disorder.

Kanner and Lesser (1958) concluded that if the outcome of all children with autism were considered in the aggregate, about one third would be able to achieve at least minimal social adjustment—independent of the kind of treatment they received. Other researchers were less optimistic... claiming that from two to five percent of children with the diagnosis of autism eventually achieved independent functioning and those few who did retained residual autistic behaviors (Gajzago \& Prior, 1974; Green, 1995). The idea of recovery from autism was mostly absent in the literature. As Rimland wrote in 1964,

"Recovery, in those few cases where it has occurred, has apparently been spontaneous. The mystery of autism deepens when we consider that among the few who have recovered are some who had been so severely afflicted that they functioned at the idiot or imbecile level in pre-school years. Some of those who have recovered have retained in adulthood vestiges of the remarkable mental powers which they showed in childhood and which have proven so baffling to investigators 
of the disease...chances for recovery are slight, however, and the great majority of the victims of early infantile autism live out their years in empty hopelessness at home or in institutions."

But in the past two decades, one approach to treating autism, a method known as Applied Behavioral Analysis (ABA), has passed repeated scientific scrutiny and come to the forefront as the one intervention for which there is sound objective evidence of comprehensive and lasting effectiveness in the treatment of autism (Green, 1995). Even though today most people with autism still require specialized treatment and support throughout their lives, recent research has shown that many can acquire a wide range of adaptive skills and reduction in problem behaviors if they are involved in interventions that employ the methods of ABA. This approach has consistently produced outcomes that are reproducible, describable in precise terms, tied to a conceptualization that has strong and extensive experimental support, and uses, as a necessary component, continuing objective evaluation (Anderson \& Romanczyk, 1999).

Applied behavior analysis had its origins in the "careful definition and measurement of the operant" (Skinner, 1938). With the ability to define and measure individual responses (and features of individual responses) came tremendous advances in treating people with developmental disorders, including autism. From the ability to define and measure behavior came attention to the environmental variables, or contingencies, that resulted in changes in behavior (Horner \& Carr, 1997). Contingencies of behaviors are all those things that are related to or associated with a specific behavior, most relevant usually being the antecedent, behavior, and consequence. By observing and then arranging the contingencies related to a certain behavior, that behavior can be changed.

As the mechanism by which behaviors are learned and maintained became clearer, researchers "demonstrated that the use of these mechanisms (interventions) could produce 
important changes in both the acquisition of desired behaviors and the reduction of problem behaviors. The advent and application of functional assessment technology improved the match between interventions and problem behavior situations" (Horner \& Carr, 1997).

The unique contribution of this approach is its insistence on analysis, replication, social importance, and accountability. An important element of ABA is precise and ongoing data collection. Data are collected continuously to determine the efficacy of the treatment, and is the basis for making any instructional or treatment adjustments.

Applied behavior analysis is not a stagnate, single continuum of prescribed methods (Greenspan \& Weider, 1999); instead it employs the use of many procedures that have been found to change behavior in systematic, measurable ways. Nor is its use confined to children with autism; ABA can be applied in various combinations across many different contexts.

Even though $\mathrm{ABA}$ is not limited to children with autism, early intervention based on the principles and practices of applied behavior analysis can produce large, comprehensive, lasting, and meaningful improvements in many important domains for a large proportion of children with autism (Green, 1996). There is strong evidence that behavioral intervention is more effective for young children with autism than no intervention, and more effective than typical early education services and assorted other therapies (Green, 1996).

In fact, some researchers using $\mathrm{ABA}$ methods have documented what they have termed recovery from autism in substantial percentages of young children who have been treated through well-planned, well-executed applied behavioral interventions. According to a content analysis of the literature describing recovery from autism (Poe, 1999), the components of recovery include:

- a previous diagnosis of autism, 
- a current IQ in the normal range with normal or above normal intellectual functioning,

- attendance in school in a regular classroom (or holding a full-time job) without supports,

- no longer demonstrates autistic behaviors,

- is indistinguishable from his or her peers,

- now displays normal (or above) adaptive, social, emotional, and verbal functioning Among the many interventions utilizing the principles of $\mathrm{ABA}$, one method, known as discrete trial training (DTT), was the primary intervention used in the studies that first reported the recovery, or normal functioning, of almost half of the participants (Anderson, Avery, DiPietro, Edwards, \& Christian, 1987; Lovaas, 1987; Birnbrauer \& Leach, 1993; Sallows \& Graupner, 1999).

Typically based on one to one teaching methods, DTT follows a basic pattern of antecedent, response, and reinforcement. The learner is helped to learn the correct response through prompting and shaping, among other methods, until he or she can perform the behavior independently. DTT emphasizes teaching small, structured, measurable units of behavior systematically, intensively, and repeatedly, until the learner has demonstrated mastery. "Every skill the child with autism does not demonstrate--from relatively simple responses like looking at others, to complex actions like spontaneous communication and social interaction--is broken down into small steps" (Green, 1996). Until the child can master the prerequisite step, he or she will not be taken to the next step. In this way, the child develops a foundation for learning based on mastery of basic skills and can move ahead only when data document his or her mastery of the preceding step. 
All skills progress from simple to complex and are integrated with other learning domains so as to provide comprehensive programming with familiar items. For example, if a child is learning verbal imitation, object manipulation, and matching (among other programs), the child should be using the same objects in each: he or she can be learning to imitate the word "car," making a car go back and forth on the table, and matching the same car used in the previous program to an identical car. Skills across many domains are taught this way, and each curriculum area is continually fine-tuned to meet the learning needs of the individual child.

For example, a child may be taught to imitate by a teacher following this simplified sequence. The teacher, sitting across from the learner, gives the command, or Discriminative Stimulus (Sd), of "Do this" while modeling the required action (such as clapping hands). The child should quickly respond by clapping his or her hands. (If the child doesn't respond or make an effort to imitate quickly after the command. the teacher prompts the child to perform the action.) When the action is completed or successfully approximated, the child is immediately given a reinforcer (something the child finds rewarding) like an M\&M or a hug. Then the threestep process of command (or Sd), response, and consequence begins again.

Through this and other systematic applications of ABA interventions with young children with autism, many parents and autism professionals have found a means of improving the prognosis for their child. Now, more than half a century after Kanner described this syndrome, there is hope and help for children with autism. 


\section{Statement of the Problem}

Though the decades-old question of how to effectively treat those children diagnosed with autism now has at least one scientifically valid answer in the application of ABA techniques, many questions remain.

In every study indicating that a number of participants have experienced good outcomes from $\mathrm{ABA}$ interventions, there remain a sizeable number of participants who have not had the same success. What are the differences between the children who succeed with this kind of treatment and those who do not? Is there a way of predicting, before beginning treatment, which children will have a positive outcome based on their characteristics and skills before treatment?

What are the treatment variables unique to applied behavior analysis, or more specifically discrete trial training that makes these interventions successful? Is it, as some researchers report, the hours in treatment or progress through therapy?

While the answers to these and other questions are of great interest to professionals who work with young children with autism, they are critical to parents who need to understand how best to treat their child and, once treated, to determine how independently their child may function in adulthood. For example, learning the characteristics that predict a good outcome with discrete trial training can contribute to that parent's making a more educated decision about discrete trial as a means of improving the child's functioning.

Other stakeholders in these answers include the school systems, early intervention networks, and other public systems that fund treatments for children diagnosed with autism. When families learn of the remarkable results of discrete trial teaching with two children, for example, in Catherine Maurice's Let Me Hear Your Voice (1991), they often, and understandably, demand a chance for their child through the use of the same method described 
by Maurice. Knowing who will most benefit, and who will not, from this particular intervention can lead to better funding decisions. And, since the cost of supporting people with autism in the United State alone is estimated at $\$ 13$ billion a year (Shute, 2000), knowing who could benefit from intensive early intervention could save the nation billions, and impact service delivery policy by shifting the cost from maintenance services to early intervention with the goal of recovery, or independent functioning.

This research was undertaken to help examine these problems and, if possible, provide data that may lead to an answer to all or some of these questions. 


\section{Review of Literature}

The literature describing the predictors of good outcomes from autism can be divided into two chronological divisions: those reports written before the documentation of the success of applied behavioral interventions (including discrete trial training), and those written after the documentation of successful applied behavior analysis interventions (Appendix C).

Before Lovaas' seminal publication “Behavior Treatment and Normal Education and Intellectual Functioning in Young Autistic Children" in 1987, researchers interested in the progress of their patients used follow-up studies on those clients who had grown into their teens or adulthood. In general, they found that most people who had been diagnosed with autism did not greatly improve in independence or functioning (DeMyer et al., 1973; Kanner \& Eisenberg, 1955; Kanner, 1971; Szatmari, Bartolucci, Bremner, Bond, \& Rich, 1989). Unlike the present time, researchers found that there was no particular treatment that helped those who did function better than the others (Kanner \& Lesser, 1958). In fact, a report by Kanner (1943) indicated that children who had the most intensive psychiatric care showed poorer prognosis than those who had little or no professional treatment. (And in 1975, Knobloch and Pasamanick reported that the outcome for children with autism is not influenced by the amount and kind of psychotherapy, and so psychotherapy did not seem warranted.)

In 1956, Eisenberg described the outcomes for 63 autistic children that were reevaluated after a mean follow up period of nine years. He found that almost one third had at least moderate social adjustment, and suggested that the presence or absence of useful speech by age five was an index of the severity of autistic isolation. Half of those who possessed meaningful speech by age 5 improved, whereas only 1 in 31 without the ability to communicate by that age showed 
significant improvement.

A decade later, Rutter, Greenfeld, and Lockyer (1967) undertook a five to fifteen year follow up study to compare the course of psychotic (autistic) and non-psychotic children of the same age, sex, and intelligence. The outcome of their study, according to the authors, was closely similar to that found by Eisenberg (1956). Only a minority of the autistic children reached a good level of social adjustment by the time of adolescence, and only a few had paid employment as adults. About half were totally dependent and most of those were cared for in institutions.

They also found that psychiatric and psychological assessment of young children with autism could provide data of considerable prognostic value, especially IQ testing. They reported that the child who was untestable (after several attempts by a professional experienced in the testing of autistic children) had a very poor prognosis, and that a child with an IQ below 60 was unlikely to have a good outcome.

These authors also noted that a child's quality of play can provide a useful guide his or her prognosis. A child who doesn't show "spontaneous constructive activities" (p.499) like building objects with blocks or finding out how toys work will have a poorer outcome. From their research, and a review of others', the authors concluded that the most important prognostic factors are the child's response to IQ testing, his or her reaction to sounds, level of speech at age five, the overall severity of the autism, the quality of toy play, and the amount of schooling he or she receives.

When Barbara Fish studied the use of pharmocotherapy for children with autism (1968), she found that medication may have enhanced the speech of children with already relatively high IQ's (>70), but did not help the speech of those with lower IQ's. She concluded that the outcome for children, in terms of school placement, was related to verbal IQ. 
In 1972, Leo Kanner reported on a study he had undertaken to determine the progress of children he had identified earlier with "autistic aloneness." He, along with his colleagues, Rodriguez and Ashenden, followed the case histories of 11 of the 96 autistic children diagnosed at Johns Hopkins prior to 1953 and followed through 1971. These 11 were selected for the study because they were found to be "now capable of functioning in society" (p. 27), describing them as being sufficiently social, educated, independent, and able to hold a regular job.

In comparing those 11 with the remaining members of the study who lacked the same positive outcome, the authors found no differences in ethnic origin, family characteristics, or physical health. They did find, however, that all 11 had used some speech before age five, and that they all went through the same stages in developing speech. Each of the 11 began with no imitative speech or response, then gained immediate parroting, continued with delayed echolalia with pronomial reversals, then utterances related to obsessive preoccupations, and finally communicative dialogue with the proper use of personal pronouns and greater flexibility in the use of prepositions.

Kanner and his colleagues also found that none of the 11 had ever been placed in a state hospital or an "institution for the feebleminded" (p.29). It was the view of the authors that such institutionalization "cut short any prospect for improvement." But they also noted that many of the remaining 85 autistic children stayed at home, but failed to advance as well as these 11 did.

One recurrent theme in this research provided a clear contrast between the autistic children who did and did not improve: "a chronicle of gradual changes of self-concept and reactions to them along the road to social adaptation" (p. 29). This "remarkable change" took place when these 11 children were in their middle teens. "Unlike most autistic children, they became uneasily aware of their peculiarities and began to make a conscious effort to do 
something about them... again and again, we note a felt need to grope for ways to compensate for the lack of inherent sociability." Specifically, "they made the compromise of being, yet not appearing, alone and discovered means of interaction by joining groups in which they could make use of their preoccupations, previously immured in self-limited stereotypies, as shared 'hobbies' in the company of others," (p. 31). They were far less successful with social relationships, but that did not seem to be of concern to any of the eleven.

These authors warn that their "emergers" (p.33) grew up in the days before the introduction of therapeutic, psychopharmacological, or behavioral interventions, and questioned if the implementation of any of those treatments would have altered the results of this study. They concluded, however, that "almost 11 to $12 \%$ 'got there' without any of those techniques" (p. 33).

One year later, in 1973, DeMyer and colleagues published a lengthy and detailed followup study involving 120 children with autism who were diagnosed before age 5 and one half and followed to age 12. In this study, the autistic children were placed into one of three subgroups (high, middle, and low) on the basis of their ratings, at that point in time, in several areas: psychiatric diagnosis, conversational speech, social skills, work/school rating, family adequacy and marital status, intellectual quotients, and general neurological status. High autism students had a mixture of non-communicative and communicative speech and some intellectual or perceptual activity that was near their chronological age. Middle autistic children had little communicative speech beyond infrequent communicative words but did have at least one intellectual or perceptual-motor activity that approximated age level. Low autistic children were similar to the middle group in their language skills but their intellectual and perceptual-motor performance was globally retarded. The authors used as controls 26 children described as non- 
psychotic subnormal (SNr). These $\mathrm{SNr}$ children were described as differing from the children with autism in their positive emotional relationships with others and because they had more communicative speech. Their psychiatric problems at intake consisted of symptoms of immaturity (negativity and over-dependency on parents), lack of inhibition with other adults, and quarrelsome behavior with other children.

DeMyer et al. found that the best single predictor of how well the child would function educationally at follow-up was how well he or she functioned in this respect at the initial evaluation. A little over half of the students remained in the same educational category in which they were originally placed, a third moved to a higher category, and $12 \%$ dropped to a lower category. Interestingly, students in "all intake categories had an equal chance of being upwardly mobile" (p. 231).

Then the authors selected the 20 children who were rated as "normal" on at least one measure at follow-up to more closely scrutinize in "hopes it would yield some reasons for a better outcome than in the remaining 126 cases" (p.233). They found only the same correlation with a higher ranking at intake and less neurological dysfunction than the remaining 126 . They concluded that, at evaluation, children between the ages of three and six could be ranked according to severity of illness and such ranking had prognostic value. The five measures that related to outcome were (listed from highest to lowest predictive ability) IQ, severity of illness as reflected in the psychiatric diagnostic subcategory, social rating, speech rating, and brain dysfunction index. Intake measures that were not significantly related to follow-up placement were age at initial evaluation, age at follow-up, EEG, and family adequacy. And like Kanner and his colleagues, DeMyer et al. noted that "no child whose communicative speech developed after five years of age was normal or nearly normal at follow-up" (p.239). 
The next year, Gajzago and Prior (1974) wrote of “Two Cases of 'Recovery' in Kanner Syndrome" based on the case histories of two children diagnosed as autistic. Despite the severity of their symptoms during their preschool years, both children began "functioning adequately both intellectually and socially and were progressing normally at local schools" (p. 264). Although this paper offered no insight into characteristics that might predict a good outcome at the time of diagnosis, the authors reported that "there is more than one set of factors, residing 'within' the child, which may need to be considered in the view of previous follow-up studies" (p. 269). The most important of these is speech development, to which other writers including Kanner and Eisenberg and Rutter have attached considerable prognostic importance. In both patients, the mothers report improvements in the child's behavior "following onset of speech" (p. 268).

Harper and Williams reported on the correlation between the age and type of onset and outcome in their 1975 article in the Journal of Autism and Childhood Schizophrenia. They divided 131 autistic children seen in the Sydney, Australia, diagnosis centers between 1950 and 1970 into two groups: those with natal (at birth) onset and those with acquired (there appeared to be a period of normal development before the pathological process began) autism. Using parent report, they examined the developmental milestones, physical and psychological events that might have precipitated onset, and then followed up to determine the child's current intellectual and language development. They concluded that age and type of onset do not define subgroups within the autistic syndrome, but that they appear to have prognostic value in relation to IQ and development of language.

Also in 1975, Knobloch and Pasamanick reported on a group of autistic children to consider the relationship of autism and infantile psychosis to what they termed "para-natal" 
complications and associated disorders, and then compared their report to two other studies of older children. Among the fifty infants and preschool children diagnosed as autistic they found there was a high incidence of low birth weight, complications of pregnancy, seizure disorders, and other specific diseases associated with developmental problems, but these complications did not vary significantly from a comparison group of abnormally-developing children. Both groups differed, however, from normally developing children, whose percent of para-natal complications was much lower. Although the authors stated that in three fourths of the patients autistic behavior had disappeared as they grew older, further reading indicated that rather than losing their diagnosis of autism, they had lost some of their autistic aloneness at time of follow up. Three fourths of the children in this study developed social responses appropriate to their level of functioning when re-examined. The findings of this study were similar to other studies that suggest the intellectual ability of the child determines the usefulness of their communicative language and that an initial IQ can be a good predictor of the later adjustment.

By this time, a pattern had emerged identifying IQ and language ability as strong predictors of outcome for children with autism. Rutter explained (1978) his belief that IQ and language skills were closely related. He wrote "the deficit of autism is certainly not just an abnormality of speech. Rather it involves a wide range of language and language-related functions which include impairments in verbal understanding, sequencing, and abstraction," (p. 90). Rutter continued that the language problems in autism also impede the use of symbols in play and the use and understanding of gestures and written language. He concluded that these language deficits are the result of a severe cognitive deficit that involves language and languagerelated functions. In short, the child with better language skills would have better cognitive skills, as evidenced through higher IQ scores. 
And IQ scores for people with autism have been shown to be relatively stable over time. As early as 1969, Lockyer and Rutter reported that early performance IQ scores, especially, were "highly stable and good predictors of performance in adolescents and in adult early life, while Fish (1968) and Rutter, et al., (1971) found that verbal IQ scores were good indicators of future behavior.

A group of 100 autistic children from the Putnam Children's Center, Boston, with average or better cognitive skills were selected by Brown (1979) to examine long term outcome. She found children with average or better cognitive functioning had more potential to overcome their language handicaps, as their verbal skills improved significantly, but their performance skills showed less change. She concluded that these difficulties were due to underlying difficulties in body integration and impaired vestibular functioning, and suggested that sensorymotor integration techniques may be a promising avenue for optimizing outcome.

Lotter (1979) reported on the results of 25 studies found in the literature between 1955 and 1968, in Rutter and Schopler's Autism (1979). From these studies, the author made several conclusions. First, in all the studies, the range of outcomes was very wide. Next, children with relatively late onset had a generally better outcome. Third, children whose disorder was initially less severe had a generally better outcome. Finally, similar proportions in most studies were found to be in institutions at follow-up or had a poor or very poor outcome.

Though Lotter found no relationship between outcome and home background, type of onset, late development of seizures, social class, and family mental illness, he concluded that the combination of speech and IQ scores were a better predictor than either separately. He claimed that estimates of IQ in young autistic children derive largely from nonverbal tests, and a low score on such a test probably indicates a lesser likelihood of developing useful speech as well as 
a poor outcome. A high nonverbal score, with no subsequent language development is of no predictive value, Lotter wrote, but if language does develop, the nonverbal score is a useful guide to later general IQ scores.

Despite great variability in intellectual and linguistic functioning across patients, there was continuity of behaviors within individuals with autism, and IQ and presence of speech by age five were the best prognostic indicators, according to Rumsey, Rapoport, and Sceery’s 1984 article "Autistic Children as Adults: Psychiatric, Social, and Behavioral Outcomes.” To gather these conclusions, the authors reviewed past research and also studied the psychiatric and behavioral outcomes in 14 high functioning (IQ > 80) men diagnosed in childhood with autism.

In 1987, two Swedish researchers, Gillberg and Steffenburg, reported on a follow-up study of children in the Goteborg region of their country who had been diagnosed in childhood with autism and followed them from age 16 to age 23 . They found that IQ at diagnosis and communicative speech before six years were the most important factors and noted "other trends that were seen that also compared well with previous studies" (p. 273). One of those trends was a one-to-two year aggravation of symptoms during puberty in just over half of the cases that turned into "frank deterioration" (p.285) in one-fifth of those cases, with no difference between diagnostic groups, although girls in the autism group tended to be a little more affected than the boys.

Lord and Schopler (1989) reported, from their longitudinal comparisons of intellectual and developmental quotient (DQ) scores for three age groups of autistic children, that performance IQ scores might be a useful summary of mental handicap. They found that early DQ and performance IQ's of less than 50 are reliable indicators of the presence of greater mental handicap in children with autism. They found that the intellectual skills of some children with 
autism deteriorate at adolescence and conclude that these very earliest assessments might be better predictors of adult functioning than the more optimal scores achieved during school years. Szatmari and colleagues raised the idea that specific intellectual abilities could have prognostic value in autism in a 1989 study. They began their research by acknowledging that "it is well known that IQ is an important prognostic variable in the outcome of autistic children" (p. 213), but little information is available on the outcome of non-retarded autistic children as adults. To learn more about this group, the authors identified 16 high-functioning autistic children (based only on IQ scores over 65) from the case records of more than 800 children who were born before 1970 and who were diagnosed at the West End Crèche in Toronto, Canada. Using a variety of scales and assessments, the authors accessed the original case record data to confirm the diagnosis as well as current functioning. As was consistent in all early literature, the majority of the sixteen subjects in this study were functioning poorly in terms of occupational-social outcomes and psychiatric symptoms, while only a "surprising number (four) had a very good outcome and might be considered recovered" (Szatmari, P., Bartolucci, G., Bremner, R., Bond, S. \& Rich, S., 1989).

They wrote that "early history explained little of the variance in outcome...the good and poor outcomes groups differ little with respect to early impairments in social responsiveness, deviant language, and bizarre behaviors" and concluded that "it was surprising how much of the variance in outcome was accounted for by IQ and nonverbal problem solving” (p.223). In fact, they suggested that specific measures of cognitive abilities, such as the Wisconsin Card Sort test (which measures frontal lobe function) used in their study, were "better predictors of outcomes than overall intelligence" (p. 233). These specific tests were performed at follow-up, not at the time of diagnosis, so the authors were unclear as to what those scores would have been at the 
time of diagnosis.

In 1991, Swedish physician Christopher Gillberg reviewed outcome studies of children with autism and autistic-like conditions, and as many researchers before him, concluded that while a small minority of people with the disorder can live productive lives, about two-thirds will remain dependent throughout their lives. As mentioned above, Gillberg's contribution to the field was the finding that one half of all the children in his 1987 study (with Steffenburg) showed either a temporary or a permanent aggravation of symptoms in adolescence. The aggravation of symptoms included hyperactivity, aggressiveness, destructiveness (usually only towards themselves), and a return to insistence on sameness that is often seen in the preschool years. The deterioration was often preceded by the same kind of symptoms as the aggravation described above but then was followed by inertia, loss of some language skills, and slow intellectual deterioration. There was a strong tendency for girls to be more affected by this deterioration than boys, and this deterioration was often associated with the onset of epilepsy at puberty.

Japanese researchers Kobayashi, Murata, and Yoshinga (1992) conducted a follow up survey of 201 young adults with autism who had previously participated in intensive therapeutic camping or had therapeutic treatment as children. Their results mirrored past findings that most children with autism have poor outcomes and that IQ was a good predictor future functioning, but did not find that higher developmental levels of speech at age 6 was not a good predictor of outcome for this group, especially for girls. Girls in this study tended to be more seriously affected than boys, despite their higher level of speech. As did Gillberg, these researchers found that thirty-one percent of their subjects showed deterioration in adolescence, and in some cases, just before the onset of epilepsy. But they also found that $43 \%$ showed remarkable improvement between ages 10 and 15 . They concluded that how well children with autism manage and 
overcome their adolescent period determines whether or not they will achieve independence in the future.

In summary, at the time Lovaas was preparing his groundbreaking report on the UCLA Young Autism Project published in 1987, most earlier researchers had found at least two variables that seemed, from their retrospective research, to correlate with the future success of a person with autism. Those variables were IQ or intelligence (especially in specific non-verbal subtests like the Wisconsin Card Sort test) and the development of meaningful speech before the age of five or six. They also had found that, in these early reports, that the time of adolescence was a critical one for children with autism: it was a time when many children experienced a regression and/or a time when they became aware of their differences from normally-developing children and worked to leave behind the autistic behaviors. These early researchers generally agreed that most people with autism had poor outcomes and were dependent on some form of support throughout their lives, while acknowledging that a small group of people with autism had achieved some degree of independence. Overall, the future for a child diagnosed with autism in the middle of the $20^{\text {th }}$ century was, most often, grim.

In 1987, with the publication of Lovaas' intensive discrete trial research, one specific treatment did emerge as being instrumental in the positive outcome of almost half of the participants in an experimental group of young children with autism. As described in the Journal of Consulting and Clinical Psychology, Lovaas researched the outcomes of intensive discrete trial treatment with three groups of children: a treatment group of 19 children with autism who received 40 hours a week of one-to-one behavioral treatment from trained therapists (mostly UCLA students); and two control groups (i.e., minimal control group of 19 children with autism who were provided fewer than 10 hours a week of treatment from trained therapists; and a 
second control group of 21 comparable students who were given no treatment by the UCLA program, although they may have received eclectic treatments elsewhere in the community. All children had received a diagnosis of autism from qualified professionals not associated with the study and all began treatment before age four. The children in the three groups had similar measured developmental levels, language and play skills, and rates of stereotypic behavior when treatment began, and all participated in the treatment for at least two years.

The children in the intensive treatment group received one-to-one discrete trial teaching at home, in school, and in the community. Instruction focused on increasing language, independent play, attending, imitating, appropriate social behavior, cooperative play and self help skills, as well as decreasing aggressive and stereotypic behaviors (Green, 1995). Parents were extensively trained so that intervention could take place for almost all the child's waking hours, 365 days of the year. The focus of the instruction was to increase language, attention, imitation, social skills, independent play, cooperative peer play, and self-help skills. Children in the minimal treatment control group, Control 1, received the same kind of treatment as those in the experimental group but with less intensity (ten hours or less a week) along with a variety of treatments from other community resources including special education classes. The third group, Control 2, received no treatment at UCLA but were free to take advantage of any other treatments available in the community. All children were reevaluated after two years by examiners who did not know which group they had been in, and the results were striking.

By age seven, nine (47\%) of the 19 children in the intensive treatment group had successfully completed first grade and had obtained normal or above normal IQ scores, with average gain of 37 IQ points over the course of treatment, and an average gain of 31 points more than the minimal treatment group. 
Another eight of the students ( $42 \%$ ) from the experimental group were placed in language-delayed or learning disabled classrooms (average IQ of 70) and had made substantial gains in most other areas, but not enough to for them to be able to fully participate in regular classrooms. The remaining two (10\%) were placed in classrooms for autistic/mentally-retarded children.

In contrast, only one of the 40 students from the two control groups completed first grade successfully and had an IQ score within normal range. Eighteen (45 \%) were in classes for children with language or learning disabilities and $21(53 \%)$ were in classes for autistic/mentally-retarded children; their IQ's remaining unchanged from the beginning of treatment, which is consistent with other follow-up studies of children with autism who have received typical educational services (Green, 1996).

Furthermore, the nine children in the intensive-treatment group of this 1987 study who had achieved normal functioning by the end of first grade participated in a long term follow-up study (McEachin, Smith, \& Lovaas, 1993). These children were reevaluated when they were age 13, on average, and compared with children in the original minimal treatment control group by examiners who were not familiar with the children's history. Intelligence tests, adaptive behavior scales, and a personality inventory were given to both groups of children. Educational placements were also evaluated. Results indicated that the effects of the intensive behavioral treatment persisted; eight of the nine formerly autistic children continued to succeed in the regular classroom. One was in special education, but another child from the original experimental group who had not completed first grade successfully had later moved to regular classes. Thus, the proportion of children who were intensively treated and considered functioning normally was maintained at $47 \%$. Gains in the IQ scores of these children noted after first grade 
were maintained, and the scores remained on average 30 points above the control group average. Scores on the adaptive behavior and personality measures were also significantly higher than for the control group, whose placement in special education classes had remained stable. The 'blind' examiners could not distinguish the formerly autistic children who received early intervention from typically developing children of the same age on measures of cognitive, academic, social or adaptive skills.

The results of Lovaas and his colleagues have been partially replicated at the May Institute in Massachusetts (Anderson et al., 1987), at the Murdoch Early Intervention Program (Birnbrauer \& Leach, 1993), at UC--San Francisco (Sheinkopf \& Siegel, 1998) and most recently at the Wisconsin Early Autism Project (Sallows \& Graupner, 1999).

In 1987, Anderson and his colleagues examined the progress of 14 children with autism who were receiving behavior treatment at the May Institute in Massachusetts. After one year, 12 of the 13 children showed increases in their mental and social age scores, and nine of the eleven children with whom language tests were repeated had made gains. Children who completed a second year of intensive behavioral treatment continued to improve in the same areas at about the same rates. Though both were using intensive behavioral intervention, the children in the May Institute study differed from the UCLA group in several important ways. First, they were a year on average older than the children in Lovaas' study, and they had a larger difference between their chronological and mental ages when treatment began. They spent half of the hours in treatment than spent by the UCLA group, over a shorter period of time ( 1 to 2 years versus 2 to 6 years) and there was no control group of comparable children for direct comparison.

In another partial replication of Lovaas' UCLA study, researchers at the Langley Porter Psychiatric Institute in San Francisco (Sheinkopf \& Siegel, 1998) compared a group of 11 
children in intensive behavioral intervention home programs with 11 children who were not receiving behavioral treatment. The children in each group were matched for chronological age, mental age, specific autism-spectrum diagnosis, and the time between diagnosis and follow up evaluations. The ten children for whom scores were available at follow up in the behaviorally treated group improved on IQ measures, most by substantial amounts. In the control group, six improved but by smaller amounts, four had lower scores, and one stayed the same. When the IQ data for matched pairs was analyzed, the child treated behaviorally in seven of the pairs improved more than his partner during the same time period. The authors also reported that the number of autistic symptoms did not differ significantly for the two groups either before or after treatment, but the children in the behaviorally-treated group had much less severe symptoms following their treatment.

In the Wisconsin study, 24 autistic children completed the first year of a three-year replication study of Lovaas' 1987 research. Changes in pre-post test scores showed an average gain of 22 IQ points. Nineteen of the children matched those in Lovaas' study, and eight of those children showed an IQ score gain of 45 points, putting them into the average range. These "best outcome" children represented $42 \%$ of the experimental group (Sallows \& Graupner, 1999).

In the 1987 report, Lovaas explained that an analysis of variance was carried out on the eight pre-treatment variables to determine which variables, if any, were significantly related to outcome (gauged by educational placement and IQ). Pro-rated mental age, a measure also used by DeMyer et al. (1981), was significantly $(\mathrm{p}<.03)$ related to outcome in both the Experimental and Control Group 1. Abnormal speech was also significantly related $(\mathrm{p}<.01)$ to outcome in Control Group 1.

According to this study, a linear combination of pretreatment variables could have 
predicted outcome in the experimental group. Using a discriminant analysis and the eight variables used in the first multivariate analysis, it was "possible to predict perfectly the 9 subjects who did achieve normal functioning, and no subject was predicted to achieve this outcome who did not" (p.7). The eight variables used were chronological age at first diagnosis, chronological age at the beginning of treatment, sum of pathology, abnormal speech, self-stimulatory behavior, appropriate toy play, and recognizable words. The only variable that was not significantly related to outcome was the child's chronological age at the time treatment began (p.6).

In another article by Lovaas in 1993, he described the "best outcome" subjects from the 1987 research to be "those who acquired verbal imitation within the first three months of intensive treatment, whereas the remaining subjects failed to acquire this discrimination" (p.625). He continued, "Those who fail to acquire verbal imitative behavior often show an ease in matching visual stimuli, appearing more like 'visual learners' rather than 'auditory learners." In that same article, Lovaas declared "the success of behavioral treatment seems to make the constraints of intelligence and autism superfluous" (p. 625).

While he wrote that the "achievement of lasting average (or normal) functioning ... was extremely gratifying... what is left to do is to be of more help to the other half who did not achieve average and normal functioning." He guessed that the group that did not gain average scores on IQ and other tests was "very heterogeneous and that progress toward recovery of these children will occur in much smaller steps...” (p. 625).

Later, Lovaas (1998), along with colleague Tristam Smith, wrote, "our research has indicated that the first sign that a child will struggle (in a discrete trial program) is that he or she has difficulty acquiring speech during treatment. In most cases, we can identify such a child approximately five months after treatment onset” (p. 71). 
In 1993, researchers Jay Birnbrauer and David Leach from Murdoch University in Australia attempted to replicate the intensive early intervention program designed by Lovaas and found that the distribution of potential success (achievement of normal functioning levels) in their study paralleled that reported by Lovaas (1987). When discussing predictors of success, these authors wrote:

No characteristics at referral appear to correlate highly with good response to this program. The presence of some speech, a generally acknowledged positive sign, was not essential. Two of the high improvement subgroup $(\underline{n}=9)$ had some speech whereas two did not and one does not yet. The two control group $(\underline{n}=5)$ children who showed the most progress also had some speech at referral. The high performing subgroup included one girl and 3 boys. Two were not testable on the cognitive tests at referral while two had Standard-Binet IQs of 85 and 35. Another variable, initial rates of improvement, held for three of the children. For them, gains were most pronounced between 0 and 12 months (of treatment). The fourth child, however, did not make gains until well into his second year. At present, it is probably best to conclude that all autistic children require an intensive preschool program and that the program be continued for at least two years ( $\mathrm{p}$. 72).

Also in 1993 came the publication in the popular press of Let Me Hear Your Voice, A Family's Triumph Over Autism (Catherine Maurice), a mother's account of recovering two of her children from autism through the use of intensive behavioral therapy. Maurice chronicled the events that led to the diagnosis of her first child, her attempts to find meaningful treatment, and her initial reluctance at using discrete trial methodology as an intervention for her daughter. But the improvement that came as a result of this treatment left little doubt in Maurice's mind of its effectiveness, and when her younger son was also diagnosed with the disorder, discrete trial training was immediately implemented for him. Both children, according to Maurice and to accounts in the professional literature (Perry, Cohen, \& DeCarlo, 1995), recovered from autism, and are indistinguishable from their peers. Let Me Hear Your Voice has been the impetus for many families of newly-diagnosed children to seek behavioral interventions for their child 


\section{(Appendix F).}

Preschool children and typically-developing peers were compared on measures of intellectual functioning and language skills before and after their first year of school in a study by Harris, Handleman, Gordon, Kristoff, and Fuentes (1991). On both measures, the children with autism initially scored lower than their typically-developing peers, but the children with autism narrowed that gap after one year of school, making a nearly 19 point gain in IQ and an eight point increase in language. The IQ of the typical peers remained stable and their language quotient increased 7.73 points, almost identical to the autism group. The curriculum for both groups focused on language-enrichment, and the results of this study could indicate that all children could benefit from such a language-enriched setting. This report provided additional support for the idea that children with autism can make major developmental gains during their early years.

University of South Florida researcher Philip Drash (1995) found four variables at the beginning of treatment that were related to successful outcome in a study of 12 autistic preschool children treated in a modified "Lovaas-type" outpatient behavioral treatment program. Those four variables were:

- the severity of language delay at beginning of treatment,

- the age of the child at the beginning of treatment,

- the severity and frequency of negative, disruptive, and task-avoidant behaviors, and - a lack of responsiveness to common reinforcers.

Drash reported that the age of the child at the beginning of treatment was probably the single most important variable related to successful outcome. In his research, the younger children, between the ages of one and three years, responded better and progressed faster than older children, though children between the ages of three and four also made good progress. He 
suggested that children four to six years or older may have established a reinforcement history for nonverbal behavior that is incompatible with the development of vocal speech and language.

The second most important variable related to successful treatment outcome, according to Drash, was the severity of the language delay at the beginning of treatment. He explained that in terms of severity of language delay, children could be divided into roughly three categories. First, the children who are most difficult to teach and make the slowest progress tended to be, in this study, those who had no receptive or expressive language; children Drash described as having no words, no imitation of sounds, and no evidence of understanding language at all. The second most difficult group, he concluded, included the children who had little or no expressive language, but demonstrated some receptive language. The easiest group to teach, and the children with the best outcome, he concluded, was a third category of children who already had some expressive speech, ability to imitate sounds or words, and echolalia.

He wrote that there also appeared to be interaction between age and severity of language delay at the beginning of treatment. Even if the language delay was severe, Drash found that if treatment started early (between two or three years or younger) the outcome was more positive than if treatment began later.

In terms of severity and frequency of negative behaviors, Drash reported that in his study, children who engaged in negative behavior (e.g., screaming, kicking, hitting, or simply refusing to respond) did not progress well in therapy. He claimed that some of the least successful children in his program were those who had repertoires of highly disruptive behaviors which could not be brought under control.

And, according to Drash, one of the most difficult types of children to teach are those for whom common reinforcers have almost no reinforcing value. These are children, he described, who show almost no interest in toys, food, activities, and affection, and when offered such items, they ignore them or throw them away. Since it is necessary to establish potent reinforcers before behavioral procedures can be effective, this makes treatment more difficult.

Drash also identified nine programmatic and treatment variables that he found 
contributed to successful treatment. Those variables included:

- making language and cognitive skills the central component of therapy,

- making the suppression of negative behavior a central and ongoing aspect of treatment,

- maximizing the number of therapy sessions per week,

- maximizing the number of additional hours (outside of structured therapy) of behavioral training a week by tutors using the Lovaas model,

- maximizing the total duration or length of therapy,

- increasing the abilities of parents to implement the behavioral treatment at home,

- enhancing the skill level of the tutors and others working with the child,

- including social skill training and social interaction as a specific focus of treatment, and

- managing and monitoring school placement.

Five of the 12 children (42\%) in Drash's study achieved average or above average functioning in language and intelligence, while four more made significant gains in both areas but continued to have substantial delays. The remaining three children made some progress in language acquisition but continued to have significant delays. Drash concluded that language and cognitive training appeared to be the most important variables relating to successful outcome.

Smith, Eikeseth, Klevstrand, and Lovaas (1997) performed an archival assessment of young children in the UCLA Young Autism Project, including the Los Angeles site, a Kansas site, and another in Oslo, Norway, to determine the outcomes achieved with Lovaas' style behavioral treatment for young children with both severe mental retardation and autistic features. They found 21 children who met the criteria for the study: a chronological age of 46 months or less at time of referral, a ratio IQ of less than 35 as measured by the Mental Development Index of the Bayley Scales of Infant Development, and diagnosis by a licensed psychologist or a psychiatrist not involved in the research who had experience assessing young children with developmental disabilities. Referrals were assigned to one of two groups: an experimental group 
of 11 boys who received intensive treatment ( 30 hours or more of one-to-one treatment per week for at least two years), and a comparison group of eight boys and two girls who received minimal treatment (ten hours or less of one-to one-treatment for up to two years).

At follow-up evaluation, the intensively treated children (the experimental group) achieved a higher mean IQ (36 vs. 24) and demonstrated more expressive speech than did the minimally treated children. These analyses indicate that treatment was associated with substantial improvements, but these improvements were more modest than reported for higherfunctioning children who received the same treatment, and the children remained delayed in development.

To remedy a lack of information on the effectiveness of behavioral treatment for children older than four years, researcher Sven Eikeseth (1999) presented preliminary data from an ongoing study designed to evaluate the extent to which children with autism between ages four and seven at intake benefit from long term, intensive behavioral treatment.

At intake, there were no significant differences between the behaviorally treated group and an eclectically treated group. However, the eclectic group scored higher than the behavioral group on ten out of 11 intake variables, suggesting that at intake, the eclectic group functioned somewhat better than the behavioral group. Those intake variables included intake age, global IQ, performance IQ, language functioning, language receptive, language expressive, Vineland adaptive composite, Vineland communication, Vineland daily life, and Vineland social. But at follow-up, the behaviorally treated children scored significantly higher than the eclectically treated children on global IQ, language, receptive language, Vineland adaptive composite, and Vineland communication. The behaviorally treated group scored higher than the other group after one year of treatment for ten of ten outcome variables (intake age was not included in follow up measures). Thus, Eikeseth explained, after one year of treatment, the behavioral group outperformed the eclectic group, despite the fact that the eclectic group had scored higher than 
the behavioral group at intake. Eight of the 12 behaviorally treated children scored within the normal range on tests of intellectual functioning.

In Howlin's 1997 review article in European Child and Adolescent Psychiatry, the author used composite ratings of overall outcomes from researchers working from the 1950's through the 1990's. The author reported that, though direct comparisons between study results were complicated because of differences in methodology, it was possible to identify a number of factors related to early development that appear to be associated with later outcome. These include the development of at least simple communicative language by the age of five or six, the ability to score within the mildly retarded range or above in nonverbal tests of ability, and in many cases, the presence of additional skills or interests (like a specialized knowledge in music, computers, or math) that make it easier for people with autism to find their niche in life. Howlin also reported that the influence of other factors, such as the severity of autistic symptomology, early behavioral problems, gender of the child, or family factors is not yet known. "On the whole," Howlin wrote, "women tend to do less well than men...there are no individual differences (other than lack of speech) that are related to outcome, although the greater number of social and behavioral problems, the worse the ultimate outcome" (p. 56). Howlin noted that "there is little doubt that the use of behavioral procedures has resulted in major improvements in the education, management, and treatment of children over the last three decades. The benefits are particularly striking when parents are involved in therapy and such techniques are now widely accepted as playing a crucial role in intervention" (p.60).

In their study of the effectiveness of a TEACCH-based home program intervention, Ozonoff and Cathcart (1998) found that home program intervention was effective in enhancing development in young children with autism. Parents were taught to work with their preschool 
autistic children in their home, focusing on cognitive, academic, and prevocational skills essential to later school success. Two groups of children were compared, one a treatment group and another control group, each consisting of 11 children. Results showed that children in the treatment group had rates of progress three to four times greater than those in the control group on all tests of outcome.

In the 1999 special autism edition of the Journal of the Association of Persons with

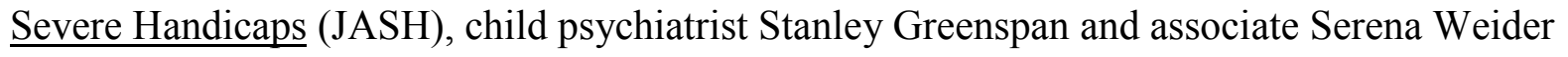
described their theory that children with autism can be divided among four subtypes of relating and communicating. Type I children progress rapidly and move from patterns of perseveration, self-stimulation, and self-absorption toward warm, emotionally pleasurable engagement, solid academic skills, and healthy peer relationships. Type II children have greater challenges and make slower but consistent progress. They are not as able as Type I children to participate in all activities of a regular classroom, but benefit from appropriately staffed integrated programs or special needs language-based classrooms in which the other children are interactive and verbal. Type III children are characterized by moderate to severe auditory and visual-spatial processing difficulties, and have more severe motor planning problems that get in the way of purposeful communication and problem solving. Type IV children are distinguished by very severe motor planning problems, as well as significant auditory and visual-spatial processing difficulties. The authors have further divided each group into additional subgroups: for example, Group IV can be divided into one group who makes very slow progress but never gain expressive language, and a second group that makes little progress and often regresses.

From their experience with these children, Greenspan and Weider (1999) concluded that the severity of symptoms such as perseveration and self-stimulation were not good predictors of 
the child's ability to progress, but the child's response to the early phases of their Developmental, Individual-Difference, Relationship-Based model (DIR) treatment can be useful predictor of progress. They cite two factors that help the child react well to the intervention program: the ability to sequence actions, and the ability to imitate. They report that children with little or no progress were four times more likely to have severe motor planning difficulties as a child who made consistent and/or good progress. The children who made the most progress were the first group--they were the "children who learn to be warm, flexible, emotionally expressive, and able to do abstract thinking in age-appropriate contexts" (p. 154).

Another feature of Greenspan and Weider's (1999) research associated with rapid progress was the availability of opportunities to interact in a developmentally appropriate way, focusing on the child's individual interests. In other words, constant reinforcing engagement of the child with capable teachers (including parents and peers) prevent the child from perseveration, self-absorption, and self-stimulatory behaviors, and enhance their emergence into more normal behaviors.

Lynn Koegel and associates (1999) sought, through a study of early, pre-treatment videotapes of children with autism who appeared to have an especially good prognosis and who had since completed treatment, to identify key target behaviors (they termed "pivotal behaviors") that if taught, would result in positive outcomes for children with autism. They identified two such factors: social initiation, and a lack of self-stimulatory behaviors.

Then the researchers used this information to teach another group of children who lacked the ability to initiate social interaction, and who had many self-stimulatory behaviors at intake, the skill of social initiation. Four years later, follow-up measures showed that these children were following typical development tracks both socially and academically, while the children in 
another group who were not taught these behaviors did not show these improvements.

"Therefore, the authors conclude, it appears that knowledge of specific behavioral factors that are indicative of positive treatment outcomes not only allows for the prediction of a child's prognosis, but can serve as an impetus in identifying target behaviors that, when taught, foster a more positive prognosis for children with autism" (p. 2).

And, in the Wisconsin study mentioned above as a recent UCLA replication site, Sallows and Graupner (1999) found that the pretreatment IQ correlated significantly $(r=.52)$ with the one year treatment IQ, and the pretreatment Vineland ABC correlated almost as highly $(\mathrm{r}=.50)$, confirming earlier studies that showed pretreatment IQ and other specific tests of ability as good indicators of prognosis. The variable with the highest correlation with one year IQ was the child's ability to imitate, especially the imitation of sounds $(\mathrm{r}=.64)$. Combining verbal imitation and pretreatment IQ yielded a correlation with one-year IQ of .72, accounting for approximately half the variance. The authors reported that seven of the eight children $(88 \%)$ who could imitate two of 20 sounds or words went on to achieve IQ's in the average range. But if the child could not do this, the likelihood of his or her achieving an average IQ at one year was reduced to six percent.

In 1999, Tristam Smith reported the findings of his review of studies on the effects of early intervention with young children with autism. Though he cautioned that most studies lack even the most basic features of scientific soundness, and warned against drawing firm conclusions from existing studies, his review suggests that some children with autism can make major, long-lasting improvements as a result of $\mathrm{ABA}$ treatment. And, among those using $\mathrm{ABA}$, the children who were relatively high functioning prior to treatment were likely to make the largest gains. In addition, Smith credits behavior analytic investigators for having identified 
many specific, empirically-supported treatment methods for young children with autism, and reports that parents and teachers whose children have participated in such treatment generally rate that treatment favorably.

Children with autism who initially learned very quickly continued to learn at very rapid rates, showed the greatest changes in autism severity and adaptive behavior, according to a report by Rutgers University's researcher Mary Jane Weiss (1999). Conversely, all children who struggled substantially to acquire a new skill continued to struggle with skill acquisition, and these children also exhibited more autistic behavior and lower adaptive behavior skills after two years of treatment.

Smith, Groen, and Wynn (2000) compared the treatment outcomes of two groups of children with autism and Pervasive Developmental Disorder (PDD), which is often considered a milder form of autism. The fifteen children were randomly assigned to one of two groups, an intensive treatment group or a parent training group. In the intensive treatment group, children were given 30 hours a week of behavioral intervention designed to maximize their intellectual, adaptive, and socioemotional functioning for two or three years. In the parent training group, parents were helped to select specific goals for their children and then taught to use treatment approaches designed by Lovaas (1987) to meet those goals. Though the children appeared similar at intake on all measures, at follow up the intensively treated group outperformed the parent training group on measures of intelligence, visual-spatial skills, academics, and language, but not on adaptive functioning or behavior. The children with PDD gained as much or more than the children with autism, which the authors suggests may indicate that intensive early intervention is effective not only for autism but for other pervasive developmental disorders. In summary, most (but not all) researchers in more recent studies, after the advent of 
$\mathrm{ABA}$ interventions for young children with autism, have found the two variables considered by early researchers remain important in predicting outcome: IQ and some meaningful speech by age six. However, some recent research has also indicated there are no solid predictors of treatment outcome (Szatmari et al., 1989; Kobayashi, Murata, \& Yoshinga, 1992; Birnbrauer \& Leach, 1993). Other current literature has shown results indicating the importance of the child's ability to imitate, especially vocal sounds (Sallows \& Graupner, 1999); the age of the child at onset of treatment and responsiveness to reinforcement (Drash, 1995); the amount of social engagement and initiation the child has before treatment (Koegel et al., 1999); and progress through therapy at the beginning of treatment as important to outcome (Lovaas, 1993; Greenspan $\&$ Weider, 1999; Weiss, 1999). In the past few years, researchers have expanded the positive findings of intensive behavioral therapy to older children, children with PDD, and children with less ability than those in Lovaas' initial study (Eikeseth, 1999; Smith, Groen, \& Wynn, 2000; Smith, Eikeseth, Klevstrand, \& Lovaas, 1997). More work is being done to replicate, at least in part, the 1987 UCLA study (Sallows \& Graupner, 1999), and some researchers (Koegel et al., 1999) are moving toward a refinement of the applied behavioral intervention methods employed by Lovaas.

The study reported in this paper relied on participating parents to recall events in their child's development over a period of time, and to accurately report the information they were remembering. In spite of Eisenberg's (1956) declaration that the parents of autistic children have "almost uncanny objectiveness and obsessive accuracy" (p. 607) when describing their children, some researchers outside the field of autism research have not been as enthusiastic about the use of recall and parent report. Reports in the literature find both support and caution for these two 
methods of obtaining information: recall as a method of gaining retrospective information and parent report as an accurate way to learn about a child's abilities.

For example, the reliability of a relative's retrospective reports of behavioral problems and symptoms in a family member with dementia was the focus of a study by LaRue, Watson, and Plotkin (1992). These authors asked relatives of patients with dementia to complete questionnaires about the patient's functions and psychiatric problems during an initial evaluation (Time 1), at a follow up 4 to 17 months later (Time 2), and retrospectively (Time 3). The retrospective questionnaire, given at the follow up meeting, was completed based on their recall of symptoms and behaviors at Time 1. On most scales, initial and retrospective accounts produced very similar mean scores. They found that the retrospective reports correlated well with initial reports, particularly with larger scales that included a wide range of alternative responses In another study to evaluate the quality of retrospective assessment in gerontology research, Kosloski, Datwyler, and Montgomery (1994) interviewed 242 caregivers anticipating in a longitudinal study of caregiving and compared their contemporaneous and retrospective responses. Their results indicated a moderate to high one-year retrospective reliability for measures of activities of daily living, their sense of duty or obligation to care for the elder, and their level of affection for the elder. In contrast, the respondents tended to significantly underestimate their levels of objective and subjective burden. They concluded that measures of physical functioning and health of the caregiver, which could also be characterized as perceptions on the part of respondent, exhibited very acceptable levels of reliability and appeared suitable for retrospective use. While both this study and the one before examined family members' recall of a relative with dementia, there are similarities with this current research, such as the amount of time of recall and the fact that the subjects generally cannot provide accurate 
information about themselves. In addition, caregivers in both studies had a strong emotional bond and a stake in the outcome of the care provided.

In 1963, Robbins found that reliability was greater for factual information compared to attitudinal information in her study of parent recall on aspects of child development. This author examined the accuracy of recall by comparing retrospective accounts of child rearing obtained from parents of three year olds with reports they had given previously in the course of a longitudinal study that began with the birth of their child. It differed from other appraisals of recall of parental accuracy by focusing on objective, non-attitudinal, long-term aspects of child development, such as the onset of toilet training. In general, Robbins found that the parents were not necessarily accurate in their memory of details about child rearing practices, in spite of having reported them frequently during the course of the longitudinal study. Inaccuracies tended to be in the direction of the recommendations of experts in child rearing, especially on the part of mothers. But, in general, mothers recalled more correctly than fathers. In this study, surveys were most often completed by the child's mother, and most of the questions were factual in nature, and not related to prevailing opinion of how typically-developing children should be raised, thus offering optimal conditions for accurate reporting.

In a 1988 study of the reliability of retrospective survey data on infant feeding, Haaga studied recall among 1200 Malaysian women. He found that women with little or no education, rural residents, and those of Malay ethnicity gave less reliable information. An educated urban woman's answers about the events that took place decades before the date of the interview were less likely to change than was an uneducated rural woman's answers about events that took place one or two years before the interview. In logistic regression analysis, these respondent characteristics were found to be more important determinants of data accuracy than the length of 
recall. The respondent characteristics in this study, in which the average respondent had completed four years of college and resided near an urban area, would suggest more accurate recall.

Sociology professor David Featherman (1980) investigated the reliability of data gathered retrospectively compared to direct observation and real time data collection across the years. He concluded that accurate longitudinal data need not be generated from over-time research designs and that retrospective reports elicited from cross-sectional one-wave studies can provide dynamic data for the study of stability and change in human behavior (Featherman, 1980). He listed the advantages of a single measurement occasion to include the elimination of bias that come from repeated contacts and re-interviews, the reduction of the risk of mortality in a panel, and the reduction of cost in a one-time study compared to repeated studies across many years.

Parent report was found to be "quite accurate" (p. 236) in the estimation of their autistic child's level of functioning, according to Schopler (1976). In his study with Reichler (1972), parents were asked, at an initial interview and before any developmental testing was done, to estimate their child's developmental levels in the areas of sociability, cognition, self-help, language, motor coordination, and overall development. Parental estimates were found to reach significantly high correlations with the results of formal test conducted at the same time. Parents were able to differentiate higher and lower levels at which their child was functioning in different areas, but the authors found that parents had greater difficulty knowing what to do and what to expect from this information.

Miller and Sedey's 1995 study on the validity of parent report measures of vocabulary development in children with Down Syndrome suggested that parents of children with developmental disabilities have lower expectations of their child's development because they 
have been told that their child's development is severely compromised, leading them to underestimate the child's abilities. But they also reported that several studies confirmed that parents estimate their child's performance on cognitive tasks at a higher level than their actual performance on standard tests. This finding of a parent's uneven reporting of their child's ability may be related to what a parent on the ME-List described as "two-headedness." "I think we have to be what a friend calls "two-headed" about our kids, which, in a funny way, means being both more optimistic and less optimistic than anyone else. I have to be the one who believes in and absolutely will not settle for less than a great life for him, and the one who completely acknowledges just how many deficits he has and how much there is still to do" (T. Mykland, Internet correspondence, October, 2000).

Cunningham and Sloper (1984) offered evidence to suggest that parents of children with developmental disabilities can provide reliable information regarding their child's language development. They explained that a parent's observation of a child with learning disorders is often a necessary and invaluable source of information, but often professionals dismiss the parent report as biased and overrated when it may be the professional, who does not observe the behavior seen and reported by the parent, who is biased against an accurate parent report. A handicapped child, they explain, will often talk more in a familiar setting and use more mature language when it serves an important function, and a parent's constant contact gives them an opportunity to observe this and to interpret unclear speech patterns that a professional may conclude is nonfunctional. In their study comparing mother's scoring of a vocabulary checklist with professional assessments of expressive and receptive language, the authors found that the maternal vocabulary scores were found to be significantly and highly correlated to the professional's assessments. And, the authors gave an example of the accuracy of parent report 
from their own research: when the professional and maternal assessments differed, Cunningham and Sloper, found, on several occasions, it was more likely the professional who failed to accurately test the child.

Bryan, Pearl, Zimmerman, and Matthews reported (1982) on their study to compare maternal assessments of their learning disabled child with similar maternal assessments of nondisabled children. They selected a sample from a school population that was not receiving special education services, so the mother's characterizations were not likely to be affected by how a special education teacher characterized their learning disabled child. They examined the mothers' perceptions of their children's strengths and weaknesses, the mother's beliefs about the cause of those strengths and weaknesses, and what effect a negative perception of a child's ability might have on that child's actual achievement. They found that, in comparison with mothers of nondisabled children, mothers of learning disabled children described their child as having fewer academic strengths, having fewer behaviors that would lead to academic and social achievement, and perceived their child was less skilled in both academic and behavioral domains. Mothers of learning disabled children were also more pessimistic about future performance than were mothers of nondisabled children.

From the research reported above, it seems that retrospective reporting and parent recall of a dependent's level functioning and activities of daily living have, in most but not all reports, correlated well with initial reports, especially when the respondent was given a variety of choices and the questions were factual in nature. The correlation was not so high when the caretaker needed to report on a psychological state or level of caretaker demand, or when the respondent was poorly educated and culturally isolated. Since the questionnaire used in this study (Appendix A), asked only questions about the child's level of functioning at a given time and did not inquire 
about the caretakers perceived attachment or burden of stress, this study would offer the opportunity for more accurate recall and parent report. 


\section{Research Questions}

The purpose of this research was to examine the differences in ranking of eight different characteristics of children with autism before they began treatment, after completing treatment, and/or at the time the survey was completed, to determine if and how those characteristics changed across time. I also wanted to find if the score on any one or group of these eight characteristics at the time of diagnosis could predict the child's outcome.

Therefore, the major research question answered by this study was "What is the difference between the ranks of eight characteristics of children at the time of their diagnosis with autism and the ranks of those same eight characteristics at the time the survey was completed?

And Sub Question A was "Which, if any, one or combination of these characteristics in young children at the time of diagnosis (Time 1) predicts the treatment outcome?"

Because some of the children who participated in the study had already completed treatment, I wanted to find if the difference in ranks were different for them than for the children who had not yet completed therapy. Thus, Subquestion B was: "Is there a significant difference between the sum of the ranks of the eight characteristic variables across the three points in time?

An ongoing discussion in the literature and among parents is whether or not more hours of treatment $(40+$ a week) led to better outcomes for children than fewer hours, so Subquestion C was included to answer that question for the children in this study. Sub Question C was: "Is treatment outcome different depending on whether a child received 1 to 30 hours, 31 to 40 hours, or more than 40 hours of discrete trial training during an average week?"

Lovaas (1987) and other researchers had indicated that a child's early progress through treatment (Weiss, 1999) predicted a better outcome for the child. I wanted to see if progress through treatment predicted a better outcome for children in this study. So Sub Question D: "What is the relationship between the child's progress through treatment and treatment outcome?" was added. 
Because discrete trial therapy is among most studied of the ABA interventions for young children with autism and has a variety of studies that indicate its efficacy, I limited the research group to children involved in an active discrete trial program for at least one year. Children who are younger, some researchers believe, have the best outcomes from this type of therapy. Therefore, the children in this study must have been diagnosed by the age of three and have completed at least one year of discrete trial treatment before they turned six.

In addition to contributing to the growing body of literature about treatment for young children with autism, the results of this study can assist parents and professionals to understand how what a child takes into treatment can effect that child's outcome from treatment. It also provides additional information on the effect of hours in treatment and progress through therapy as predictors of a child's success.

Perhaps the most unique contribution this study makes to the body of research on autism is the use of a summary definition of recovery as one measurement of treatment outcome. This study was the first to incorporate specific criteria, based on content analysis, for measuring and defining recovery from autism. This definition of recovery includes a broader range of characteristics and behaviors than used by most previous researchers in defining the success of treatments for young children with autism. 


\section{Method}

\section{Measurement}

The instrument used in this research was a 17 page, 50-item survey (see Appendix B). In the survey, participants were asked to recall and rate, through review of their child's records and from memory, eight characteristics possessed by their child around the time of diagnosis (Time 1); at the end of treatment, if applicable, (Time 2); and/or at the time the survey was completed (Time 3). Those eight characteristics were: level of meaningful language; appropriateness of toy play; appropriateness of play with peers; social initiation; the amount of stereotypies observed in the child; amount of sensory concerns; amount of tantruming; and the degree to which the child is successfully toilet trained. These characteristics were based on a scoring system similar to that used by Smith and colleagues to determine each child's functioning at time of diagnosis (Smith, Eikeseth, Klevstrand, \& Lovaas, 1997). In their research, Smith and colleagues used the results of a one-hour parent interview to get diagnostic and descriptive information that they then summed to provide a pathology score (what I will call a "characteristics" score). That score will be used in the current study to determine the characteristics score at diagnosis (Time 1), the characteristics score when treatment ended (Time 2), and the current characteristics score, or characteristics score at the time the survey was completed (Time 3). The Smith et al. research was not the first to use a sum of pretreatment characteristics to determine a child's level of functioning before and after treatment. As early as 1973, DeMyer and colleagues used a similar rating scale, measuring, among other variables, speech, social skills, and intellectual ability. Birnbrauer and Leach (1993) used what they termed "Severity of Disorder" rating at referral and two years later, including all the characteristics included in this research except for the rating of sensory concerns. Eikeseth (1999) used ratings, including intellectual functioning, chronological 
age, language functioning, and social skills, as his pre and post treatment assessment.

The survey used in this study included questions about the child's current age, age at diagnosis, a professional's description of the child's functioning before and after treatment and the results of any intelligence or assessment testing the child had. It also contained a question about other diagnoses the child may have been given, progress through therapy, and average number of hours per week in therapy. Parents were also asked demographic information about their geographic location, level of education, income, and age, and were asked what advice they would give parents of newly diagnosed children.

The survey was piloted on four parents of young children with autism from my practice, and their suggestions were incorporated into the final version. These parents suggested increasing the number of choices for both the Speech and Tantruming items, as well as some changes in the original organization of the survey.

Evidence supporting the content validity of the items used in this questionnaire can be found in the DSM-IV (APA, 1995) diagnostic criteria for autism. Each of the characteristics in the questionnaire was related directly or indirectly to the DSM-IV guidelines for diagnosing an autism spectrum disorder. As mentioned above, the use of a sum score of characteristics as a predicator of outcome has been used successfully in the past (Birnbrauer \& Leach, 1993; DeMyer et al., 1981; Lovaas, 1987).

The summary definition of recovery, new to this research, was based on a content analysis of previous research into recovery from autism, and included the most often used characteristics of recovery as a way of measuring a child's outcome (Poe, 1999). This content analysis was undertaken to gain a better understanding of what the term recovery meant to the professionals and parents who used it in relation to autism. This researcher located, through peer- 
reviewed journals, descriptions in postings on an autism-related listserve, and descriptions in popular press accounts of autism, 26 units of analysis to be analyzed for frequency of specific themes. The units of analysis were sentences and/or phrases used to describe or modify the subject of recovery in the literature. Within those units were recording units, the actual phrases or terms that were coded and categorized under the various themes. Once the recording units were coded and categorized, the frequency of each recording unit was counted in each theme. The most frequently used themes were summarized to develop the definition of recovery used in this research. From this content analysis came the following definition of recovery: A person is considered recovered from autism when he or she has an IQ in the normal range with normal intellectual functioning, attends school in a regular classroom (or holds a full-time job) without supports, no longer demonstrates autistic behaviors, is indistinguishable from his or her peers, and displays normal adaptive, social, emotional, and verbal functioning.

This summary definition was used as the basis for a checklist in Question Number 44 of the Parent Survey (Appendix B). Participants were asked to check as many of the eight elements of recovery (found in the above definition) that applied to their child, and the number of checks became that child's recovery score.

\section{Procedure}

Volunteers who chose to participate were given the choice of receiving the survey by email attachment, by fax, or by U.S. Postal Service. About a third were sent an email attachment of the survey, four were sent the survey by fax, and the rest of surveys were mailed. Each participant also received a cover letter explaining the purpose of this research and acknowledging the approval of the West Virginia University College of Human Resources and 
Education Institutional Review Board. This letter explained that participation in the study was voluntary, participants need not answer all of the questions, they could withdraw from the participant group at any time, and that all results would be held in confidence. Instructions were included on the survey as to how it could be emailed, faxed, or mailed back to me. For those who chose to receive and return the survey via the U.S. Postal Service, I included a self-addressed, stamped envelope in which the survey could be returned.

Approximately 160 parents and/or professionals who worked with families (two respondents were therapists who offered to give the survey to the families they worked with) responded to my online requests for volunteers to complete the survey. One hundred fifty-one of those respondents fit the criteria set for participants and were sent the 17-page questionnaire (Appendix B). Most (100) were sent by U.S. Mail, four were faxed, and the remaining were attached to an email message.

I analyzed survey results once I had received thirty completed responses, and continued to analyze those in excess of thirty responses until the data entry was concluded, at which time I had received 85 useable survey responses.

\section{Participants}

Participants were parents of young children who were formally diagnosed with autism before age four and whose child had been involved in an active discrete trial training program (also referred to from here on as "the treatment" or "therapy") for at least one year before age six. Though this research was limited to those using discrete trial methodology, a form of ABA, for at least one year, participants could also have employed additional interventions.

Any parent with a child that met these criteria and who agreed to respond was included in the study. These participants were recruited by an explanatory email (Appendix A) posted on 
four autism-related list serves, the Me-List, the FEAT Newsletter, the DTT-NET list, and the Recovery List.

The Me-List is a private, closed-membership list that provides a forum for families and professionals using the discrete trial method of intervention. According to list owner Ruth Allen, about 2,500 people subscribe to the Me-List, and about 75 to $85 \%$ of those are parents of children with autism. (Allen, 2000, Internet correspondence).

The FEAT (Families for Early Autism Treatment) Newsletter serves professionals and families across the country who are who are involved with the intervention for a young child with autism; it has 11,000 subscribers and a pass-along, or forwarding readership ratio of 1:1, which puts the actual circulation at 22,000, according to FEAT Newsletter editor Lenny Schafer (Schafer, 2000, internet correspondence).

The DTT-NET list, which has 844 members (J. Godwin, Internet correspondence, 2000), serves families and professionals that are interested in or utilizing both discrete trial methodologies and Natural Environment Training, also known as Mand Training or Verbal Behavior training. The Recovery List Group is an offshoot of the Me-List, and is composed of people who are specifically interested in recovery from autism through discrete trial training.

Ninety-two surveys were returned, a response rate of $57 \%$. Of those ninety-two, 85 met the criteria for inclusion. The other seven surveys that were not used either represented children who did not meet the criteria of the study (4) or arrived after the data was analyzed (3). Respondents represented at least 28 states and three foreign countries (Australia, the Philippines, and Great Britain). All responses were from parents of children with autism or an autism spectrum disorder. 


\section{Research Design and Data Analysis}

This research was designed to provide descriptive information as well as correlational and causal-comparative results. Statistical analysis of the data was performed separately on the two different groups represented by respondents: those who had completed treatment and those who had not.

The research questions and the variables used to answer them are displayed in the following table (Table 1).

Table 1: Variables used in each research question.

\begin{tabular}{|c|c|c|c|c|c|c|}
\hline 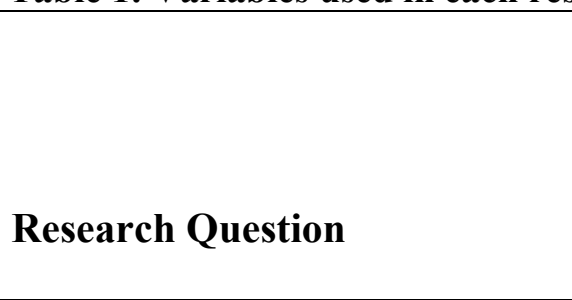 & $\begin{array}{c}\text { Time 1 } \\
\text { Character } \\
\text {-istics at } \\
\text { time of } \\
\text { diagnosis }\end{array}$ & $\begin{array}{c}\text { Time } 2 \\
\text { Character } \\
\text {-istics at } \\
\text { time } \\
\text { treatment } \\
\text { ended }\end{array}$ & $\begin{array}{c}\text { Time } 3 \\
\text { Character- } \\
\text { istics at } \\
\text { time } \\
\text { survey } \\
\text { completed }\end{array}$ & $\begin{array}{l}\text { Rec- } \\
\text { overy } \\
\text { Score }\end{array}$ & $\begin{array}{l}\text { Hours in } \\
\text { Therapy }\end{array}$ & $\begin{array}{l}\text { Progress } \\
\text { through } \\
\text { therapy }\end{array}$ \\
\hline $\begin{array}{l}\text { What is the difference between the } \\
\text { ranks of eight characteristics of } \\
\text { children at the time of their diagnosis } \\
\text { with autism and the ranks of those } \\
\text { same eight characteristics at the time } \\
\text { the survey was completed? }\end{array}$ & $X$ & & $X$ & & & \\
\hline $\begin{array}{l}\text { Which, if any, one or combination of } \\
\text { these characteristics in young children } \\
\text { at the time of diagnosis (Time 1) } \\
\text { predicts the treatment outcome? }\end{array}$ & $\begin{array}{c}\mathrm{X} \\
(\text { each } \\
\text { variable })\end{array}$ & & & $X$ & & \\
\hline $\begin{array}{l}\text { Is there a significant difference between } \\
\text { the sum of the ranks of the eight } \\
\text { characteristic variables across the three } \\
\text { points in time? }\end{array}$ & $X$ & $X$ & $X$ & & & \\
\hline $\begin{array}{l}\text { Is treatment outcome different } \\
\text { depending on whether a child received } \\
\text { one to } 30 \text { hours, } 31 \text { to } 40 \text { hours, or } \\
\text { more than } 40 \text { hours of discrete trial } \\
\text { training during an average week? }\end{array}$ & & & & $X$ & $X$ & \\
\hline $\begin{array}{l}\text { What is the relationship between the } \\
\text { child's progress through treatment and } \\
\text { treatment outcome? }\end{array}$ & & & & $X$ & & $X$ \\
\hline
\end{tabular}


Those who had completed treatment, regardless of the reason, had already used the discrete trial method for one year or more and had moved on to other age-appropriate learning and/or interventions. This group ( $\underline{n}=26)$ included seven of the eight children who had the highest score possible on the recovery question, but also included children who had not done well in this treatment or whose parents thought their child needed a different type of treatment at the time discrete trial training was halted. The group who had not yet completed treatment $(\underline{n}=59$ were still actively involved in discrete trial intervention at the time this survey was completed.

Two different dependent variables were used as outcome measures, depending on the research question and/or the requirements of the statistical test. For the Main Research Question and Research Sub Question B, the Current Characteristic Sum (also referred to as Time 3, the sum of all rankings on the eight characteristics at the time the survey was completed) was used as the dependent variable. For Research Sub Questions A, C, and D, the dependent variable was the Recovery Score (derived from survey Question 44). Treatment outcome, then, could refer to either of Recovery Score or Current Characteristic Sum, depending on the question.

For each of the eight variables representing the characteristics ranking at Time 1, Time 2, and Time 3, parents were asked to mark the description of functioning that best described their child at that time from the four (or in the questions about speech and tantruming, five) choices listed. Those choices were organized beginning with the lowest functioning and concluding with the highest functioning choice (see questionnaire in Appendix B). The parent's mark denoting their child's functioning at each time was ranked, during data entry, on a scale from one to four (or five, depending on the question), with one representing the lowest level of functioning and four (or five) representing the highest level of functioning. 
The data were examined to determine if/how the sum of the eight characteristics, based on the parent's estimation at the time of diagnosis (Time 1), changed for either group after at least one year of discrete trial training. Then each of those eight Time 1 variables were correlated with the recovery score for each group using Spearman's Rho, to determine if any individual characteristic correlated with recovery.

This study also used ANOVA to examine the differences in amount of treatment hours per week and the child's rate of progress through treatment to see if they differed with recovery score. Other questions were included to learn more about what parents described as the success of other treatment options as well as their best advice to give other parents. A detailed description of the data analysis for each research question follows.

The Wilcoxon Paired Rank Test was the statistical analysis used to answer the major research question "What is the difference between the ranks of eight characteristics of children at the time of their diagnosis with autism and the ranks of those same eight characteristics at the time the survey was completed?"

Those eight characteristics, also referred to as variables or characteristics variables, were speech, social attachment, toy play, sensory problems, peer play, tantruming, stereotypes, and toilet training, and they were measured, depending on the group, across two or three time periods. Those time periods were:

- Time 1: also referred to as the Characteristics Sum at Diagnosis (all groups)

- Time 2: also referred to as the Characteristics Sum immediately after treatment ended, (only the group that had completed treatment, $\mathrm{n}=26$ )

- Time 3: also referred to as the Current Characteristics Sum, or the Sum of characteristics when the survey was completed (all groups) 
The Wilcoxon was used to compare the rankings of the sum of the eight variables for the participants who had not yet completed treatment $(\underline{n}=59)$ from the time of diagnosis (Time 1$)$ to the time the survey was completed (Time 3). A Wilcoxon was also completed for each of the eight variables at Time 1 and Time 3 to determine if each variable was significant when examined separately and not just within the sum.

The Wilcoxon Paired Ranks test is a nonparametric equivalent to $t$ tests for dependent means, which means that there are two scores for each subject (Time 1 and Time 3 ). The test ranks the difference in the participant's raw scores between the two time points, retaining the signs of the differences. It reports the number of participants who had negative ranks, meaning that participants lost ground between Time 1 and Time 3, as well as the number of positive scores, those who gained between Time 1 and Time 3 . The test then determines whether there is a significant difference in the magnitude of the positive and negative ranks.

The Spearman's Rho uses ranked data to determine if there was any significant correlation between each of the eight variables at the time of diagnosis and the recovery score to answer Sub Question A, Which, if any one or combination of these characteristics in young children at the time of diagnosis (Time 1) predicts the treatment outcome (Time 3)?

The Spearman was chosen because it is the correlation test used for ranked data. It is derived from ranking both the dependent and the independent variable. Like the Pearson product moment coefficient of correlation, it ranges from -1 to +1 . When each individual has the same rank on both variables, the correlation coefficient will be +1 , and when their ranks on one variable are opposite of their ranks on the other variable, the correlation coefficient will be -1.00 . If there is no relationship at all between the variables, the coefficient will be zero. (Ary, Jacobs, \& Razavieh, 1985). The Spearman was utilized with each of the two groups. 
The Friedman Rank Test for K correlated samples was chosen to answer Sub Question B, Is there a significant difference between the sum of the ranks of the eight characteristic variables across the three points in time?" It was used for only the group that had completed treatment $(\underline{n}=26)$.

The Friedman Test for correlated samples is a nonparametric equivalent to a repeated measures analysis of variance and uses ranked data and tests the null hypothesis that there are no differences in the mean ranks across the different points in time. In this study, it was used to test the differences between the sums of the eight characteristic variables across the three different times: Time, 1, Time 2, and Time 3, for the respondent group who had already completed therapy. It was also used to examine the changes in each individual variable across the time periods.

An ANOVA was used for both the group that had completed treatment and the group that had not to determine the answer to Sub Question C: Is treatment outcome different depending on whether a child received 1 to 30 hours, 31 to 40 hours, or more than 40 hours of discrete trial training during an average week? For this question, the independent variable had three levels of time: fewer than 30 hours, 31 to 40 hours, and 41 or more hours per week on average. These levels were collapsed from those offered as choices in Question 17, and were divided into those particular categories because they best represented the research literature examining the importance of hours in treatment with outcome (Birnbrauer \& Leach, 1993, Lovaas, 1987). The dependent variable was the recovery score.

An ANOVA was also utilized with each of the two groups to answer the last of the research questions Sub Question D: What is the relationship between the child's progress through treatment and treatment outcome? The independent variable had three levels, slow, moderate, 
and quick, collapsed from the nine choices offered in survey question 18. In the responses to this question, there were no participants claiming the first three answers (regressed, no progress, very slow) and the remaining six choices represented the subcategories of slow, moderate, and quick. Each subcategory had two choices. The dependent variable was the recovery score.

An ANOVA was the most appropriate way to test the variation among those with more or fewer hours in treatment as well as greater to lesser progress through treatment (using categorical or nominal scores) against outcome based on the recovery score (an interval measurement).

I also asked participants "If you know a child who has recovered from autism, what do you think was the single most important skill or ability that child possessed BEFORE treatment began that led to his or her recovery?"

By using content analysis for the question of the participant's impression of the most important skill or ability leading to recovery, I was able to determine what these participants believed, from their own experience, to be the most important characteristic.

Content analysis is the scientific method of research developed for describing various facets of communication content in summary fashion. It can be used unobtrusively in any type of communication from which the researcher desires a means of systemizing and quantifying information that has not been previously organized to suit the researcher's purpose. In general, content analysis requires extensive reading, sorting, and searching through relevant materials, organizing that material and developing appropriate themes or categories, comparing categories, and then summarizing the findings.

Additionally, I asked parents the open-ended question "If you were counseling a parent whose child was recently diagnosed with autism, what would be the most important information you could give them based on your own experiences?" in order to learn what 
parents would consider to be the best advice they had gained from their own experiences. I again used content analyses to create a list of the most frequently mentioned answers.

Many children with autism have more than one diagnosis, and many experience more than one treatment because parents understandably want to do all they can to improve their child's functional abilities. I included two questions to identify additional diagnoses as well as additional treatments and analyzed those results using content analysis. 


\section{Results}

\section{Participants:}

Of the 85 children in this study, 72 were male $(84 \%)$ and 13 were female $(15 \%)$. Their median age at the time of this study was 5 years, 7 months, and the median age at diagnosis was 2 years, 8 months. Autism was the most common label given them for a diagnosis with 52 children (61 \%), 36 were labeled as having Pervasive Developmental Disorder, Not Otherwise Specified (PDD-NOS), one with Asperger's, and one “other," explained as a child with "multiple disabilities with autistic tendencies."

Participants were asked to identify any and all applicable answers to Question 5, "What kinds of assessments were used to determine that diagnosis?" "Observation by a professional" was the single most often marked means of assessment (18 respondents) used for diagnosis, and was almost always included (by 63 respondents) as one of the methods of assessment in every completed answer. Nine respondents reported their children had been assessed using all five methods listed, while nine reported that observation, a rating scale, and another type of assessment (e.g., language, hearing evaluation, etc) had been used in forming the diagnosis. Eight responded that their child had been assessed in four ways: by a professional, the use of a rating scale, a functional assessment of ability, and another type of assessment. Another eight reported their children were diagnosed using only observation and a rating scale; while still another eight were diagnosed using observation, a rating scale, and a functional assessment of ability. Observation by a professional was clearly the most common method of assessing the child to obtain a diagnosis in this study.

Fifty-six (66\%) had no other diagnosis than one in the autism spectrum, while $29(34 \%)$ did have an additional diagnosis. The most commonly mentioned additional diagnoses were food 
allergies with eight responses, followed by seizure disorder (including Landau Kleffner variant and absent seizure activity) with six responses, and Obsessive Compulsive Disorder with four respondents. Asthma and allergies each received three responses, while hypotonia, yeast buildup in the intestine, mental retardation, and Attention Deficit Hyperactivity Disorder received two mentions each. Other conditions mentioned only once included chronic sinusitis, spastic diplegia (a type of cerebral palsy), heavy metal toxicity, hypothyroidism, metopic synostosis, metatarsus abductus, sensory integration dysfunction, a chromosomal anomaly (IDIC 15), hyperinsulinemia, obesity, narrow trachea, recurrent croup, dyspraxia, auditory processing problems, NIDS (neuroimmune dysfunction syndrome, which the parent reported "cause the autism symptoms"), intestinal problems (part of the intestine is missing), GERD (reflux disorder), and gastritis. Children in this survey had been in discrete trial therapy, on average, 27 and one half months. The median number of hours a week the children spent in discrete trial training each week was between 31 to 40 hours a week. For the analysis of the child's progress through discrete trial therapy and recovery, the original 10 choices were collapsed into three categories: slow, moderate, and quick. But before collapsing these data, the raw numbers indicated that more than a third of the children's response through treatment was "quick in most areas, but variable." For children who had completed their discrete trial training, the average number of months the child was actively involved in the treatment was 24 months. On average, the amount of time since discrete trial treatment had stopped was 18.41 months, with a range of 1 month to 70 months. Twenty-eight respondents answered Questions 23, explaining why they had stopped discrete trial treatment. The most often cited reason for ending treatment was the child had completed the treatment successfully (14 respondents, $50 \%$ of responses), followed by the child had begun school, with 5 responses (18\% of respondents). Four stopped treatment to concentrate 
on developing other skills, primarily social skills; two moved out of state from the services they were receiving, one thought the school that offered discrete trial training was failing to deliver it correctly, one thought their child needed a "fresh approach," and one stopped because her son was being physically abused in his program (tied to the chair).

The amount of time that passed between the child's diagnosis and the beginning of discrete trial training averaged 6.6 months, with a range from 0 to 27 months. The most often cited single reason (parents could choose more than one) for delay in getting treatment were "on a waiting list" with 13 responses $(16.5 \%)$ and "tried other treatments first" (15.3\%) followed by “didn't know about DTT” with 9 responses $(10.6 \%)$.

Autism professionals often try to give inquiring parents an idea of the severity of their child's disorder by describing the child in terms of how well they believe the child is functioning. This survey asked parents how their child might have been described at the time of diagnosis, immediately after treatment, and at the time the survey was completed. Choices included "high functioning," " moderately functioning," " low functioning," "mentally retarded" " none of the above," and "other," with "recovered" added as a choice for Time 3. Twenty-nine of those responded reported that their child's level of functioning, according to an autism professional/educator, increased from the time of diagnosis to the current time. Thirty reported that the professional's description stayed the same over the same time period, and only four reported that the professional's description of functioning had decreased.

Demographically, the average respondent had completed a four-year college or university degree, lived in a medium-sized city, had an annual income of between $\$ 40,000$ to $\$ 50,000$, and was in his or her thirties. 


\section{Statistical Analysis:}

\section{Major Research Question}

The Wilcoxon Matched Pairs Test, a nonparametric statistical test equivalent to the $t$ test for dependent means, was used to test the differences in ranks of the sum of the eight variables at Time 1 and Time 3. This group included only the 59 respondents who had not yet completed treatment. The results of the Wilcoxon indicated that there was a significant difference in the magnitude of the sums of positive versus negative ranks $(Z=-6.684, p<.001)$. That is, there is a significant difference between the ranking of the sums of characteristic variables at diagnosis (Time 1) and at the time the survey was completed Time 3. In fact, all 56 participants had a positive rank, meaning that each participant's child improved in these eight areas from the time of diagnosis to the time the survey was completed.

A descriptive examination of the increase in this group's ratings from Time 1 to Time 3, is illustrated in Table 1, where the median ranks from each of the eight variables are compared from Time 1 to Time 3.

Table 2: Median Characteristics Scores Across Two Points in Time for Group Who Had Not Yet Completed Treatment $(n=59)$

\begin{tabular}{|c|c|c|}
\hline & $\begin{array}{c}\text { Time 1: At } \\
\text { Diagnosis }\end{array}$ & $\begin{array}{c}\text { Time 3: Survey } \\
\text { Completed }\end{array}$ \\
\hline Amount of Speech & 1 & 5 \\
\hline Social Attachment & 2 & 3 \\
\hline Toy Play & 1 & 3 \\
\hline Sensory Problems & 2 & 3 \\
\hline Peer Play & 1 & 2 \\
\hline Tantruming & 3 & 4 \\
\hline Stims & 2 & 3 \\
\hline Toilet Training & 1 & 4 \\
\hline
\end{tabular}


While the Wilcoxon showed the positive growth in the sums of all eight characteristic variables from Time 1 to Time 3, Table 1 illustrates that for each of the eight characteristics the median scores also increased over the time of treatment. The greatest increase was in Amount of Speech, at 4 points, followed by Toilet Training at 3 points, then Toy Play with 2 points difference. Overall, the Wilcoxon test indicated a significant difference between time periods on each variable, and the means increased for each time for all eight characteristic variables $(\mathrm{p}<.005)$.

I also looked at the variability between characteristics at the time of diagnosis (Time 1) using a boxplot graph. The results are below in Table 3 .

Table 3: Boxplot illustration of variability among characteristics at time of diagnosis.

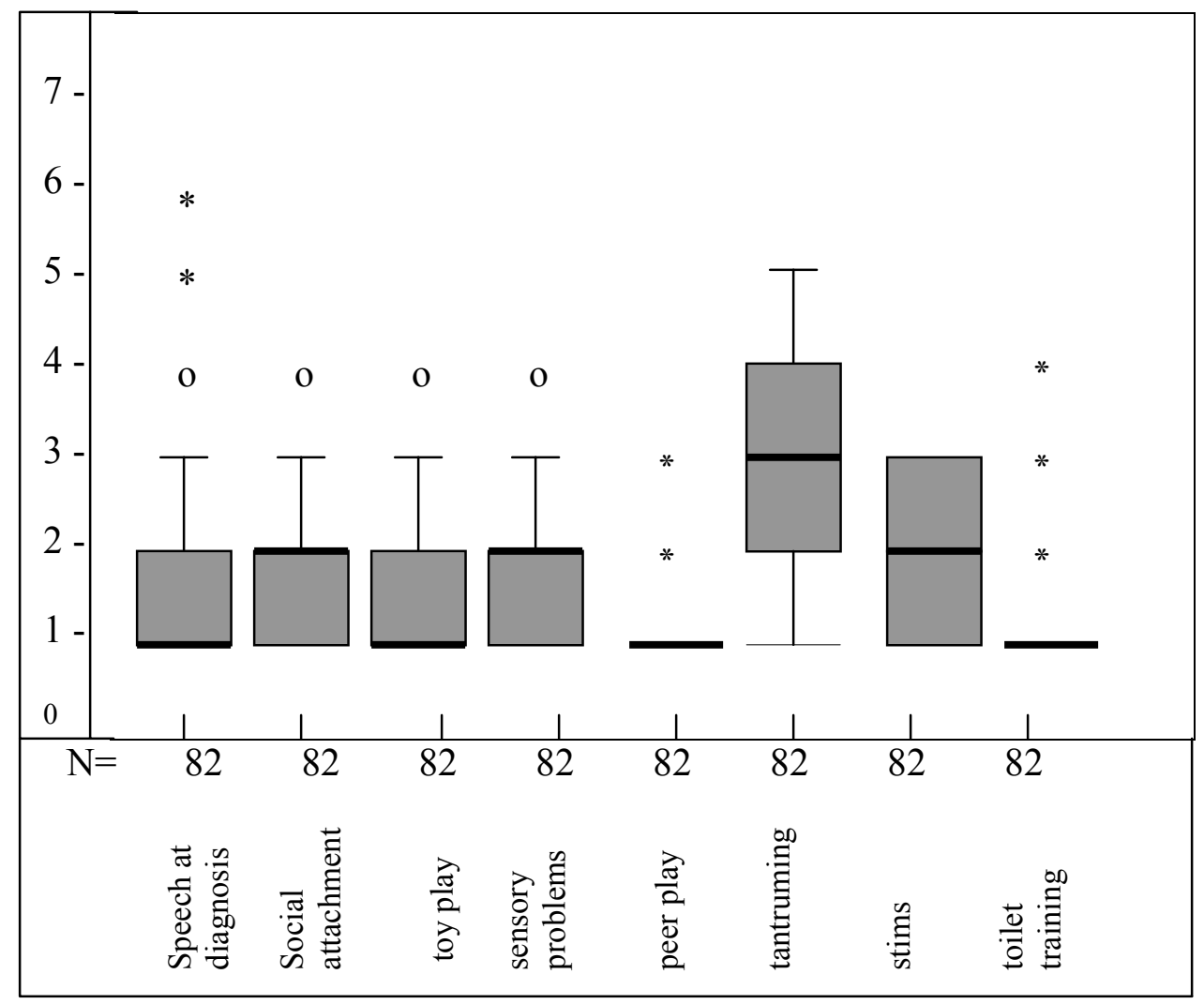

In Table 3, the longer rectangles for the two variables "tantruming" and "stims" indicate more variability in those characteristics than the remaining six variables. That is, the middle $50 \%$ 
of the values is contained within a larger range of the data. The flat lines for "peer play" and for "toilet training" indicate no variability, or a value of one (except for the outliers, indicated by an asterisk). The amount of variation illustrated above, coupled with the lack of significant findings in any of the characteristics for this group, indicate that the variability of the characteristics probably had little effect on the outcome of the data.

The Wilcoxon statistic and Table1 both answer the main research question, "What is the difference between the ranks of eight characteristics of children at the time of their diagnosis with autism and the ranks of those same eight characteristics at the time the survey was completed?" The difference between the group ranks of the eight characteristics, as well as each individual characteristic, is positive and indicates improvement across characteristics measured.

\section{$\underline{\text { Research Sub Question A }}$}

I then used Spearman's Rho to answer Sub Question A: "Which, if any, combination of these characteristics in young children at the time of diagnosis (Time 1) predicts the treatment outcome?" to find the relationship between each of the eight characteristic variables and the recovery score for those children who had completed treatment and those who had not yet completed treatment (Table 2). Among the children who had not yet completed treatment, (last column) there were no significant correlations. But for the group who had completed treatment (middle column), one variable, toy play, was negatively correlated with recovery, predicting that children with lower toy play scores at the time of diagnosis, will have a higher recovery score at the end of treatment. 
Table 4: Correlation Between Eight Characteristics Before Treatment and Recovery Score

\begin{tabular}{|l|c|c|}
\hline Characteristic & $\begin{array}{l}\text { Treatment Concluded } \\
(\underline{\mathrm{n}}=26)\end{array}$ & $\mathrm{r}$ \\
\hline & $\mathrm{r}$ & .055 \\
\hline Amount of Speech & -.132 & -.122 \\
\hline Social Attachment & -.203 & .107 \\
\hline Toy Play & $-.545^{*}$ & .018 \\
\hline Sensory Problems & .178 & -.038 \\
\hline Peer Play & -.336 & .007 \\
\hline Tantruming & .058 & .113 \\
\hline Stims & .069 & -.007 \\
\hline Toilet Training & .134 & \\
\hline
\end{tabular}

* $(\mathbf{p}<.01)$

\section{$\underline{\text { Research Sub Question B }}$}

To answer Sub Question B, Is there a significant difference between the sum of the ranks of the eight characteristic variables across the three points in time?" I utilized the Friedman Rank Test to examine the mean ranks on the sum of the eight characteristic variables for the 26 participants that had scores for all three points in time, Time 1, Time 2, and Time 3. The results of this test show a significant increase in all score differences at the time of diagnosis, immediately after treatment, and the time the survey was completed. The Friedman Test was also used to test each characteristic variable across time, and the results indicate a significant difference between time periods, with the means increasing between each time for all eight $(\mathrm{p}<.005)$. 
These findings also confirms the answer to my major research question these eight variables for young children with autism improve across the time of treatment $\left(\chi^{2}=25.879, \mathrm{df}=2\right.$, $\mathrm{p}<.001)$.

The resulting mean ranks were, for the characteristic sum at diagnosis, 1.23; for the characteristic sum at time treatment ended, 2.21; and for the characteristic sum at time survey was completed, 2.56 .

In a descriptive examination, Table 3 illustrates how the ranks of each variable changed across three time periods.

Table 5: Median Characteristics Scores Across Three Points in Time for Group Who Had Completed Treatment ( $\underline{n}=26)$

\begin{tabular}{|l|c|c|c|}
\hline & $\begin{array}{c}\text { Time 1: At } \\
\text { Diagnosis }\end{array}$ & $\begin{array}{c}\text { Time 2: Imm. } \\
\text { Aft. Tx. }\end{array}$ & $\begin{array}{c}\text { Time 3: Time } \\
\text { Survey Compltd }\end{array}$ \\
\hline $\begin{array}{l}\text { Amount of } \\
\text { Speech }\end{array}$ & 2 & 5 & 6 \\
\hline $\begin{array}{l}\text { Social } \\
\text { Attachment }\end{array}$ & 2 & 4 & 4 \\
\hline Toy Play & 1.5 & 4 & 3 \\
\hline $\begin{array}{l}\text { Sensory } \\
\text { Problems }\end{array}$ & 2 & 3 & 3 \\
\hline Peer Play & 1 & 3 & 4 \\
\hline Tantruming & 2.5 & 4 & 3 \\
\hline Stims & 2 & 3 & 4 \\
\hline $\begin{array}{l}\text { Toilet } \\
\text { Training }\end{array}$ & 1 & 4 & 4 \\
\hline
\end{tabular}

Again, with this group of 26, each variable showed an increase from the time of diagnosis (Time 1) until the time the survey was completed (Time 3), and the greatest increases were in Amount of Speech and Toilet Training followed by Toy Play. But for this group, there is a middle time to compare--the time treatment ended. In every case, the score increased from the 
time of diagnosis until time treatment ended (Time 2), and, except for Amount of Speech, the chart shows no more increase in ability for these variables from the time treatment ended (Time 2) to the time the survey was completed (Time 3 ).

It's clear from these scores that, for all 85 children in this study, whether they had completed treatment or not, the trend is to improve in at least these eight areas from the time of diagnosis until after at least one year of treatment. The most improvement is seen in Amount of Speech, regardless of whether or not treatment has ended, as well as in the areas of Toilet Training and Toy Play.

\section{$\underline{\text { Research Sub Question C }}$}

For research question $\mathrm{C}$, “Is treatment outcome different depending on whether a child received 1 to 30 hours, 31 to 40 hours, or more than 40 hours of discrete trial training during an average week?" an ANOVA was conducted on both the group that had completed treatment and the group that had not. For both groups, the dependent variable was the recovery score and the independent variable was time in treatment each week. There were three levels for this independent variable (0-30 hours, 31-40 hours, and 41 hours or more), collapsed from the original six choices. For the group that had completed treatment $(\underline{n}=21)$, the results were not significant $(\mathrm{F}=.655 ; \mathrm{df}=2,20 ; \mathrm{p}>.05)$. The number of participants included this test was reduced from the group number of 26 because only 21 participants in this group answered the survey question from which the recovery score was derived (Question 44).

But for the group of children who had not yet completed treatment $(\underline{n}=34)$, the difference was significant $(\mathrm{F}=3.687 ; \mathrm{df}=2, ; \mathrm{p}<.05)$.

A post hoc examination of these results using Tukey HSD indicated that there were no significant mean differences for the pairs of training times $(p>.05)$. This could be because the test was not powerful enough to determine any differences or because the group sizes were unequal. The size of the sample for these groups were, for less than 31 hours, 21 respondents; for 31 to 40 hours, 12 respondents; and for more than 41 hours, two respondents. Again, the number 
of participants included in this test was reduced from the group number of 59 because only 34 participants in this group answered the survey question from which the recovery score was derived.

Table 6: Means for ANOVA for each group for Sub Question C

\begin{tabular}{|c|c|c|c|}
\hline Group who had completed Tx & Number & Mean & Standard Deviation \\
\hline Level 1: 0-30 hours & 17 & 4.24 & 2.88 \\
\hline Level 2: 31-40 hours & 4 & 5.50 & 3.0 \\
\hline Level 3: 41 or more hours & 1 & 2.00 & - \\
\hline
\end{tabular}

Group that had NOT completed Tx

$\begin{array}{llll}\text { Level 1: } 0-30 \text { hours } & 21 & 1.81 & .27\end{array}$

$\begin{array}{llll}\text { Level 2: } 31-40 \text { hours } & 12 & 3.25 & 2.30\end{array}$

Level 3: 41 or more hours $\quad 2 \quad 4.00 \quad 1.82$

Because the questionnaire instructed parents to select between six options for time in treatment (these six were collapsed into three levels for the ANOVA described above), that original data was used to run individual ANOVA's on each of the six time selections. There were no significant differences for any of those six time periods and the recovery score.

The six options for time in treatment each week were then collapsed into two levels, the first representing one to thirty hours and the second representing 31 to 51 or more hours, to see if this division of hours would indicate any significant difference between amount of hours in treatment and recovery. There were no significant differences in this ANOVA.

\section{$\underline{\text { Research Sub Question D }}$}

Research Question D "What is the relationship between the child's progress through treatment and treatment outcome?" was tested also using an ANOVA for both groups. Again the dependent variable was the recovery score but this time the independent variable was the nature of progress, with three levels (slow, moderate, and quick). The results were significant for the group that had completed treatment $(\underline{\mathrm{n}}=21)(\mathrm{F}=5.794, \mathrm{df}=2,19 ; \mathrm{p}<.05)$.

Again the Tukey HSD was used as a post hoc test to determine any significance between the different levels of progress. This time there was a significant difference between the slowest 
group and the quickest group $(\mathrm{p}=.008)$, but not between the slowest and the moderate group and the moderate and quickest group.

The results of the ANOVA were not significant for those children who had not yet completed therapy $(n=34),(F=1.909 ; d f=2,32 ; p>.05)$.

Table 7: Means for ANOVA for each group for Sub Question D

$\begin{array}{llccc}\text { Group who had completed TxNumber } & \text { Mean } & \text { Deviation } \\ \text { Level 1: slow progress } & 5 & & 1.40 & .55 \\ \text { Level 2: moderate } & 4 & 4.00 & 2.83 \\ \text { Level 3: quick progress } & 13 & 5.62 & 2.60\end{array}$

Group that had NOT completed Tx

$\begin{array}{llll}\text { Level 1: slow progress } & 3 & 1 . & .00 \\ \text { Level 2: moderate } & 11 & 2 . & .43 \\ \text { Level 3: quick progress } & 21 & 2.86 & .44\end{array}$

Content analysis

Question 45 asked parents "If you know a child who has 'recovered' from autism, including your own child, what do you think was the single most important skill and/or ability the child possessed BEFORE treatment that led to his or her recovery?" Thirty-four parents responded with one or more answers. Using content analysis (Appendix D) the most commonly mentioned skill or ability was language skills (15 references), followed by intellectual ability (5). Two responses each were made for easily reinforced, eye contact, willingness to learn, desire to please, ability to imitate, no sensory issues, and progressed normally through the first 12 months of life.

When asked, "If you were counseling a parent whose child was recently diagnosed with autism, what would be the most important information you could give them?" (Question 46), 75 parents shared one or more bits of information they thought would be valuable (Appendix E). The most common response was to give them information about ABA (42), and of those 12 parents specifically mentioned discrete trial training. Twelve mentioned that they would suggest trying a special diet, usually the gluten-free, casein free (GFCF) diet. Nine urged 
parents of newly diagnosed children to utilize speech and language services. Seven references were made to encourage parents to read about autism and its treatments, and the most commonly mentioned book was Catherine Maurice's Let Me Hear Your Voice, a 1993 account of Maurice's use of ABA to recover her two children previously diagnosed with autism. Seven more references were made for becoming involved, including being persistent and a constant advocate. Five mentions were made suggesting parents find support groups or other support, four would tell parents of newly-diagnosed children not to give up hope (for a bright future, for example) for their child, and four suggested finding a good preschool. Four respondents would encourage parents to find out all they could about different kinds of treatment, including the variations in ABA, and four would encourage parents of newly-diagnosed children to expose their children with autism to normally developing children as much as possible.

Using a DAN doctor (a member of Defeat of Autism Now, doctors who use biomedical treatments for children with autism), applying for waiver (or Title 19), trying verbal behavior training, enrolling in Early Intervention, finding a competent ABA consultant, and using Sensory Integration services were suggestions listed three times each. Two suggestions each were made for going online to learn about autism, finding out about allergy and yeast testing, keeping their child engaged as much as possible, and urging parents to take care of themselves.

Respondents were asked "What (if any) treatments for autism have you chosen for your child in addition to applied behavioral methods?" (Table 4) Seventy- six of the 85 respondents answered that they did use additional treatments, and almost all of those used more than one additional treatment. The most frequently named additional treatment was speech and language pathology intervention, with 23 responses, 21 with what the parent considered a positive outcome and two with no significant progress noted. The use of a GFCF diet was the next most-often mentioned additional treatment, with 21 responses. Of those, 18 parents thought the results of this treatment were positive, and three reported no improvement/change. Occupational therapy was the third most commonly mentioned additional treatment, with 19 responses, 18 positive and one with no change noted. Thirteen responded that sensory 
integration had been used with their child (which is considered a form of Occupational Therapy but was listed separately in this study) and of those, 11 considered the results positive and two thought there was no change from the treatment. (See Appendix D for a more complete report).

It is important to note that the parents who utilize a certain type of treatment might be biased in their perception of its effectiveness. In addition, respondents who found a treatment ineffective might not have continued that treatment and would not include it in this accounting. Another consideration is that many of the treatments listed here have not been shown to be effective in the research literature, even though they are reported to be effective by parent report. And, since many of these treatments were used at the same time as discrete trial therapy, the effectiveness of each treatment alone could not be determined. A functional analysis of each treatment for each child could be completed to provide a more accurate account of treatment effectiveness.

Table 8 - Listing of Additional Treatments, Parent's Impression of Outcome

\begin{tabular}{|l|c|c|c|c|}
\hline $\begin{array}{l}\text { Additional } \\
\text { Treatment }\end{array}$ & Number Reporting & $\begin{array}{l}\text { Positive } \\
\text { Response }\end{array}$ & $\begin{array}{l}\text { Negative } \\
\text { Response }\end{array}$ & $\begin{array}{l}\text { No Change } \\
\text { Reported }\end{array}$ \\
\hline Accupressure & 1 & & & 1 \\
\hline Anti-fungal Tx & 1 & & & 1 \\
\hline Anti-stealth VH & 1 & 7 & & 2 \\
\hline AIT & 9 & 1 & & \\
\hline B6 Vitamin & 2 & 1 & & \\
\hline Cod Liver Oil & 1 & 1 & & \\
\hline Comm. Ther. & 2 & 2 & & \\
\hline Cranial sacral & 3 & 3 & & \\
\hline DAN protocol & 5 & 2 & & \\
\hline Diet Manipultn & 2 & 3 & & \\
\hline DMG & 2 & & & \\
\hline Dr. Goldberg & 2 & & & \\
\hline
\end{tabular}




\begin{tabular}{|c|c|c|c|c|}
\hline Fast Forward & 3 & 3 & & \\
\hline Flax Seed Oil & 1 & 1 & & \\
\hline Floor Time/Dev & 9 & 7 & & 2 \\
\hline Fluency/VB & 1 & 1 & & \\
\hline GCFC & 21 & 18 & & 3 \\
\hline Gym Class & 1 & 1 & & \\
\hline Hvy Met Detox & 2 & 1 & & 1 \\
\hline Homeopathy & 2 & 2 & & \\
\hline Hippotherapy & 3 & 2 & & 1 \\
\hline ImmuneGG & 2 & 1 & & 1 \\
\hline Medications & 13 & 9 & 1 & 3 \\
\hline Music therapy & 2 & 2 & & \\
\hline NOT & 1 & 1 & & \\
\hline Occup Therapy & 19 & 18 & & 1 \\
\hline PECS & 5 & 5 & & \\
\hline Phys Therapy & 7 & 6 & & 1 \\
\hline PRT/Koegels & 2 & 2 & & \\
\hline PBS & 1 & 1 & & \\
\hline Secretin & 11 & 3 & 1 & 4 \\
\hline Self-Mngmt. & 1 & 1 & & \\
\hline Sensory Integ. & 13 & 11 & & 2 \\
\hline Special Ed & 6 & 5 & & 1 \\
\hline Speech/Lang P & 23 & 21 & 1 & 1 \\
\hline SuperNuThera & 7 & 4 & & 3 \\
\hline Other Supplemt & 4 & 3 & & 1 \\
\hline TEACCH & 2 & & & 2 \\
\hline
\end{tabular}




\begin{tabular}{|l|c|c|c|c|}
\hline Ther Listening & 1 & 1 & & \\
\hline TMG & 2 & 1 & 1 & \\
\hline Typical Preschl & 1 & 1 & & \\
\hline Total CommLP & 1 & 1 & & \\
\hline Verbal Bhavior & 1 & 1 & & \\
\hline Vitamin Ther & 8 & 5 & & 3 \\
\hline
\end{tabular}

\section{Additional Findings}

Though not part of the research questions in this study, two additional descriptive examinations were included here because their subjects have been mentioned as prognostic in the literature. Providing an explanation of these differences could provide additional information for future researchers.

The importance of pretreatment IQ or functional ability as a predictor of treatment outcome is well represented in the literature. Past researchers have indicated that the child's ability at the time of treatment correlated with treatment outcome (Lovaas, 1987). In this survey, respondents were asked to record IQ scores or functional assessment scores for the child before treatment and again after treatment (Time 1 and Time 3) Only five respondents (see Table 5) offered scores that could be compared across time for that child, and this number represented so few cases that converting them to similar scores was not attempted. Still, these five reports of IQ or functioning scores indicated an increase in ability from before treatment to after treatment. 
Table 9 - Differences in IQ/Functional Skills Before and After Treatment

\begin{tabular}{|l|l|l|l|c|}
\hline Test & First Score & Second Score & Elapsed time & Recovery Score \\
\hline CARS & $\begin{array}{l}32 \text { (mildly- } \\
\text { moderately } \\
\text { autistic) }\end{array}$ & $\begin{array}{l}28 \text { (non- } \\
\text { autistic) }\end{array}$ & 40 months & 4 \\
\hline GARS & $\begin{array}{l}108 \text { (average } \\
\text { probability of } \\
\text { autism) }\end{array}$ & $\begin{array}{l}82 \mathrm{AQ} \text { (below } \\
\text { average } \\
\text { probability of } \\
\text { autism) }\end{array}$ & 17 months & 5 \\
\hline WPPSI-R & $\begin{array}{l}\text { FSIQ } 91 \\
\text { Vineland }\end{array}$ & $\begin{array}{l}\text { FSIQ 131 } \\
\text { Comp. } 60 \text { (low) } \\
\text { Comp } 88\end{array}$ & $<14$ mos & 3 \\
\hline CARS & $\begin{array}{l}34 \text { (mildly- } \\
\text { moderately } \\
\text { autistic) } \\
\text { Vineland }\end{array}$ & $\begin{array}{l}20.5 \text { (non- } \\
\text { autistic) }\end{array}$ & 29 months & 2 \\
\hline WPPSI-R & $\begin{array}{l}\text { Verbal-81 } \\
\text { low) }\end{array}$ & $\begin{array}{l}\text { Verbal-115 } \\
\text { Perform - 124 }\end{array}$ & 16 months & 8 \\
\hline
\end{tabular}

Twelve characteristics of the eight children who fit the criteria for recovery (as well as possessing among the highest "Current Characteristic Sum") were compared with the same characteristics for the children who had the eight lowest "Current Characteristic Sum" (See Table 6). These variables were selected for comparison because they had special mention in the literature: gender was included because some researchers have indicated that females were more severely affected than males, speech at the time of diagnosis was completed was included because of the importance many researchers have linked to the development of communicative speech as a prognostic factor; specific diagnosis was included to determine if the diagnosis between the groups varied; progress through treatment and hours in treatment each week have been considered by many current researchers as important to outcome; and the demographic 
descriptors of geographic location, parent education, and income were included to see if there was a difference between the demographics of the group that had recovered and the group that was functioning on a lower level. The sums at the three time periods (Time 1, Time 2, and Time

3) were also included to look at where each group started and where each group ended.

Table 10: Comparison Among Some Characteristics of Recovered/Lowest Scoring Children

\begin{tabular}{|c|c|c|c|c|c|c|c|c|c|c|c|c|}
\hline $\begin{array}{l}1 \\
\text { Case } \\
\#\end{array}$ & $\begin{array}{l}2 \\
\text { Gen } \\
\text { der }\end{array}$ & $\begin{array}{l}3 \\
\text { Sum } \\
\text { Diag }\end{array}$ & $\begin{array}{l}4 \\
\text { Sum } \\
\text { Atftx }\end{array}$ & $\begin{array}{l}5 \\
\text { Curr } \\
\text { Sum }\end{array}$ & $\begin{array}{l}6 \\
\text { Spch } \\
\text { Diag }\end{array}$ & $\begin{array}{l}7 \\
\text { Spec } \\
\text { Diag }\end{array}$ & $\begin{array}{l}8 \\
\text { Hrs/ } \\
\text { week }\end{array}$ & $\begin{array}{l}9 \\
\text { Prog } \\
\text { Ther }\end{array}$ & $\begin{array}{l}10 \\
\text { Geo }\end{array}$ & $\begin{array}{l}11 \\
\text { Inco } \\
\text { me }\end{array}$ & $\begin{array}{l}12 \mathrm{E} \\
\text { duca } \\
\text { tion }\end{array}$ & $\begin{array}{l}13 \\
\text { Rec- } \\
\text { Very }\end{array}$ \\
\hline \multicolumn{13}{|c|}{ "Recovered" Children } \\
\hline 1 & 2 & 18 & 34 & 34 & 1 & 2 & 2 & 9 & 5 & 2 & 5 & 8 \\
\hline 42 & 1 & 15 & 33 & 33 & 2 & 1 & 4 & 8 & 3 & 3 & 7 & 8 \\
\hline 63 & 1 & 14 & 32 & 30 & 1 & 1 & 1 & 9 & 1 & 4 & 8 & 8 \\
\hline 64 & 1 & 17 & 30 & 33 & 3 & 1 & 1 & 9 & 1 & 2 & 2 & 8 \\
\hline 73 & 1 & 16 & 31 & 35 & 1 & 1 & 2 & 8 & 1 & 4 & 2 & 8 \\
\hline 74 & 1 & 21 & 34 & 33 & 3 & 2 & 3 & 8 & 1 & 4 & 2 & 8 \\
\hline 75 & 1 & 13 & & 35 & 1 & 1 & 4 & 8 & 4 & 4 & 8 & 8 \\
\hline 83 & 1 & 12 & 18 & 35 & 1 & 1 & 4 & 6 & 1 & 4 & 8 & 8 \\
\hline $\begin{array}{l}\text { Ave/ } \\
\text { Med }\end{array}$ & 1 & 16 & 30 & 33 & 1 & 1 & 2.5 & 8 & 1 & 4 & 6 & 8 \\
\hline \multicolumn{13}{|c|}{ Lowest Scoring Children } \\
\hline 7 & 1 & 14 & & 16 & 1 & 1 & 4 & 8 & 3 & 4 & 8 & 1 \\
\hline 34 & 1 & 9 & & 18 & 2 & 2 & 4 & 5 & 2 & 3 & 8 & 1 \\
\hline 38 & 1 & 15 & & 19 & 1 & 1 & 2 & 5 & 2 & 4 & 8 & 1 \\
\hline 46 & 1 & 16 & & 17 & 1 & 2 & 4 & 6 & 4 & 3 & 8 & 1 \\
\hline 57 & 1 & 18 & & 14 & 1 & 1 & 2 & 3 & 1 & 4 & 4 & 1 \\
\hline 65 & 1 & 14 & & 17 & 1 & 1 & 4 & 8 & 3 & 4 & 6 & 2 \\
\hline 69 & 1 & 8 & & 12 & 1 & 1 & 4 & 3 & & & & \\
\hline 70 & 1 & 12 & & 17 & 1 & 2 & 2 & 5 & 2 & 4 & 5 & 1 \\
\hline $\begin{array}{l}\text { Ave/ } \\
\text { Med }\end{array}$ & 1 & 13 & & 16 & 1 & 1 & 4 & 5 & 3 & 4 & 8 & 1 \\
\hline & & KEY: & \multicolumn{10}{|c|}{$\begin{array}{l}\text { Column 1: Survey number } \\
\text { Column 2: Child's gender ( } 1=\text { male, } 2=\text { female) } \\
\text { Column 3: Child's Characteristic Sum at Time } 1 \text { (sum of all } 8 \text { characteristic variables) } \\
\text { Column 4: Child's Characteristic Sum at Time } 2 \text { (sum of all } 8 \text { characteristic variables) } \\
\text { Column 5: Child's Characteristic Sum at Time } 3 \text { (sum of all } 8 \text { characteristic variables) } \\
\text { Column 6: Ranking of Speech at Diagnosis (Ranked from } 1 \text { to } 7 \text {, less to more typical) } \\
\text { Column 7: Child's specific diagnosis (select from } 6 \text { choices, numbered 1-6) } \\
\text { Column 8: Hours a week in DTT treatment (Ranked from 1-6, from fewer to more hours) } \\
\text { Column 9: Ranking of child's progress through therapy (rank from 1-10, fewer to more) } \\
\text { Column 10: Family's location (select from four general population choices) }\end{array}$} \\
\hline
\end{tabular}


Column 12: Parent's level of education (select from 8 choices, less to more)

Column 13: Child's recovery score (Number of choices checked, Question 44)

Column 11: Parent's level of income (select from 4 general income levels, less to more)

The sum at diagnosis for both groups of children (Column three) indicated that, before treatment, both groups were only three points apart in sum of the eight characteristics. But the higher scoring group's sum immediately after treatment illustrated, in most of the seven reported cases, that their pretreatment sum had doubled. The improvement in this high scoring group continued until the time the survey was completed for three of the children, while two dropped a point or two, and two maintained the same score as immediately after treatment. The lowest scoring children, though, gained an average of only four rating points across the eight variables from time of diagnosis to the time the survey was completed.

According to this table, the highest scoring children had a higher score (median of eight) for their Progress Through Therapy (Column 9) than did the lower scoring children (median of five). More from the higher group, on average, lived in populated urban areas than the lower scoring group.

The lower scoring group had experienced more hours in therapy (median of 4 compared to the higher group's median of 2.5) and their parents had a higher level of education ("completed a four year college degree" to "completed a post graduate degree"), while speech at diagnosis (Column 6), specific diagnosis (Column 7), and income (Column 11) both groups were equal.

The demographics means of parent age, income, education, and geographical location were close to equal for both the 26 who had completed treatment and the remaining 59 respondents who had not completed treatment. 


\section{Discussion}

My goal in undertaking this research was to learn more about the characteristics a child with autism may possess before treatment that could predict his or her treatment outcome. I chose this topic for two reasons; one, in my reading before I began this study, I found conflicting reports of the abilities and characteristics possessed by the child who did well in treatment. While many researchers reported the dyad of IQ and speech as necessary to a good outcome, others claimed that no variable at intake could predict the child's success. And, in my own practice, I wanted to be able to predict, when I first assessed a child, how effective discrete trial training might be, given his or her beginning skills and characteristics. At the time I decided on this topic, I did not personally know any child who had recovered from autism, and I was curious about what diagnostic and treatment history such a child might possess.

For parents, perhaps the most optimistic finding in this research was that there was no one variable, at least among the eight included in this study, that would predict treatment outcome for most children.

In addition, the results of this study indicated that young children with autism will improve in their functioning throughout the course of discrete trial treatment, according to the perception of the parents who participated in this survey. The children in this study not only improved overall based on the comparison of characteristics ranks across time, but they also showed increases in the ranks of all eight of the characteristics variables. That result--that young children with autism improved after a period of discrete trial treatment--has been found in most, if not all, of the literature detailing this kind of treatment since Lovaas published his results of the UCLA study in 1987. While other studies have looked at increases in language, IQ, and functional abilities through the use of formal assessments, this is the first study that specifically 
compared progress before and after at least one year of treatment in the areas of toy play, toilet training, peer play, attachment, sensory issues, and amount of tantruming. It also indicated that, of these eight variables, speech had the greatest increase for most children, followed by toilet training and toy play.

For the larger group, those that had not yet completed discrete trial training, no one variable, or groups of variables within the eight characteristics, were found to significantly predict the outcome (recovery score) more than the others. This finding could have several explanations. These results could indicate, like Birnbrauer and Leach's (1993) study, that for a group of children of many levels of ability, there is no one variable that weighs more than another in predicting how well a child will do in discrete trial treatment as a whole. Or, the variables considered might not have included all of those that are critical to outcome for this larger group of children. For example, IQ, often cited in the literature as an early predictor of later functioning, was a critical variable to consider. One of the limitations of these results was that, in spite of a question relating to IQ and functional ability, there were no meaningful, comparable responses. Perhaps if this question been given more emphasis, and had thus been answered more completely, the examination of this variable might have resulted in a difference in the study outcome. Again, in retrospect, a question about the child's early ability to imitate might have also been an important variable to include, as many researchers have found that the ability to imitate predicts good treatment outcome.

With those limitations in mind, however, there was one variable among the eight, toy play, that did negatively correlate with outcome for the 29 children who had completed treatment. That finding could mean that children who had less toy play ability at the time of diagnosis had better outcomes at the time treatment was completed. It is interesting that this was 
the only variable that was identified, and that it was negatively correlated. From the literature, and from my own experience, this finding is difficult to explain. While toy play was mentioned in the literature (Rutter, Greenfeld, Lockyer, 1967) as a possible predictor (always in a group of other characteristics), it was more normal toy play, not abnormal toy play, that was seen as prognostic. And, from my experience, lack of appropriate toy play has never seemed, by itself, to have any relation to outcome.

However, I know of no other study that has looked at toy play by itself as a predictor of treatment outcome, instead of one characteristic among many comprising a pathology sum. It could be that toy play is a strong predictor that has never before been singled out. Interestingly, toy play is also one of the three variables that had the greatest increase in rank from time of diagnosis to time the survey was completed. Perhaps the ability to learn to play normally with toys is one area in which most children can make greater improvement, and for those children who are going to do well, the lowest ranking of toy play can take a large leap, thus becoming a predictor of treatment outcome.

More predictable was the finding that, for children who had completed treatment, progress through therapy was significant. As other researchers have found (Smith \& Lovaas, 1997; Weiss, 1999; Smith, Groen \& Wynn, 2000), the children who do best in ABA treatments are those who are more successful from the start of treatment. The fact that all children in this group had already completed treatment (some of them in fewer than two years), and that among this group were seven of the eight who had met all the criteria for recovery, would indicate that their progress was rapid. A visual comparison is offered in Table 5, where the recovered children had a higher score, on average, than those lowest scoring children. It would seem that the children who have better outcomes from therapy have the abilities, whatever they may be, to 
quickly grasp and master the requirements of discrete trial training. Although not confirmed by this study, perhaps this quick success of these children is related to higher IQ scores, as many researchers have found with other populations, and the participants with lower IQ, while making progress, were still working on more basic skills.

For the group that had completed therapy, the number of hours in treatment each week was not significant. That could mean that the forty or more hours, as recommended by Lovaas (1987), was not necessary for their success. Coupled with the significant finding on progress through therapy, the assumption might be that, for this subgroup of children, discrete trial training does not need to be a long and intense process.

That does not mean, however, that the children who take longer in therapy will not do well, as this study and others before have shown (Birnbrauer \& Leach, 1993), there are some children who do have good outcomes who failed to start out with quick success but have made steady but slow progress over several years. Like Birnbrauer and Leach (1993), I have children in my practice who have worked for years to gain basic learning skills, but then make breakthroughs that moved them to a higher level of functioning.

This fits into the possible explanation for the significant finding that, among children who have not completed discrete trial training, the more hours in therapy a week is coupled with a better outcome. For these slower children, more intense therapy may be necessary to provide the break downs and the repetition necessary for fluency.

The response rate of $57 \%$ was, I believe, an excellent one for a long-distance, 17-page questionnaire. While the length of the survey could have been a deterrent to completion, and perhaps those who did not respond or did not send back a completed questionnaire found it daunting, no respondent who completed a survey commented on the number of questions or 
length. Instead, many parents added pages of unsolicited information about their child, one sent a family picture, and others wrote notes of thanks for this research. This follows my experience as a professional in the field of autism intervention. The parents I work with and those who answered this survey readily talk about their children, their experiences through treatment, and help in finding answers to questions all of us in the field have asked. In fact, 75 of the 85 who completed this study agreed to be contacted for participation in further research.

\section{Additional Limitations}

Response bias is probably the most critical limitation of this study. Of the more than 150 initial responses to the request for survey participants, only about $60 \%$ actually returned the completed survey. It's possible that those parents whose children had not done well in treatment chose not to complete the questionnaire, and that the ones that were returned represent only the children for whom discrete trial training has proven to be a valuable intervention.

Because volunteers were sought via email list serves that supported the use of discrete trial training (Me-List, FEAT), recovery from autism (the Recovery List), or other ABA treatments (Verbal Behavior group), it would follow that the groups from which this sample derived were pro-discrete trial or ABA approaches.

No control group was used in this study, so there is no way of knowing if the progress shown in each of these areas was specific only to those children who were involved in discrete trial training or would be true for all children with autism who are involved in any kind of treatment.

The delivery of the discrete trial training could not have been uniform for all participants. In this survey, no distinction was made between home-based or center-based programs, family 
motivation, training of staff, qualifications of program consultant, among other elements. Though the results indicated that all children in this study improved after one year of discrete trial training in at least the eight characteristics measured, certainly none of these children experienced exactly the same treatment or experienced treatment in the same way. And, of course, discrete trial treatment was not all that happened to these children over the period of a year or more. Each child was influenced by additional interventions, family circumstances, and/ or developmental growth, so, while the treatment, DTT, could have been one factor in the improvement, it certainly wasn't the only factor that effected the child's outcome.

This study turned out to be, I think, one of parent perception of outcome rather than a true study of predictors. For the most part, parents' impressions of treatment and outcome have not been part of the research literature but because they are the basis of the data for this study, the accuracy of parent recall should be considered when interpreting these results.

According to the literature, parent perception and parent recall, both used in this study, have not always been considered an accurate way to get information. Some researchers have found parents overstate their child's abilities, or that their recall changes in the direction of meeting the expectations of the child raising experts of that day. But there were studies in which parent recall was found to be accurate, especially in areas of functional abilities, like language development, and among parents of children with autism (Eisenberg, 1956; Schopler \& Reichler, 1972).

While there may be a limitation of parent inaccuracy, I believe that there are good reasons why parents are good sources of information of their child's abilities and thus the best respondents for this survey. Parents are, course, the most constant evaluators of their child. They are the consumers of treatments for autism; the final decision-makers about what type of 
intervention to pursue for their own child. They also have the greatest stake in the outcome of the treatment. Understanding more about what parents believe contributed to their child's outcome is essential in understanding the direction the field will take in terms of demand for specific treatments.

In this study, a limitation was that there was no built-in way to indicate that the information provided by parents was accurate. This study required no case records or professional report to confirm the accuracy of the parent's responses in this study, although Questions 5 and 42 did ask for scores on IQ and functional assessments (and received very few meaningful responses). To insure the accuracy of each parent's response would have required documentation from at least one well-trained professional who had consulted with the family and assessed the child. And even if I had received that documentation, I would not have been able to confirm the professional's skill or expertise in conducting the test or communicating the results, nor would I have confirmation that that one professional was correct in his or her evaluation without another professional's unbiased assessment confirming the first.

Another way to confirm progress through therapy would have been to review the data sheets of the children who participated in this study over the time they were participating in DTT. Objective data keeping is essential to a well-run DTT program, and should have been available if the parent had been willing to make copies and send them along with the completed survey. However, reviewing the sheer amount of data collected for 85 children and comparing it to survey results would have probably been beyond the resources of one researcher.

Though this study proposed to look at the differences in ranking of eight variables after at least one year of discrete trial treatment, there were, undoubtedly, many other variables that contributed to the child's outcome. Many of the children had additional treatments, and some had 
many additional treatments that their parents reported as successful. Separating the most valuable supplemental treatment effects from the discrete trial effects was not part of this research. It is possible that the group who had completed treatment, and who had no significant difference in outcome and hours in treatment, were involved in other treatments that provided as much or more for the child's success as DTT.

Because so much of the outcome literature focused on Lovaas' UCLA study and its replications, I looked at the similarities and differences between my results and those of Lovaas. Of my entire group of respondents, only eight children, or nine percent, had met the full criteria for recovery. In Lovaas' best outcome group, $49 \%$ of the children had met his initial criteria (successful completion of first grade in a normal classroom). At first glance, the findings of this study, might be seen as the same as earlier researchers who found as many as 10 to $12 \%$ of all children had developed independence, probably without any formal or specific behavioral intervention (Kanner, Rodriguez, \& Ashenden, 1972).

There were several differences--and similarities - between the results of this study and the UCLA replications. The major difference was, of course, that this was a study of parent perception and not an experimental study. And, the criteria for participation was very different for the group described in this research compared to the children in Lovaas' study. For example, Lovaas' students were screened, initially, for IQ, and he only accepted those students who had a prorated mental age of 11 months or more at a chronological age of 30 months (Lovaas, 1987). In this study, the children were not sorted by IQ or mental age--all respondents who had been diagnosed by age three and had completed at least one year of treatment by age 6 were included.

Lovaas' treatment continued for at least two years for each child, longer for those who were not yet ready for first grade. Most of the children in this study had completed two years of 
treatment by the time the survey was completed, but only seven had entered school without support. If Lovaas' measure of success was dependent on the child's ability at the end of treatment, rather than the child's ability at a given point in treatment, then the results of this study would more closely match his outcome. Seven of the 26 children (26\%) in this study who had completed treatment were considered recovered, compared to his $49 \%$.

Another difference is that Lovaas' study utilized well-trained and well-supervised graduate students in a systematic manner to provide the intervention, as well as an emphasis on teaching parents to use ABA methods all day everyday. In my study, there was no measure of the integrity of treatment, the training of the providers, and the extent to which treatment actually used ABA principles in all environments.

The participants in this study, then, might be more like those in the study reported by Birnbrauer and Leach's Murdoch Early Intervention (1993). Their population, like the one used in this study, included children of all abilities, and used volunteers trained by professionals but supervised by parents, as was most common in this study. Most children in this study, as in the Murdoch program, received fewer than Lovaas' prescribed 40 hours a week of therapy. While “almost half” of Birnbrauer and Leach's children developed "normal functioning" after two and one half years of treatment, like Lovaas', these authors did not use the detailed criteria for recovery used in this study. In fact, the authors comment that the best outcome children still displayed self-stimulatory behavior and had deficits in social and play behaviors. As in the study described here, Birnbrauer and Leach did not find any single or pairs of characteristics that correlated highly with good response to the program when examining the entire group.

The May Institute sample (Anderson et al., 1987) is more like the group who participated in his study. The children were older than the average age (30 months) in Lovaas' study, they 
had greater differences between chronological and mental age when treatment began, spent half the hours in treatment as Lovaas' experimental group, and had no control group. While the 14 children in the May study showed increases in mental and social age and made gains in language, as did the children in the current study, the authors made no claims of recovery for any of the children, only improvement.

In the San Francisco study (Sheinkopf \& Siegel, 1998), the children receiving ABA interventions had, according to parent report, improved in their intellectual ability and the severity (but not the frequency) of their self-stimulatory behavior was reduced compared to the children who were not receiving those interventions as intensively.

And in the Wisconsin study (Sallows \& Graupner, 1999), the report after one year of treatment was that almost half of the children increased in IQ score enough to fall into the average range. These children received forty hours of therapy a week, a prescribed and intense treatment protocol, and the selection criteria matched Lovaas'. On average, all children in the Wisconsin treatment group increased in Vineland (adaptive functioning) and IQ scores and language ability. Though these best outcome children reached a low normal IQ score, most still remained delayed in language and in social skills, which the author described as more complex than building speech or adaptive skills.

\section{Recovery Score}

While the success of these children is heartening and underscores the efficacy of ABA treatments, the criteria for "best outcome," which some reviewers have renamed "recovery," was not as stringent as the criteria used in this study and so, for this reason and others, the nine 
percent of recovered children in this study can't realistically be compared with the best outcome children in prior studies.

The children who were considered recovered in this study met all of the criteria for recovery gleaned from a thorough content analysis of the autism literature. They had, for the most part, completed DTT and were all included in a normal school environment and considered indistinguishable from their peers. That is, a stranger could not determine, by observing the child's behavior, which child in a group of peers had a diagnosis of autism. No such specific criteria were used in earlier research. Instead, a review of the literature on the success of DTT indicates that what has been called recovery (not necessarily by the researchers themselves but more often by parents and the popular press) is more accurately described as an increase in IQ scores and sometimes in measures of social and adaptive functioning. Therefore, it may be fair to say that "best outcome" does not equal recovery.

If the criteria Lovaas used in the UCLA study were applied to this study (24 months in therapy, 40 hours or more a week of discrete trial training, normal IQ and successful placement in a regular classroom), two of the 26 children who had completed therapy in this study would meet that criteria. Those two were part of the group of eight who scored as recovered using the new definition of recovery described in this study. Interestingly, the other seven recovered students as defined by this study met the requirements for recovery with fewer months in therapy and fewer hours in therapy each week.

It was helpful to find, from this study, that regardless of progress through treatment and the outcome of therapy, most children made the greatest improvement in the variables of speech, followed by toilet training and toy play. For parents and professionals, knowing that this progress in these areas is likely, even if limited, is valuable. 


\section{Conclusions}

Perhaps the only truth that has become clear to this researcher, after conducting this study and reviewing the results of others, is how little we know about what we do. Study after study has shown that ABA interventions help most young children with autism, but what part of those many techniques are most efficacious? Why do some children have more immediate success than others? We are on the doorstep of the story of autism, but we only have one foot inside.

While this study was undertaken to determine predictors for treatment outcome only in young children, future researchers might consider the very interesting finding of several studies that the time around of puberty may be a critical one. As the literature described, adolescents may either become more severe around the time of puberty or, conversely, experience an awareness of their being different and work successfully to overcome it and become as indistinguishable as possible from their peers. Were there any differences in these children in their very early years that might have predicted who would have developed the self-awareness and ability to change the course of their disorder?

Even with the unanswered questions and clear limitations noted above, I believe these results contribute to the field in several ways. They confirm, at least by parent report, that this type of $\mathrm{ABA}$ intervention improves the abilities of children who have experienced at least one year of treatment. It underscores the findings that progress through therapy can contribute to a better outcome, and that, at least for children who are moving more slowly through treatment, more hours in therapy are related to a better outcome. It even adds a new consideration for those seeking predictors of treatment outcome: that for children who finish DTT quickly, that the lack of toy play may indicate a better outcome. 
Another contribution of this study to the field of autism research, I believe, is the concentration of parents' voices about the effectiveness of other treatment options and the advice they would give to parents whose children were recently diagnosed with autism. In my experience, parents are the greatest source of information for other parents. They are most often approachable, interested, and supportive to parents of newly-diagnosed children, so having a window into these perceptions is valuable to professionals who don't often enjoy the same access and approachability.

Because parents from more than 28 states and three foreign countries, of differing incomes, geographic areas, and levels of education contributed their point of view to this research, these results provide a rich resource for those professionals who are dedicated to improving the outcomes for all children with autism. 


\section{References}

American Psychiatric Association. (1994). Diagnostic and statistical manual of mental disorders, Fourth Edition. Washington, DC: Author.

Anderson, S.R., Avery, D.L., DiPietro, E.K., Edwards, G.L., \& Christian, W.P. (1987). Intensive home-based early intervention with autistic children. Education and Treatment of Children, 10, 352-366.

Anderson, S.R., \& Romanczyk, R.G., (1999). Early intervention for young children with autism: continuum based behavioral models. The Journal of the Association for Persons with Severe Handicaps, 24, 162-173.

Aron, Arthur \& Aron, Elaine (1994). Statistics for Psychology. Englewood Cliffs, NJ: Prentice Hall, Inc.

Ary, Donald, Jacobs, Lucy Cheser, \& Razavieh, Asghar ( 1985). Introduction to Research in Education. New York: Holt, Rinehart, \& Winston.

Baer, Donald M., Wolf, Montrose M., \& Risely, Todd (1968). Some current dimensions of Applied Behavior Analysis. Journal of Applied Behavior Analysis, 1, 91-97.

Birnbrauer, Jay S., \& Leach, David (1993). The Murdoch early intervention program after two years. Behavior Change, 10, 63-74.

Bristol, Marie (1996). Proceedings from The Child With Special Needs Pre-conference on Autism: State of the Art Informed by State of the Science. Contemporary Forums. Washington, D.C., May 14-15, 1996.

Brown, Janet L. (1979). Long-term follow-up of 100 "atypical" children of normal intelligence. In Rutter, Michael, \& Schopler, Eric, (Eds.). Autism. A Reappraisal of Concepts and Treatment. New York: Plenum Press.

Bryan, Tanis, Pearl, Ruth, Zimmerman, Deborah, \& Matthews, Frances (1982). Mother's evaluations of their learning-disabled children. The Journal of Special Education, 16, 149-159.

Bryson, S.E. (1996). Brief report--Epidemiology of autism. Journal of Autism and Developmental Disorders, 26, 165-167.

Cunningham, C.C. \& Sloper, P. (1984). The relationship between maternal ratings of First Word vocabulary and Reynell language scores. British Journal of Educational Psychology, 54, 160-167.

Dawson, G., \& Osterling, J. (1997). Early intervention in autism. In Guralnick, M.J. (Ed). The effectiveness of early intervention. Austin, TX: Pro-Ed. 
DeMyer, Marian K., Barton, Sandra, DeMyer, William, Norton, James A., Allen, John, \& Steele, Robert (1973). Prognosis in autism: A follow-up study. Journal of Autism and Childhood Schizophrenia, 3, 199-246.

Donnellan, Anne M. (1999). Invented Knowledge and Autism: Highlighting our strengths and expanding the conversation. The Journal of the Association of Persons With Severe Handicaps, 24, 230-236.

Drash, Philip W. (1995). Successful treatment of young autistic children in an outpatient behavioral treatment program. Paper presented at the Florida Association for Behavioral Analysis, Fifteenth annual convention, Tampa, Fl., Sept. 21, 1995.

Eikeseth, Svein (1999). Intensive school-based behavioral treatment for four to seven year old children with autism: A one-year follow-up. Paper presented at the PEACH "Putting Research Into Practice" conference held in London, June 18, 1999.

Eisenberg, Leon (1956). The autistic child in adolescence. American Journal of Psychiatry, 112, 556-566.

Featherman, David L. (1980). Retrospective longitudinal research: methodological considerations. Journal of Economics and Business, 32, 152-169.

Filipek, Pauline A, Accardo, Pasquale, Baranek, Grace, Cook, Edwin H., Jr., Dawson, Geraldine, Gordon, Barry, Gravel, Judith, Johnson, Chris, Kallen, Ronald, Levy, Susan, Minshew, Nancy, Prizant, Barry, Rapin, Isabelle, Rogers, Sally, Stone, Wendy, Teplin, Stuart, Tuchman, Roberto, \& Volkmar, Fred R. (1999). The screening and diagnosis of autistic spectrum disorders. Journal of Autism and Developmental Disorders, 29, 439-484.

Fish, Barbara (1968). Pharmocotherapy for autistic and schizophrenic children. In Ritvo, Freeman, Ornitz, \& Tanguay (Eds). Autism. Diagnosis, Current Research, and Management, pp. 107-120. New York: Spectrum Publications.

Gajzago, Christine, \& Prior, Margot (1974). Two cases of "recovery" in Kanner Syndrome. Archives of General Psychiatry, 31, 264-268.

Gillberg, Christopher (1991).Outcome in autism and autistic-like conditions. American Academy of Child and Adolescent Psychiatry, 30, 375-382.

Gillberg, Christopher \& Steffenburg, Suzanne (1987). Outcome and prognostic factors in infantile autism and similar conditions: A population-based study of 46 cases followed through puberty. Journal of Autism and Developmental Disorders, 17, 273-287.

Green, Gina (1995). Early intervention for children with autism: The need for intensive behavior analytic treatment. Handout received in packet from the New England Center for Children. 
Green, Gina (1996). Early behavioral intervention for young children with autism: What does research tell us? In C. Maurice, G. Green, \& S. Luce (Eds.) Behavioral interventions for young children with autism: a manual for parents and professionals. (pp. 29-44). Austin, TX: Pro-Ed.

Greenspan, Stanley, \& Weider, Serena (1999). A functional developmental approach to autism spectrum disorders. Journal of the Association for Persons with Severe Handicaps, 24 , $147-161$.

Gresham, Frank \& MacMillan, Donald L. (1997). Autistic recovery? An analysis and critique of the empirical evidence on the Early Intervention Project. Behavioral Disorders, 22, 185-201.

Gresham, Frank, \& MacMillan, Donald L. (1997). Denial and defensiveness in the place of fact and reason: Rejoinder to Smith and Lovaas. Behavioral Disorders, 22, 219-230.

Gresham, Frank M. \& MacMillan, Donald L. (1998). Early Intervention Project: Can its claims be substantiated and its effects replicated? Journal of Autism and Developmental Disorders, 28, 5-13.

Haaga, John G. (1988). Reliability of retrospective survey data on infant feeding. Demography, 25, 307-314.

Harper, Juliet, \& Williams, Sara (1975). Age and type of onset as critical variables in early infantile autism. Journal of Autism and Childhood Schizophrenia, 5, 25-35.

Harris, Sandra, Handleman, Jan, Gordon, Rita, Kristoff, Barbara, \& Fuentes, Felicia (1991). Changes in cognitive and language functioning of preschool children with autism. Journal of Autism and Developmental Disorders, 21, 281-290.

Herin, Juane L. \& Simpson, Richard L. (1998). Interventions for children and youth with autism: Prudent choices in a world of exaggerated claims and empty promises. Part 1: Intervention and treatment option review. Focus on Autism and Other Developmental Disabilities, 13, 194-225.

Hermelin, B. (1976). Coding and the sense modalities. In L. Wing, (Ed.), Early childhood autism: Clinical, educational and social aspects $\left(2^{\text {nd }} E d\right)$ (pp.135-168). Oxford, Pergamon Press.

Horner, Robert. \& Carr, Edward (1997). Behavioral Support for students with severe disabilities: functional assessment and comprehensive intervention. Journal of Special Education, $\underline{31,84-104 .}$

Howlin, P. (1997). Prognosis in autism: do specialist treatments affect long-term outcome? European Child and Adolescent Psychiatry, 6, 55-72. 
250.

Kanner, Leo (1943). Autistic disturbances of affective contact. Nervous Child, 2, 217-

Kanner, Leo (1954). General concept of schizophrenia at different ages. Proceedings for the Association of Researchers of Nervous and Mental Disorders, 34, 451-453.

Kanner. L. (1971). Follow-up study of 11 autistic children originally reported in 1943. Journal of Autism and Childhood Schizophrenia, 1, 112-145.

Kanner, L. \& Eisenberg, L. (1955). Notes on the follow-up studies of autistic children, in Hoch, P.H. \& Zubin, J. (Eds.) Psychopathology of Childhood (pp. 227-239). New York: Grune $\&$ Stratton, Inc.

Kanner, L, \& Lesser, L. (1958). Early infantile autism. Pediatric Clinics of North America, 51, 711-730.

Kanner, Leo, Rodriguez, Alejandro, \& Ashenden, Barbara (1972). How far can autistic children go in matters of social adaptation? Journal of Autism and Childhood Schizophrenia, 2, 9-33.

Knobloch, Hilda, \& Pasamanick, Benjamin (1975). Some etiologic and prognostic factors in early infantile autism and psychosis. Pediatrics, 55, 182-191.

Kobayashi, Ryuji, Murata, Toyohisa, \& Yoshinga, Kazuhiko (1992). A follow-up study of 201 children with autism in Kyusha and Yamaguchi areas, Japan. Journal of Autism and Developmental Disorders, 22, 395-411.

Kosloski, Karl, Datwyler, Mary McGlinn, \& Montgomery, Rhonda J.V. (1994). Evaluating retrospective measures in gerontological research. Research on Aging, 16, 38-401.

Koegel, Lynn Kern, Robert L. Koegel, Harrower, Joshua, \& Carter, Cynthia M. (1999). Pivotal response intervention I: Overview of approach. Journal of the Association for Persons With Severe Handicaps, 24, 174-185.

Koegel, Lynn Kern, Robert L. Koegel, Shoshan, Yifat, \& McNerney, Erin (1999). Pivotal response intervention II: Preliminary long-term outcome data. Journal of the Association for Persons with Severe Handicaps, 24, 186-198.

La Rue, Asenath, Watson, Jennifer, \& Plotkin, Daniel (1992). Retrospective accounts of dementia symptoms: Are they reliable? The Gerontologist, 32, 240-245.

Lotter, V. (1976). Follow-up studies. In Rutter, Michael, \& Schopler, Eric, Eds. (1979). Autism. A Reappraisal of Concepts and Treatment (pp. 475-496). New York: Plenum Press. 
Lord, Catherine, \& Schopler, Eric (1989). The role of age at assessment, developmental level, and test in the stability of intelligence scores in young autistic children. Journal of Autism and Developmental Disorders, 19, 483-499.

Lovaas, O. Ivar (1987). Behavioral treatment and normal educational and intellectual functioning in young autistic children. Journal of Consulting and Clinical Psychology, 55, 3-9.

Lovaas, O. Ivar (1989). Autism: A new behavioral treatment. The Harvard Medical School Mental Health Letter, http://www.mentalhealth.com/mag1/p5h-aut2.html

Lovaas, O. Ivar (1993). The development of a treatment-research project for developmentally disabled and autistic children. Journal of the Association for Persons with Severe Handicaps, 24, 617-630.

Lund, Stein, \& Barnard, John (1999). "The Anatomy of a Successful Program for Teaching Children with Autism." Presented at the Autism Society of West Virginia's Fall Conference, Fairmont State College, November 13, 1999.

Luyben, P. (1998). Discrete trial training: Harmful or helpful? Editorial comment in the Newsletter of New York State Association for Behavioral Analysis. 10, 4-5.

Maurice, C. (1993). Let me hear your voice. New York: Knopf.

McEachin, J.J., Smith, T., \& Lovaas, O.I. (1993). Long-term outcome for children with autism who received early intensive behavioral treatment. American Journal of Mental Retardation, 4, 359-372.

McLennan, J.D., Lord, C. \& Schopler, E. (1993). Sex difference in higher functioning people with autism. Journal of Autism and Developmental Disorders, 23, 217-227.

Miller, Jon F. \& Sedey, Allison L. (1995). Validity of parent report measures of vocabulary development for children with Down Syndrome. Journal of Speech and Hearing Research, 38, 1037-150.

New York State Department of Health, Early Intervention Program (1999). Clinical Practice Guideline: Report of the Recommendations. Autism and Pervasive Developmental Disorders, Assessment and Intervention for Young Children (Age 0-3 Years). Publication No. 4215. Albany, N.Y.

Ornitz, E.M. (1973). Childhood autism. A review of the clinical and experimental literature. California Medicine, 118, 21-47.

Ozonoff, Sally, \& Cathcart, Kristina (1998). Effectiveness of a home program intervention for young children with autism. Journal of Autism and Developmental Disorders, $\underline{28}, 25-32$. 
Parisy, Diana (1999). Early intervention: The view from a distance. Journal of the Association for Persons with Severe Handicaps, 24, 226-229.

Perry, R., Cohen, I., \& DeCarlo, R. (1995). Case study: deterioration, autism, and recovery in two siblings. Journal of the American Academy of Child and Adolescent Psychiatry, $\underline{34}, 232-237$.

Poe, Susannah (1999). A summary definition of recovery from autism using content analysis. Unpublished research competency, West Virginia University. Department of Educational Psychology.

Rimland, Bernard (1964). Infantile Autism: The syndrome and its implications for a neural theory of behavior. Englewood Cliffs, NJ:Prentice-Hall, Inc.

Ritvo. Edward R., Freeman, Betty Jo, Ornitz, Edward M, \& Tanguay, Peter, (Eds.) (1976). Autism. Diagnosis, Current Research, and Management. New York: Spectrum Publications, Inc.

Robbins, Lillian Cukier (1963). The accuracy of parental recall on aspects of child development and of child rearing practices. Journal of Abnormal and Social Psychology 66, 261270.

Rumsey, Judith, Rapoport, Judith, \& Sceery, Walter (1985). Autistic children as adults: Psychiatric, social, and behavioral outcomes. Journal of the American Academy of Child Psychiatry, 24, 465-473.

Rutter, Michael, Greenfeld, David, \& Lockyer, Linda (1967). A five to fifteen year follow-up study of infantile psychosis. British Journal of Psychiatry, 113, 1183-1199.

Rutter, Michael (1979). Developmental issues and prognosis. In Rutter, Michael, \& Schopler, Eric, Eds. Autism. A Reappraisal of Concepts and Treatment (pp.497-506). _New York: Plenum Press.

Sallows, Glen O. \& Graupner, Tamlynn D. (1999). Replicating Lovaas' treatment and findings: preliminary results. Paper presented at the PEACH conference, London, England, June, 1999.

Schafer, Lenny (Ed) (November, 1999). FEAT's Daily Online Newsletter. Prognostic Factors for Children with Autism, November, 1999, week 2. Reprinted from the UCSB Clinic web site: http://education.ucsb.edu/ doniel/index.html

Schafer, Lenny (Ed.). (July 29, 2000). Private email correspondence.

Schopler, Eric (1976). In L. Wing (Ed). Early Childhood Autism (pp.221-246). Oxford: Pergamon Press. 
Schopler, Eric, \& Reichler, R.J., (1972). How well do parents understand their own psychotic child? Journal of Autism and Childhood Schizophrenia, 1, p. 87.

Schopler, E., Short, A., \& Mesibov, G. (1989). Relation of behavioral treatment to 'normal functioning:' Comment on Lovaas. Journal of Consulting and Clinical Psychology, 57, 162-164.

Schopler, E., Lansing, M. Waters, L. (1983). Individualized assessment and treatment for autistic and developmentally disabled children: Vol. 3. Teaching Activities for autistic children. Austin, TX: Pro-Ed.

Sheinkopf, S.J. \& Siegel, B. (1998). Home-based treatment of young children with autism. Journal of Autism and Developmental Disorders, 28, 15-23.

Shute, Nancy (2000). A maddening disconnect: Autism. U.S.News and World Report. June 5,2000.

Skinner, B.F. (1938). The behavior of organisms. New York: Appleton-Century-Crofts.

Smith, Tristam (1999). Early intervention in autism. Clinical Psychology: Science and Practice, 6, pp. 33-49.

Smith, Tristam (1996). Choosing an effective treatment. In Maurice, C., Green, Gina, \& Luce, S. (Eds.) Behavioral interventions for young children with autism (pp.45-62). Austin, TX: Pro-Ed.

Smith, Tristam, Eikeseth, Svein, Klevstrand, Morton, \& Lovaas. O. Ivar (1997). Intensive behavioral treatment for preschoolers with severe mental retardation and pervasive developmental disorder. American Journal on Mental Retardation, 1, 238-249.

Smith, Tristam, Groen, Annette, \& Wynn, Jacqueline (2000). Randomized trial of intensive early intervention for children with pervasive developmental disorder. American Journal of Mental Retardation, 105, 269-285.

Smith, Tristam, \& Lovaas, O. Ivar (1997). The UCLA Young Autism Project: A reply to Gresham and MacMillan. Behavioral Disorders, 22, 202-218.

Smith, Tristam, \& Lovaas, O. Ivar (1998). Intensive and early behavioral intervention with autism: The UCLA Young Autism Project. Discrete Trial Intervention for Young Children with Autism, IYC: 10, Aspen Publishers, Inc., 67-78.

Szatmari, P., Bartolucci, G., Bremner, R., Bond, S. \& Rich, S. (1989). A follow-up study of high-functioning autistic children. Journal of Autism and Developmental Disorders, 19, 213225 . 
Volkmar, F.R., Szatmari, P. \& Sparrow, S. S. (1993). Sex differences in pervasive developmental disorders. Journal of Autism and Developmental Disorders, 23, 579-591.

Weiss, Mary Jane (1999). Differential rates of skill acquisition and outcomes of early intensive behavioral intervention for autism. Behavioral Interventions, 14, 3-22.

Wing, Lorna (1976). Early Childhood Autism. Clinical, Educational, and Social Aspects. Second Edition. Oxford, England: Pergamon Press Ltd.

Wing, L. \& Gould, J. (1979). Severe impairments of social interaction and associated abnormalities in children: Epidemiology and classification. Journal of Autism and Developmental Disorders, 9, 11-29.

Wolf, L. \& Goldberg, B. (1986). Autistic children grow up: an eight to twenty-four year follow-up study. Canadian Journal of Psychiatry, 31, 550-556.

Wrobel, Nancy Howells \& Lachar, David (1998). Validity of self- and parent-report scales in screening students for behavioral and emotional problems in elementary school. Psychology in the Schools, 35, 17-28. 


\section{Appendix A: \\ Recruitment Letters to Parents}




\section{Dear Parents,}

Original version, used in Me-List, Recovery List, and DTT-NET listserves:

I need your help! If you are a parent of a child who was diagnosed with autism and who has completed at least one year of discrete trial treatment, I invite you to help with my doctoral dissertation research. I am researching early "predicators" of treatment outcome--or the relationship, if any, between the skills and characteristics a child has before therapy and how well he or she functions during and after therapy.

In addition to being a doctoral student in educational psychology at West Virginia University, I am a consultant providing applied behavior analysis interventions (primarily discrete trial programming) to more than 25 families in West Virginia through the Life Quilters Program at the WV Affiliated Center for Developmental Disabilities. I have been a member of the Me-List for about four years (and was a discrete trail therapist for a young boy with autism before any of the above). In my experience, every child can improve using discrete trial treatment, but some progress much more quickly than others, some make slow and steady progress, and others have splinter abilities and troublesome areas. I want to learn more about the relationship, if any, between what a child starts out with and how he or she will respond to treatment.

To help with this research, you must be the parent (or caretaker) of a child who was diagnosed with autism (or autism spectrum disorder) by age three and who has had at least one year of intensive discrete trial treatment before age six. I am interested in your feedback regardless of how your child has progressed in discrete trial therapy-parents of children who could be considered "recovered," parents of children who may not yet be recovered, and parents whose children who may not recover are all encouraged to participate.

In addition to intensive discrete trial therapy, I'm also interested in what supplemental treatments you have implemented with your child, so I have included questions about those treatments and your impressions of their effectiveness.

If you agree to be part of this study, you will receive a 50-item questionnaire that will take about 20-30 minutes to complete. It will include questions about:

- your child's abilities before treatment;

- your child's rate of progress throughout the discrete trial program;

- his or her level of ability right after treatment, and

- his or her current abilities and characteristics (if your child has been out of a discrete trial program for more than six months)

The survey will also include some (optional) demographic questions to develop a general profile of those who helped with this research.

Your participation in this research is completely voluntary and, if you chose to participate, you can withdraw from the survey group at any point. You do not need to answer every item to participate. All survey information will be coded by number, not by name, and individual responses will be kept strictly confidential. There are no foreseeable risks or benefits from your participation. This research was approved on July 13, 2000, by Dr. Ernest Goeres, who is the WVU College of Human Resources and Education representative for the Institutional Review Board for the Protection of Human Subjects.

If you are willing to participate, please email me at sgpoe@juno.com and specify how you would like to receive your survey-- by US Mail (I'll include a self-addressed, stamped envelope for return), or by fax, or by an attachment to an email.

Thanks!

Susannah G. Poe, MA 


\section{FEAT newsletter adaptation, fewer words than original letter to meet FEAT space requirements:}

\section{Dear Parents,}

I need your help! If you are a parent of a child who was diagnosed with autism and who has completed at least one year of discrete trial treatment, I invite you to help with my doctoral dissertation research. I am researching early "predicators" of treatment outcome--or the relationship, if any, between the skills and characteristics a child has before therapy and how well he or she functions during and after therapy.

In addition to being a doctoral student in educational psychology at West Virginia University, I am a consultant providing applied behavior analysis interventions (primarily discrete trial programming) to more than 25 families in West Virginia through the Life Quilters Program at the WV Affiliated Center for Developmental Disabilities. I have been a member of the Me-List for about four years (and was a discrete trail therapist for a young boy with autism before any of the above). In my experience, every child can improve using discrete trial treatment, but some progress much more quickly than others, some make slow and steady progress, and others have splinter abilities and troublesome areas. I want to learn more about the relationship, if any, between what a child starts out with and how he or she will respond to treatment.

To help with this research, you must be the parent (or caretaker) of a child who was diagnosed with autism (or autism spectrum disorder) by age three and who has had at least one year of intensive discrete trial treatment before age six. I am interested in your feedback regardless of how your child has progressed in discrete trial therapy-parents of children who could be considered "recovered," parents of children who may not yet be recovered, and parents whose children who may not recover are all encouraged to participate.

In addition to intensive discrete trial therapy, I'm also interested in what supplemental treatments you have implemented with your child, so I have included questions about those treatments and your impressions of their effectiveness.

If you agree to be part of this study, you will receive a 50-item questionnaire that will take about 20-30 minutes to complete. It will include questions about:

- your child's abilities before treatment;

- your child's rate of progress throughout the discrete trial program;

- his or her level of ability right after treatment, and

- his or her current abilities and characteristics (if your child has been out of a discrete trial program for more than six months)

The survey will also include some (optional) demographic questions to develop a general profile of those who helped with this research.

Your participation in this research is completely voluntary and, if you chose to participate, you can withdraw from the survey group at any point. You do not need to answer every item to participate. All survey information will be coded by number, not by name, and individual responses will be kept strictly confidential. There are no foreseeable risks or benefits from your participation. This research was approved on July 13, 2000, by Dr. Ernest Goeres, who is the WVU College of Human Resources and Education representative for the Institutional Review Board for the Protection of Human Subjects.

If you are willing to participate, please email me at sgpoe@juno.com and specify how you would like to receive your survey-- by US Mail (I'll include a self-addressed, stamped envelope for return), or by fax, or by an attachment to an email.

Thanks

Susannah G. Poe, MA 


\section{Appendix B: \\ Parent's Survey Instrument}




\section{Prognostic Factors in Treatment Outcome For Young Children with Autism}

Thank you for agreeing to participate in this voluntary study. The questionnaire contains a total of fifty questions in seven parts, and should take you approximately 20 to 30 minutes to complete. Some questions are accompanied by explanatory information for your use in selecting the most appropriate answer.

Part One: Please read the following six questions and answer each with the choice that best describes your child.

1. My child's gender (check one):

$\longrightarrow \mathrm{M} \quad \mathrm{F}$

2. My child's current age in years and months:

years _ months

3. My child was diagnosed with an autism-spectrum disorder when he/she was years __ months old.

4. When first diagnosed, my child received the autism spectrum diagnosis of:

(Please check the one you heard most often)

autism

PDD-NOS (Pervasive Developmental Disorder, Not Otherwise Specified)

Asperger's Syndrome

Retts Syndrome

Childhood Disintegration Disorder

other (please describe ) 


\section{What kinds of assessments were used to determine that diagnosis?}

(check all that apply)

observation by a professional

a rating scale

Test/s used, and child's scores:

Examples of rating scales include the GARs (Gilliam Autism Rating Scale), the CARS

(Childhood Autism Rating Scale), the CHAT (Checklist for Autism in Toddlers), and the ADOS (Autism Diagnostic Observation Schedule).

an IQ test (examples: Wechsler (WPPSI or WISC), Stanford-Binet, Leiter) Test/s used and child's scores:

a functional assessment of ability

Tests used and child's scores:
A functional assessment of ability is usually completed with help from the parent - examples include the Bayley Scales of Infant Development and the Vineland Adaptive Behavior Scales. other (including language assessments, hearing evaluations, etc.)

Please describe:

don't know

6. In addition to autism, has your child been diagnosed with any other medical condition?

no

yes (please describe) 


\section{Part Two: Please answer the following nine questions about your child's abilities at the} time of his or her diagnosis:

\section{Speech at time of diagnosis:}

\section{At the time he/she was diagnosed, my child had:}

(check one)

no meaningful vocal speech

fewer than 10 functional spoken words

10 or more functional spoken words, but not conversational

functional speech, some conversational skills but not yet age-appropriate age-appropriate functional vocal speech

a functional non-vocal communication system.

other

Social attachment at time of diagnosis:

8. At the time of diagnosis, my child: (check one)

had little or no typical social attachment had poor social attachment a majority of

the time

had poor social attachment about half the time had mostly typical social attachment

Social attachment refers to the physical, visual, and verbal ways of interacting with familiar people.

A child with typical social attachment prefers to be with others, enjoys cuddling and praise, seeks and shares attention, makes and responds to eye contact, and responds to the comings and goings in his or her environment.

A child with poor social attachment may have poor eye contact, resists close cuddling, seems indifferent to the presence of a caregiver, may back into someone's lap rather than approach face on, etc.

Toy play at time of diagnosis:

\section{At the time of diagnosis, my child:}

(check one)

had no typical toy play: all play was unusual, stereotypic and/or repetitive occasionally played typically with toys, but 8 out of 10 times his or her play was unusual, stereotypic, and/or repetitive) the time

played typically about half the time, but still had unusual toy play about half _ played like typical children 8 out of 10 times 
Sensory problems at time of diagnosis:

10. At the time of diagnosis, my child had:

(check one)

sensory problems that often prevented him or her from participating in or focusing on expected activities (i.e., more than 10 times a day)
Sensory problems are hyper or hypo-sensitivities to touch, taste, smell, hearing, balance, and body space. Examples include fear of noises (like the vacuum cleaner), craving deep pressure, focusing on light or movement (following a shadow or ceiling fan), etc.

sensory problems that sometimes prevented him or her from participating in or focusing on expected activities (i.e., 1 to 10 times a day)

sensory problems that rarely prevented him or her from participating in or focusing on expected activities (i.e., less than daily, just once in awhile)

no sensory problems, or ones that did not prevent him or her from participating in

or focusing on expected activities

Peer play at time of diagnosis:

11. At the time of diagnosis, my child: (check one) with peers

never initiated age-appropriate play

sometimes initiated age-appropriate play with

typically-developing child fair play; desire to show off skills

often initiated age-appropriate play, played most often (but not always) like

a typically-developing child would

always initiated age-appropriate play with peers

\section{Tantruming at time of diagnosis:}

\section{At the time of diagnosis, my child:}

(check one)

averaged more than 10 tantrums a day

averaged 5-10 tantrums a day

averaged 1 to 4 tantrums a day

had tantrums once in a while, but not daily

had no tantrums 
Stereotypies (stims) at time of diagnosis:

13. At the time of diagnosis, my child:

(check one)

had many noticeable self-stimulatory

behaviors (more than 20 throughout the day)

had a moderate amount (about 10 to 20

spread throughout the day)

Stereotypies or self-stimulatory behaviors (stims) are frequent repetitions of movement or posture including, but not limited to, hand-flapping, finger movements, toe walking, rocking, head banging, bouncing, staring at objects, holding objects close to the eyes, peripheral vision, covering ears, making high-pitched or on-going noises, etc.

\section{Toilet training at time of diagnosis:}

14. At the time of diagnosis, my child (check one)

was not toilet trained

had begun toilet training but could not yet manage either urine or bowel control more than $20 \%$ of the time

my child was in the process of being successfully toilet trained (was reliably trained for urine $80 \%$ of the time but not for bowel movements)

my child was successfully toilet trained (successfully self-initiated all toileting tasks $80 \%$ of the time or more)

Professional's description of child's level of functioning at time of diagnosis:

15. At the time of diagnosis, my child was described by an autism/ education professional as:

(check all that apply:)

high functioning

moderately functioning

low functioning

mentally retarded

none of the above

other (please describe: 
Part 3: Please answer the following nine questions about your child's intervention

16. My child has been/was in an intensive discrete trial training program for: years \& months

17. Once the program was up and running, my child averaged the following number of hours of discrete trial therapy each week:

(select one)

one to ten hours

eleven to twenty hours

twenty-one to thirty hours

thirty-one to forty hours

forty-one to fifty hours

fifty-one or more hours

18. I would characterize my child's progress through discrete trial therapy as:

(check one) regressed

no progress

very slow, makes little progress across all areas and sometimes loses skills

in already mastered areas

slow, steady progress

slow in some areas but with good skills in others

moderate, steady progress in all areas

moderate, slow in some areas but easily masters other areas

quick in most areas, has one or two programs that are slow to master

quick and steady, learns quickly and retains new skills easily

other (describe 
19. Once my child was diagnosed with autism (or autism spectrum disorder), how much time passed before he or she actually began discrete trial training?

years and months after diagnosis.

20. If there was a delay between diagnosis and the beginning of discrete trial treatment, what was the reason? (check all that apply)

tried other treatments first (explain: did not know about this treatment option was on a waiting list for consultation could not find a provider could not afford consultation/therapists could not find therapists school or early intervention didn't support this treatment other (please explain

21. If you have ended your child's discrete trial training, how many months/years was he or she actively involved in discrete trial training before stopping? years \& months

22. If you have ended your child's discrete trial treatment, how long has it been since he or she stopped the discrete trial treatment? years \& months

23. If you have ended your child's intensive discrete trial treatment, why did you end it? 
24. What (if any) treatments for autism have you chosen for your child in addition to applied behavioral methods?
Applied behavioral methods, or the uses of applied behavioral analysis, refers to interventions that use methods based on scientific principles of behavior to assess, guide, and monitor interventions to build socially-useful behaviors and to reduce problematic ones.

Treatment:

Duration

Results

Part 4: Now, please answer the following eleven questions describing your child's characteristics and abilities immediately after completing discrete trial treatment.

If your child is currently still in a discrete trial program, or has completed his or her treatment within the last six months, please skip this section and go on to Part 5, question 34.

Speech immediately after treatment:

25. Immediately after treatment, my child had:

(check one)

no meaningful vocal speech

fewer than 10 functional spoken words

10 or more functional spoken words, but not conversational

functional speech, some conversational skills but not yet age-appropriate age-appropriate functional vocal speech

a functional non-vocal communication system

(Please explain:

other

(Please explain: 
Social attachment immediately after treatment:

26. After treatment ended, my child:

(check one)

had little or no typical social attachment

had poor social attachment a majority of the time

had poor social attachment about half the time

had mostly typical social attachment

Toy play immediately after treatment:

27. After treatment, my child:

(check one)

had no typical toy play: all play was unusual, stereotypic and/or repetitive occasionally played typically with toys, but 8 out of 10 times his or her play

as unusual, stereotypic, and/or repetitive)

played typically about half the time, but still had unusual toy play about half the time or less

played with toys like typical children 8 out of 10 times or more often

always plays with toys like a typical child his/her age would

Sensory problems immediately after treatment:

28. Immediately after treatment, my child had:

(check one)

sensory problems that prevented him or her from participating or focusing in expected activities more than ten times a day

sensory problems that prevented him or her from participating in or focusing on expected activities one to ten times a day

sensory problems that rarely prevented him or her from participating in or

focusing on expected activities (not daily, but once in awhile)

no sensory problems that prevented him or her from participating in or focusing on expected activities 
Peer play immediately after treatment:

29. Immediately after treatment, my child:

(check one)

never initiated age-appropriate play with peers

sometimes initiated age-appropriate play with peers, but not like a typically

developing child

often initiated age-appropriate play, played most often (but not always) like

a typically-developing child would

always initiated age-appropriate play with peers

Tantruming immediately after treatment:

30. Immediately after treatment, my child:

(check one)

averaged more than 10 tantrums a day

averaged 5-10 tantrums a day

averaged 1 to 4 tantrums a day

had tantrums once in a while, but not daily

had no tantrums

Stereotypies (stims) immediately after treatment:

31. Immediately after treatment, my child:

(check one)

had many noticeable self-stimulatory behaviors (had more than 20

throughout the day)

had a moderate amount (about 10 to 20 spread throughout the day)

had few noticeable stimulatory behaviors (less than 4 to 5 a day)

had no noticeable stimulatory behaviors 
Toilet training after treatment:

32. Immediately after treatment ended, my child (check one) was not toilet trained had begun toilet training but could not yet manage either urine or bowel control more than $20 \%$ of the time

my child was in the process of being successfully toilet trained (was reliably trained for urine $80 \%$ of the time but not for bowel movements)

my child was successfully toilet trained (successfully self-initiated all toileting tasks $80 \%$ of the time or more)

Professional description of child's level of functioning immediately following treatment:

33. Immediately after treatment ended, my child was described by an autism/ education professional as (check all that apply):

high functioning moderately functioning low functioning mentally retarded recovered none of the above other (please describe:

\section{Part 5: Please answer the next 13 questions about your child's current level of} functioning.

Current speech:

34. At this time, my child has:

(check one) no meaningful vocal speech fewer than 10 functional spoken words more than 10 functional spoken words, but not conversational functional speech, some conversational skills but not yet age appropriate age-appropriate functional vocal speech a functional non-vocal communication system (explain: other (please explain: 
Current social attachment:

\section{Currently, my child:}

(check one)

has little or no typical social attachment

has poor social attachment a majority of the time

has poor social attachment about half the time

has mostly typical social attachment

Current toy play:

36. Currently, my child:

(check one)

has no typical toy play: all play is unusual, stereotypic and/or repetitive

occasionally plays typically with toys, but 8 out of 10 times his or her play is unusual, stereotypic, and/or repetitive) the time

plays typically about half the time, but still has unusual toy play about half plays like typical children 8 out of ten times or more often

\section{Current sensory problems:}

37. Currently, my child has:

(check one)

sensory problems that prevent him or her from participating or focusing in expected activities more than ten times a day

sensory problems that prevent him or her from participating in or focusing on expected activities one to ten times a day

sensory problems that rarely prevent him or her from participating in or $\overline{\text { focusing on expected activities (not daily, but once in awhile) }}$

no sensory problems that prevent him or her from participating in or focusing on expected activities 


\section{Current peer play:}

38. At this time, my child:

(check one)

never initiates age-appropriate play with peers

sometimes initiates age-appropriate play with peers, but not like a typically developing child

often initiates age-appropriate play, plays most often (but not always) like a typically developing child would

always initiates age-appropriate play with peers

Current amount of tantruming:

39. At this time, my child:

(check one)

averages more than 10 tantrums a day

averages 5-10 tantrums a day

averages 1 to 4 tantrums a day

has tantrums once in a while, but not daily

has no tantrums

Current amount of stereotypies (stims):

40. At this time, my child:

(check one)

has many noticeable self-stimulatory behaviors (had more than 20

throughout the day)

has a moderate amount (about 10 to 20 spread throughout the day)

has few noticeable stimulatory behaviors (less than 4 to 5 a day)

has no noticeable stimulatory behaviors 
Current toilet training:

41. At this time, my child

(check one)

is not toilet trained

has begun toilet training but can not yet manage either urine or bowel

control more than $10 \%$ of the time

is in the process of being successfully toilet trained (is reliably trained for urine $90 \%$ of the time but not for bowel movements)

$\%$ of the time or more)

is successfully toilet trained (successfully self-initiated all toileting tasks 90

Recent measures of intelligencelfunctioning:

42. Since the original diagnosis and beginning of treatment, my child has been retested for intelligence or functional abilities:

yes no

If yes, please describe results:

Name/or type of test:

Results:

Professional's description of child's current ability level

43. Currently, my child has been described by an autism/ education professional as: (check all that apply)

high functioning

moderately functioning

low functioning

recovered

mentally retarded

none of the above

other (please describe: 


\section{Outcome Checklist:}

44. My child:

(please check all that apply to your child)

was previously diagnosed with autism or an autism spectrum disorder now has an IQ in the normal range with normal or above normal intellectual functioning no longer has autistic behaviors is indistinguishable from his or her peers now attends school in a regular classroom without supports now displays normal social functioning now displays normal emotional functioning now displays normal vocal functioning

45. If you know a child who has "recovered" from autism, including your own child, what do you think was the single most important skill and/or ability the child possessed BEFORE treatment began that led to his or her recovery?

46. If you were counseling a parent whose child was recently diagnosed with autism, what would be the most important information you could give them?

Any additional comments? 
Part 6: The answers to these questions will be used only to describe, in general terms, the characteristics of the entire group of people who responded to this questionnaire. Answering these questions is optional.

47. Your home is located in a

large urban area

medium-sized city

small town

rural area

other

\section{Your highest level of education:}

did not graduate from high school

high school graduate

completed a technical or trade school

completed a two-year associate degree

attended some college but did not graduate

completed a four-year college or university degree

took some courses toward a postgraduate degree but did not graduate completed a postgraduate degree (describe:

\section{Your approximate age:}

less than 20 years

20 to 29 years

30 to 39 years

40 to 49 years

50 or older

50. Your approximate annual family income:

below $\$ 20,000$

between $\$ 20,000$ and $\$ 39,000$

between $\$ 40,000$ and $\$ 59,000$

$\$ 60,000$ and above 
Part Seven: If you would like to consider participation in any follow-up study based on the results of this study, please indicate your permission to be contacted in the future by filling out the name and address information below. This information will be kept confidential, and if you agree to be contacted in the future your participation will remain optional.

I would like to be contacted if you do future research in this area do not contact me in the future

If yes, please fill out the information below and sign your permission to be contacted in the future.

Name

Address

Signature:

Thank you for completing this survey.

If you are responding by attachment online, please save the new responses and then forward to me (email to sgpoe@juno.com). If you are responding by mail, please put the completed questionnaire in the self-addressed, stamped envelope and mail back to me at your earliest convenience (Susannah Poe, Rt. 2, Box 196A, Fairmont, WV 26554), or fax to 1-304-366-1705. 


\section{Appendix C: \\ Research/ Reports on Prognosis of Outcome from Autism}


Research /Reports on Prognosis of Outcome from Autism

\begin{tabular}{|c|c|c|c|c|c|}
\hline Date & Researcher & $\begin{array}{l}\text { Type of } \\
\text { Research }\end{array}$ & $\begin{array}{l}\text { Sample } \\
\text { Size }\end{array}$ & Description of Research & Outcome/Predictors \\
\hline 1956 & Eisenberg & Follow-up & $\underline{N}=63$ & $\begin{array}{l}\text { Re-evaluation of autistic } \\
\text { children after years, at } \\
\text { mean age of } 5\end{array}$ & $\begin{array}{l}\text { Prognosis varies with } \\
\text { presence of useful } \\
\text { speech at age } 5 \text {, half of } \\
\text { those with speech at } 5 \\
\text { improve }\end{array}$ \\
\hline 1967 & $\begin{array}{l}\text { Rutter, } \\
\text { Greenfeld, \& } \\
\text { Lockyer }\end{array}$ & Follow-up & $\begin{array}{l}\underline{\mathrm{n}}=63 \\
\text { autistic } \\
\underline{\mathrm{n}}=61 \\
\text { control }\end{array}$ & $\begin{array}{l}\text { Researchers followed the } \\
\text { developmental course of } \\
\text { children diagnosed with } \\
\text { autism }\end{array}$ & $\begin{array}{l}\text { Predictors of better } \\
\text { outcome include } \\
\text { meaningful speech by } \\
\text { age } 5, I Q>70, \\
\text { appropriateness of toy } \\
\text { play, and severity of } \\
\text { disorder }\end{array}$ \\
\hline 1968 & Fish & Follow-up & $\underline{\mathrm{N}}=32$ & $\begin{array}{l}\text { Study to determine if } \\
\text { language improved with } \\
\text { the use of medication. } \\
\text { Children sorted into } \\
\text { groups according to } \\
\text { language skills }\end{array}$ & $\begin{array}{l}\text { Outcome, in terms of } \\
\text { school placement, is } \\
\text { related to verbal IQ }\end{array}$ \\
\hline 1972 & Kanner & Follow-up & $\underline{\mathrm{N}}=96$ & $\begin{array}{l}\text { Compared those with best } \\
\text { outcome to those without } \\
\text { good outcome }\end{array}$ & Speech before age 5 \\
\hline 1973 & $\begin{array}{l}\text { DeMyer, } \\
\text { Barton, } \\
\text { DeMyer, } \\
\text { Norton, Allen } \\
\text { \& Steele }\end{array}$ & Follow-up & $\begin{array}{l}\underline{\mathrm{n}}=126 \\
\text { autistic } \\
\underline{\mathrm{n}}=36 \\
\text { sub } \\
\text { normal }\end{array}$ & $\begin{array}{l}\text { Divided into high, middle, } \\
\text { and low functioning } \\
\text { groups and compared } \\
\text { progress }\end{array}$ & $\begin{array}{l}\text { Level of educational } \\
\text { functioning at intake } \\
\text { predicted outcome, } \\
\text { based on these factors: } \\
\text { IQ, severity of } \\
\text { diagnosis, age at } \\
\text { follow-up, EEG }\end{array}$ \\
\hline 1974 & $\begin{array}{l}\text { Gajzago \& } \\
\text { Prior }\end{array}$ & Follow-up & $\underline{N}=2$ & $\begin{array}{l}\text { Report on the functioning } \\
\text { of two autistic children } \\
\text { with good outcome }\end{array}$ & Speech development \\
\hline 1975 & $\begin{array}{l}\text { Harper \& } \\
\text { Williams }\end{array}$ & $\begin{array}{l}\text { Retro- } \\
\text { spective }\end{array}$ & $\underline{N}=131$ & $\begin{array}{l}\text { Children divided into } \\
\text { "acquired" and "natal" } \\
\text { groups based on age at } \\
\text { onset of autism, to } \\
\text { determine if age of onset } \\
\text { defines different } \\
\text { subgroups }\end{array}$ & $\begin{array}{l}\text { Age and type of onset } \\
\text { do not define subgroups } \\
\text { but appear to have } \\
\text { prognostic value in } \\
\text { relation to IQ and } \\
\text { language development }\end{array}$ \\
\hline
\end{tabular}




\begin{tabular}{|c|c|c|c|c|c|}
\hline Date & Researcher & $\begin{array}{l}\text { Type of } \\
\text { Study }\end{array}$ & $\begin{array}{l}\text { Sample } \\
\text { Size }\end{array}$ & $\begin{array}{c}\text { Description of } \\
\text { Research/Report }\end{array}$ & Outcome/Predictors \\
\hline 1975 & $\begin{array}{l}\text { Knoblock \& } \\
\text { Pasamanick }\end{array}$ & Follow-up & $\underline{N}=150$ & $\begin{array}{l}\text { Follow-up study to } \\
\text { determine the relationship } \\
\text { of para-natal } \\
\text { complications and the } \\
\text { development of autism to } \\
\text { see how children } \\
\text { functioned later in life }\end{array}$ & $\begin{array}{l}\text { Found } 3 / 4 \text { of children had } \\
\text { developed social } \\
\text { responses appropriate to } \\
\text { their level of functioning: } \\
\text { IQ is basic factor in } \\
\text { determining eventual } \\
\text { adjustment }\end{array}$ \\
\hline 1979 & Brown & Follow-up & $\underline{N}=100$ & $\begin{array}{l}\text { Selected material on } 100 \\
\text { children who had } \\
\text { profound disturbances in } \\
\text { interpersonal functioning } \\
\text { but average or better } \\
\text { cognitive functioning }\end{array}$ & $\begin{array}{l}\text { Average or better IQ } \\
\text { children had better } \\
\text { potential to overcome } \\
\text { language handicaps, } \\
\text { verbal scores increased, } \\
\text { performance stayed the } \\
\text { same }\end{array}$ \\
\hline 1979 & Lotter & Follow-up & $\begin{array}{l}21 \\
\text { studies }\end{array}$ & $\begin{array}{l}\text { Surveyed } 21 \text { follow-up } \\
\text { studies describing some } \\
\text { aspect of later progress in } \\
\text { children diagnoses as } \\
\text { psychotic_-autistic--at an } \\
\text { early age }\end{array}$ & $\begin{array}{l}\text { Combination of speech } \\
\text { and IQ may be more } \\
\text { useful considered together } \\
\text { than either separately }\end{array}$ \\
\hline 1979 & Rutter & $\begin{array}{l}\text { Retro- } \\
\text { spective }\end{array}$ & $\mathrm{N} / \mathrm{A}$ & $\begin{array}{l}\text { Discussion of his--and } \\
\text { others--clinical experience } \\
\text { and research }\end{array}$ & $\begin{array}{l}\text { Child's quality of play, } \\
\text { level of language } \\
\text { comprehension, and use } \\
\text { of babble important to } \\
\text { prognosis }\end{array}$ \\
\hline 1985 & $\begin{array}{l}\text { Rumsey, } \\
\text { Rapoport \& } \\
\text { Sceery }\end{array}$ & Follow-up & $\underline{\mathrm{N}}=14$ & $\begin{array}{l}\text { Examined psychiatric and } \\
\text { behavioral outcomes in } 14 \\
\text { unusually high } \\
\text { functioning men with } \\
\text { autism }\end{array}$ & $\begin{array}{l}\text { Entire sample continued } \\
\text { to have social } \\
\text { impairments and varied } \\
\text { psychiatric and behavioral } \\
\text { symptoms }\end{array}$ \\
\hline 1987 & $\begin{array}{l}\text { Gillberg \& } \\
\text { Steffenburg }\end{array}$ & Follow-up & $\begin{array}{l}\underline{\mathrm{n}}=23 \mathrm{w} / \\
\text { autism, } \\
\underline{\mathrm{n}}=23 \\
\mathrm{w} / \mathrm{psy}- \\
\text { chosis }\end{array}$ & $\begin{array}{l}\text { Comparison of outcome } \\
\text { for two groups of } \\
\text { children: one autistic, one } \\
\text { with childhood psychosis }\end{array}$ & $\begin{array}{l}\text { IQ at diagnosis }>50 \text { and } \\
\text { communicative speech } \\
\text { before age } 6\end{array}$ \\
\hline 1987 & Lovaas & $\begin{array}{l}\text { Experi- } \\
\text { mental }\end{array}$ & $\begin{array}{l}\underline{\mathrm{n}}=19 \mathrm{tx}, \\
\mathrm{n}=21 \\
\text { control } 1, \\
\underline{\mathrm{n}}=21 \\
\text { control } 2\end{array}$ & $\begin{array}{l}\text { Compared discrete trial- } \\
\text { treated children with those } \\
\text { with fewer hours of } \\
\text { behavioral tx, and those } \\
\text { with none }\end{array}$ & $\begin{array}{l}\text { Of the intensively-treated } \\
\text { group, achieved normal } \\
\text { functioning and all } \\
\text { improved }\end{array}$ \\
\hline
\end{tabular}




\begin{tabular}{|c|c|c|c|c|c|}
\hline Date & Researcher & $\begin{array}{l}\text { Type of } \\
\text { Research }\end{array}$ & $\begin{array}{c}\text { Sample } \\
\text { Size }\end{array}$ & Description of Research & Outcome/Predictors \\
\hline 1987 & Anderson & $\begin{array}{l}\text { Exper- } \\
\text { imental }\end{array}$ & $\underline{\mathrm{N}}=14$ & $\begin{array}{l}\text { Replication of UCLA } \\
\text { project/with } 15-25 \text { hours } \\
\text { of in-home intensive } \\
\text { discrete trial intervention }\end{array}$ & $\begin{array}{l}\text { Higher IQ at time of } \\
\text { diagnosis, imitation of } \\
\text { speech by three months } \\
\text { in treatment }\end{array}$ \\
\hline 1987 & $\begin{array}{l}\text { Lord \& } \\
\text { Schopler }\end{array}$ & $\begin{array}{l}\text { Longitud } \\
\text {-inal }\end{array}$ & $\underline{N}=213$ & $\begin{array}{l}\text { Studied the stability and } \\
\text { reliability of IQ and } \\
\text { developmental test } \\
\text { scores for children with } \\
\text { autism }\end{array}$ & $\begin{array}{l}\text { Very early IQ scores are } \\
\text { better as a predictor that } \\
\text { IQ scores obtained } \\
\text { during the school years }\end{array}$ \\
\hline 1989 & $\begin{array}{l}\text { Szatmari, } \\
\text { et al. }\end{array}$ & $\begin{array}{l}\text { Follow- } \\
\text { up }\end{array}$ & $\underline{N}=16$ & $\begin{array}{l}\text { Selected } 6 \text { higher } \\
\text { functioning children } \\
\text { from group of } 800 \text { with } \\
\text { autism, looked for } \\
\text { predictors of outcome }\end{array}$ & $\begin{array}{l}\text { Higher IQ before } \\
\text { treatment and non-verbal } \\
\text { problems-solving skills }\end{array}$ \\
\hline 1991 & Gillberg & $\begin{array}{l}\text { Follow- } \\
\text { up }\end{array}$ & $\underline{\mathrm{N}}=23$ & $\begin{array}{l}\text { Review of past research } \\
\text { and author's study of } \\
\text { Swedish children }\end{array}$ & $\begin{array}{l}\text { IQ }>56 \text { and } \\
\text { communicative speech } \\
\text { before age } 6 \text { led to best } \\
\text { outcome }\end{array}$ \\
\hline 1991 & $\begin{array}{l}\text { Harris, } \\
\text { et al.. }\end{array}$ & $\begin{array}{l}\text { Pre and } \\
\text { post tests }\end{array}$ & $\begin{array}{l}\underline{\mathrm{n}}=9 \mathrm{w} / \\
\text { autism, } \\
\underline{\mathrm{n}}=9 \text { in } \\
\text { control } \\
\text { group }\end{array}$ & $\begin{array}{l}\text { Preschool children with } \\
\text { autism and typical peers } \\
\text { compared on IQ and } \\
\text { language scales before } \\
\text { and after one year of } \\
\text { school }\end{array}$ & $\begin{array}{l}\text { Autistic children in } \\
\text { language-enriched } \\
\text { school environment } \\
\text { showed greater increases } \\
\text { in intellectual progress } \\
\text { that typical control } \\
\text { group }\end{array}$ \\
\hline 1992 & $\begin{array}{l}\text { Kobayashi, } \\
\text { Murata \& } \\
\text { Yoshinga }\end{array}$ & $\begin{array}{l}\text { Follow- } \\
\text { up }\end{array}$ & $\underline{N}=210$ & $\begin{array}{l}\text { Follow-up survey of } \\
\text { adults who had intensive } \\
\text { therapeutic involvement } \\
\text { as children }\end{array}$ & $\begin{array}{l}\text { Higher IQ was a good } \\
\text { predictor of outcome, } \\
\text { speech (especially in } \\
\text { females) was not }\end{array}$ \\
\hline 1995 & Drash & $\begin{array}{l}\text { Experi } \\
\text { mental }\end{array}$ & $\underline{\mathrm{N}}=12$ & $\begin{array}{l}\text { Modified UCLA-type } \\
\text { outpatient behavioral } \\
\text { treatment program }\end{array}$ & $\begin{array}{l}\text { Found the best outcomes } \\
\text { with young children, } \\
\text { those with more } \\
\text { language and fewer } \\
\text { behavioral problems }\end{array}$ \\
\hline 1997 & $\begin{array}{l}\text { Smith, } \\
\text { Eikeseth, } \\
\text { Klevstrand } \\
\text { \& Lovaas }\end{array}$ & $\begin{array}{l}\text { Follow- } \\
\text { up }\end{array}$ & $\begin{array}{l}\underline{\mathrm{n}}=11 \\
\text { inten- } \\
\text { sively } \\
\text { trained, } \\
\underline{\mathrm{n}}=11 \\
\text { control }\end{array}$ & $\begin{array}{l}\text { Used intensive } 1: 1 \\
\text { treatment with lower } \\
\text { functioning children } \\
\text { with autism/MR }\end{array}$ & $\begin{array}{l}\text { Children with lower IQ } \\
\text { at time of treatment } \\
\text { make improvement, but } \\
\text { not as much as higher IQ } \\
\text { children }\end{array}$ \\
\hline
\end{tabular}




\begin{tabular}{|c|c|c|c|c|c|}
\hline Date & Researcher & $\begin{array}{l}\text { Type of } \\
\text { Study }\end{array}$ & $\begin{array}{l}\text { Sample } \\
\text { Size }\end{array}$ & Description of Research & Outcome/Predictors \\
\hline 1997 & $\begin{array}{l}\text { Smith \& } \\
\text { Lovaas }\end{array}$ & $\begin{array}{l}\text { Impress- } \\
\text { ions based } \\
\text { on UCLA } \\
\text { project }\end{array}$ & $\mathrm{N} / \mathrm{A}$ & $\begin{array}{l}\text { Impressions after success } \\
\text { of UCLA studies }\end{array}$ & $\begin{array}{l}\text { First sign that a child will } \\
\text { have a poorer outcome is } \\
\text { difficulty acquiring speech } \\
\text { during the first five months } \\
\text { of treatment }\end{array}$ \\
\hline 1998 & $\begin{array}{l}\text { Sheinkopf \& } \\
\text { Seigel }\end{array}$ & Follow-up & $\begin{array}{l}\underline{n}=11 \mathrm{tx} \\
\text { group } \\
\underline{\mathrm{n}}=11 \\
\text { control in } \\
\text { matched } \\
\text { pairs }\end{array}$ & $\begin{array}{l}\text { Partial replication of } \\
\text { UCLA study, comparing } \\
\text { matched pairs, one child } \\
\text { in intensive DTT and the } \\
\text { other not receiving } \\
\text { intensive services }\end{array}$ & $\begin{array}{l}\text { Seven of the } 11 \text { children } \\
\text { receiving intensive } \\
\text { behavioral treatment had } \\
\text { better outcome than their } \\
\text { match }\end{array}$ \\
\hline 1999 & Eikeseth & $\begin{array}{l}\text { Experi } \\
\text { mental }\end{array}$ & $\underline{\mathrm{N}}=12$ & $\begin{array}{l}\text { Replicated and extended } \\
\text { Lovaas' work by } \\
\text { providing intensive } \\
\text { behavioral treatment to } \\
\text { "older" children, ages 4- } \\
7\end{array}$ & $\begin{array}{l}\text { Children ages } 4-7 \text { can } \\
\text { also benefit from } \\
\text { intensive behavioral } \\
\text { intervention }\end{array}$ \\
\hline 1999 & $\begin{array}{l}\text { Greenspan } \\
\& \text { Weider }\end{array}$ & $\begin{array}{l}\text { Review of } \\
\text { cases }\end{array}$ & $\underline{N}=200$ & $\begin{array}{l}\text { Children divided into } \\
\text { four groups based on } \\
\text { ability and affect: based } \\
\text { on Greenspan's DIR } \\
\text { model }\end{array}$ & $\begin{array}{l}\text { Child's early response to } \\
\text { treatment is a predictor } \\
\text { of outcome; ability to } \\
\text { sequence actions and } \\
\text { have ability to imitate }\end{array}$ \\
\hline 1999 & $\begin{array}{l}\text { Koegel, et } \\
\text { al. }\end{array}$ & $\begin{array}{l}\text { Experi } \\
\text { mental } \\
\text { based on } \\
\text { follow-up }\end{array}$ & $\mathrm{N}=7$ & $\begin{array}{l}\text { Identified target } \\
\text { behaviors that, if taught, } \\
\text { would result in more } \\
\text { favorable outcomes }\end{array}$ & $\begin{array}{l}\text { Reviewed old tapes/ } \\
\text { follow-up experiment } \\
\text { indicated that children } \\
\text { who presented with high } \\
\text { initiation, low self-stim } \\
\text { behaviors, toy play, and } \\
\text { some pretend play have } \\
\text { better outcomes }\end{array}$ \\
\hline 1999 & $\begin{array}{l}\text { Sallow \& } \\
\text { Graupner }\end{array}$ & $\begin{array}{l}\text { Experi } \\
\text { mental }\end{array}$ & $\underline{N}=24$ & $\begin{array}{l}\text { First year response in a } \\
\text { three year replication } \\
\text { study of UCLA's '87 } \\
\text { studies }\end{array}$ & $\begin{array}{l}\text { Higher pre-treatment IQ } \\
\text { and other significant } \\
\text { tests of ability can } \\
\text { indicate better } \\
\text { prognosis; child's ability } \\
\text { to imitate (especially } \\
\text { sounds) }\end{array}$ \\
\hline 1999 & Smith & $\begin{array}{l}\text { Review of } \\
\text { early } \\
\text { interven- } \\
\text { tion } \\
\text { effects }\end{array}$ & N/A & $\begin{array}{l}\text { Review of 12-peer } \\
\text { reviewed outcome } \\
\text { studies }\end{array}$ & $\begin{array}{l}\text { In ABA treatment, } \\
\text { relatively high- } \\
\text { functioning children } \\
\text { make largest gains }\end{array}$ \\
\hline
\end{tabular}




\begin{tabular}{|c|c|c|c|c|c|}
\hline Date & Researcher & $\begin{array}{l}\text { Type of } \\
\text { Study }\end{array}$ & $\begin{array}{l}\text { Sample } \\
\text { Size }\end{array}$ & Description of Research & Outcome/Predictors \\
\hline 1999 & Weiss & $\begin{array}{l}\text { Retros- } \\
\text { pective }\end{array}$ & $\underline{\mathrm{N}}=20$ & $\begin{array}{l}\text { Looked at how rate of } \\
\text { learning in first two years } \\
\text { correlated with treatment } \\
\text { outcome }\end{array}$ & $\begin{array}{l}\text { Early learning rates may } \\
\text { predict outcomes }\end{array}$ \\
\hline 2000 & $\begin{array}{l}\text { Smith, } \\
\text { Groen, \& } \\
\text { Wynn }\end{array}$ & $\begin{array}{l}\text { Experi } \\
\text { mental }\end{array}$ & $\underline{\mathrm{N}}=15$ & $\begin{array}{l}\text { Compared intensive } \\
\text { treatment with parent training } \\
\text { in similar groups of children } \\
\text { with Pervasive } \\
\text { Developmental Disorder } \\
\text { (PDD) }\end{array}$ & $\begin{array}{l}\text { Intensively-treated group } \\
\text { out-performed parent } \\
\text { training group in measures } \\
\text { of intelligence, visual- } \\
\text { spatial skills, language, anc } \\
\text { academics but not in } \\
\text { behavior or adaptive } \\
\text { functioning }\end{array}$ \\
\hline
\end{tabular}




\section{Appendix D: \\ Responses to Question 24}




\section{Responses to Question \# 24:}

"What (if any) treatments for autism have you chosen for your child in addition to applied behavioral methods?"

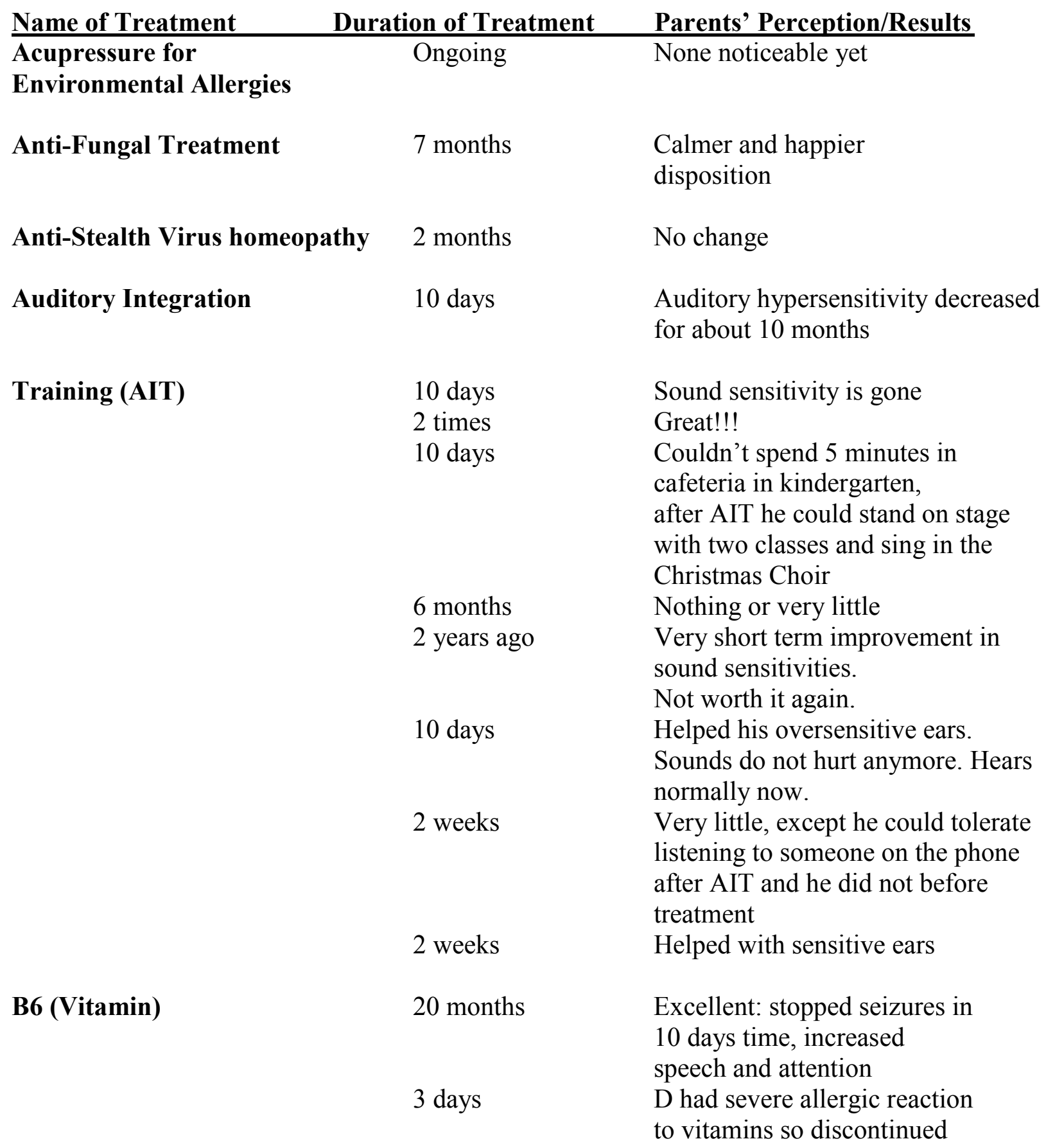

Cod Liver Oil

(Including bethanecol urecholine) 2 years Good 
2.5 months

Communication Therapy

Cranial Osteopathy

Cranial sacral therapy

DAN Protocol/ Tests/ Supp.

Diet Manipulations

DMG

Dr. Goldberg (NIDS)
6 years

4 months

3 months

8 months

1 year

1 year

1 year

Ongoing

6 months

6 months

$1 \mathrm{yr}, 4$ mos.

3 years

Periodically

3 months

2.6 years

6 months

6 months

2-3 months

1 year

1 week

Current

3 years +
Behavior dramatically deteriorated upon administration of bethanol urecholine

Taught him to use augmentative communication --he has learned to be a good communicator Better speech, articulation Very promising, calmer, more connected, new words

Evens out his behavior Good

Increased eye contact and socialization, better ability to focus and think clearly during therapy, less irritation Showed us that he has a yeast infection that is very hard to get rid of

We are seeing great results

No change

None

Wonderful! Fabulous!

Reasonable

Candida diet—very good results! Clears confusion

Made him hyper

Better focus and attending Better language, but no regression since stopping Initially thought we saw good results, then limited so we discontinued

None

Better eye contact

Very hyperactive!

Great

Fantastic. A major reason for our son's full recovery. 
Fast Forward

Flax Seed Oil

Floor Time/Play Therapy (Developmental)
3 months

6 weeks

8 weeks

3 years

2.7 years

7 days a week

1 year

8 months

1 yr, 4 mos.

Current

6 months

2 years

$1 \mathrm{hr} / 2 \mathrm{x}$ week

2.5 years

8 weeks

7 months

2 years

4 months

1.5 years

1 year

10 months
Helped a little with receptive language

Good improvement in auditory processing

Progressed in auditory processing skills...11 months in auditory comprehension and 9 months in expressive communications

Excellent progress in speech

Excellent, great behavior control

Excellent

Progress

Good

Excellent

Good

No change

Little progress

Excellent

Got his attention. I'm noticing more results, but I think it's because skills are also targeted in $\mathrm{ABA}$

Excellent

No improvement

Follow-up testing has shown it is still present—we are consulting a nutritionist

Good

None

Increased eye contact and socialization. Better ability to focus and think clearly during therapy. Less irritation.

Most stereotypies gone, hyperactivity down $95 \%$, language increased $100 \%$, attentive, enabled much more progress in ABA program Great 
2.5 years

9 months

$1 \mathrm{yr}, 3 \mathrm{mos}$

9 months

5 months

Daily

3 months

7 months

1.5 years

More than 2 years

4 months

7 years

4 months

2 years

Grapeseed Extact

Gym class with other children

Heavy Metal Detox

(including chelation)

Homeopathy

Current
Had to wait for Zoloft to kick in so he would eat different foods, but has helped with constantly runny nose, and dark black or red circles under his eyes.

Cannot exclude small benefitbehavior improving with and without gluten

Excellent, especially gastrointestinally Initial improvement, but once wheat/milk reintroduced, no regression

Decreased stereotypies, increased language?

Appears to help health and behavior (bowels hardened)

Much more "with it," more eye contact, more talking

Marked decrease in self-stim behaviors, and oppositional behaviors, particularly at school, more alert, tuned in, oriented $100 \%$ better

No change

Good loss of language skills when on dairy products

We built up to this. We began with milk free diet at two years due to allergies. We live GFCF...Excellent results

change in behavior for better-sleeps better, too

Less hyper, stopped getting eczema on his legs, more eye contact

Increased attention

Good

Very good

No change

1 time Constit. Imp.
Some behavioral improvements 
3.5 years

Horseback Riding

Immune gamma globulin

Medications

Depakote

Luvox

Melatonin

Peptide enzymes

Probiotic/

digestive enzymes 3 years

Prozac

Risperdol

Serotonin drops

Zoloft

Music therapy

Piano Lessons
1 year

6 months
6 months

Currently

3 months

6 months

$1 \mathrm{x}$ week

15 months

1 year

1 year

2 yrs, 8 mos.

4 years

2 months

6 months

1 year

3 months

14 months

2 months

3 years now
Great decrease in SIB's. Improved speech/verbalization. No more ear infections or antibiotics.

Good

None

Got his attention

No effects

Excellent results, great

improvements in speech, eye contact, and is increasingly social

Very good, though not long term

Some benefit to control OCD, hyperactivity

Extremely effective - we didn't know he was having absence seizures - when he kicked out we just assumed it was part of his autism. Before Depakote we had a very small window to teach through, after, we had a doorway.... Happier and less obsessive Much improved sleep - all through the night

No change

We began three years ago and we are about 14\% from recovery

Very effective

No change

Horrible

Very effective

No change

Extremely effective, esp with repetitive behavior and even got rid of migraine headaches

He likes this

Helpful with fine motor skills, he loves it 
Neural Organization Technique

(NOT)

1 year

3 months

Neurofeedback

Neuropathic Remedies

Occupational Therapy
2 years

2 years

4 years

2 years

14 months

$4 \mathrm{x}$ a week

1.5 years

4 years

$1 \mathrm{hr} /$ week

Ongoing

Ongoing

3.5 years

1 year

3 years

Currently

2 years

6 years

3 years

5.5 years
This is the \#1 intervention that has enabled everything else we have tried to work. It is a holistic treatment for the whole person

Gaining control of BM's for Toileting, improved focus and speech, decreased tantruming, esp. at school

Good. Neutralizes food sensitivities, opens pathways in the brain

Okay

Helps some, but not that much

No change

Fair to good

Progress

Helped with sensory problems, trained us to work on those areas in our home program

improved fine motor skills

Good results/OT room very reinforcing

Many positive results in area of sensory integration

Improved sensory integration, fine motor, balance

Improved ability in gross and fine motor skills. Now pedals a tricycle and is beginning with training wheels. Knows how to form letters and numbers but has poor hand control. Is no longer afraid of everything.

Excellent

Very good

Improvement in motor skills

Gross motor much improved, fine motor quite improved

Moderate gains

Not as tactile defensive

Okay 
3x week

\section{PECS (Picture \\ Exchange Comm. System)}

Physical therapy

Pivotal Response Training

(Koegels)

\section{Positive Behavior Support}

Secretin

\author{
10 months \\ 3 months \\ 6 months \\ 9 months
}

1.5 years

2.7 years
6 months
5 years
$1 \mathrm{hr} /$ week

Currently

6 years

2 years

2 years

3 years

1.5 years

One infusion

15 months

3 infusions

9 months

5 weeks (oral)

1 shot
Got his attention

Began speaking

Good

Excellent-language progressed to

the point of no longer needing it

Excellent/not needed anymore. Child

has gone from little speech to

complete sentences including

initiating communication

Good

Good

No longer needs these services

Improved gross motor skill

Excellent-less sensory defensive, stronger, more confidence, more capable (would like more)

No change

Moderate gains

Okay

\section{Excellent}

Excellent

\section{Excellent}

None

Significant results - improved so much that he no longer required a self-contained classroom setting for children with autism. Even his teachers and therapists were amazed. Excellent the first shot, good the second, ok the third (not as much improvement noted) Some positives regarding "with itness", but no language development Did not tolerate well, increased hyperactivity, peaked in third week (seemed to have positive results in boys)

No noticeable improvement 
3 infusions

Ongoing

One dose

2 years

2 times

\section{Self Management}

Sensory Integration

Special Ed (including Preschool) 3 years

18 months

Better eye contact, socialization, sleep gastrointestinal issues (now daily transdermal)

Better eye contact and language

No change

Formed stool, sleeps through night, improved socialization

Increased eye contact, helped him go from 4 urine accidents a week to none. Made him quite hyper for weeks, so we did not continue.

2 years

$15 \mathrm{hrs} /$ week

6 months

6 months

2 years

2 months/ongoing

1 year, 4 mos

9 months

1 yr., 2 mos.

$1 / \mathrm{hr}$ week

5/week

Currently

1 year

6 years

Ongoing
Very good

Helped a lot with sensory issues

No change

Slight improvement so far

Excellent

Helped his nervous system a great deal, set stage for success in DTT Increased postural strength and coordination

Excellent, less sensory defensiveness, more confidence, stronger. More capable

Very good, really got him over his sensory problems and made it easier for him to attend in ABA

Loves to be touched now. His selfstimming has been dramatically reduced.

No change

Wonderful! Fabulous!

Moderate gains

I believe this therapy coupled with tabletop ABA was what brought T's speech back

Helped him get used to a school routine, although he learned more in DTT than he did in school Small gains in tolerating change/sensory issues Good for social skills/have a peer model and mostly 1:1 academic 
1 year

4 years

1 year

Speech/Language

Pathology/Therapy work. Teacher consults with my Certified Behavior Analyst.

Increase in social overtures to staff and peers

Gaining

No noticeable improvement

10 months

2.7 years

4 years

$3 \mathrm{lhr} /$ week

3 years

4 years

4 years

2 years

2 years

4 years

$2 \mathrm{hrs} /$ week

$5 \mathrm{hrs} /$ week

$4 \mathrm{hrs} /$ week

3.5 years

1 year

1 year

3 years

Currently

Ongoing

$4+$ years

2.5 years

3.5 years
No significant progress; mostly Generalization from home ABA program

Nice progress, helps him generalize what he's learning at home in discrete trials

Okay

Useful, but varies between therapists

Progress

Good

Good progress

Good, works best with 1:1 training

Excellent

Not as effective as DTT, speech therapists traditional approach to teaching does not reach our kids... don't allow for processing delays Helped with pronunciation, verbal skills, slow steady gains Moderate progress as in ABAspeech teacher did naturalistic teaching

Excellent

Great! Learns valuable language skills

Uses verbal language. Has a good deal of perseverative speech. Uses pronouns correctly, working heavily on pragmatics.

Steady improvement

Excellent

Good

Use of computer programs very motivating Much improved Has gained functional speech Excellent

very good 
SuperNuThera

(Vitamin Supplement) 89 months

2.6 years

2-3 weeks

6 months

4 months

2 months

4.4 years

\section{Supplements (other)}

VRS Nutritional

Pfeiffer Treatment Center-

zinc def/imbal. 10 months

2.5 years

4 years

TEACCH

Therapeutic Listening calmer

TMG (Improved DMG)

Typical preschool

Total Communication

Language Program

Verbal Behavior

Vitamin Therapy

(Rimland and other)
10 months

6 hrs a day

7 months

3 months

1 month

3x week

1.5 years

1 month

1yr, 6 mos.

3.6 years

1 year
Excellent. He needs Vitamin B6, this multivitamin in best

Better focus and attention

No noticeable results

No noticeable changes

Decreased stereotypies, increased

attention to people and appropriate

behavior

Not sure yet

He began to speak four weeks after he began SuperNuThera

\section{No Change}

Huge improvement in impulsivity/self-awareness/cognition and language

$100 \%$ better

Excellent, more focus, more speech, less behaviors

None

Still going on

Good. Better sleep, eye contact,

Using on advice of pediatrician to increase serotonin levels

Think it makes her hyper, probably will discontinue

Good

Very slow progress

Very good

Seems to stim less

Helps with functioning/language

No change 
7 months

6 months

6 months

6 months

3 years

Wilbarger Protocol

Yeast Control Medication

(including Nystatin)

Yeast Treatment
6 months

1 year

Over two years

2 years

Ongoing

7 months
Calmer

No real change

Very good

Not sure

Wonderful! Fabulous!

Ineffective

No change

Very good

Cuts down on stimming and silly behavior

Yeast levels recently tested normal. Noted increased stimming 
Appendix E:

Responses to Question 45 
Responses to Question 45: If you know a child who has "recovered" from autism, including your own child, what do you think was the single most important skill and/or ability the child possessed BEFORE treatment began that led to his or her recovery?

- The ability to imitate interactions

- Staying connected

- I don't believe there is any one skill or ability that leads to recovery.

- Willingness to learn-smart kid

- Ultimately the recovery is due to the autism itself-how severe, the reason it developed, etc. I believe that children who develop autism as a result to toxins or vaccinations, will seem much better when this gets out of their systems.

- The characteristic most observable in the child I know who recovered was tantrums! Also, once treatment started, the same child was able to learn to imitate speech very quickly.

- The want, and most have none.

- The ability to play or have language prior to therapy.

- That they progressed and developed normally prior to the age of 12 months

- That they developed normally in the first twelve months of life.

- He was very intelligent and responded quickly to primary reinforcers.

- Curiosity

- GFCF diet

- Intelligence

- Persistence

- You could "woo" my child into something. And most importantly, he could learn in a 1:1 format.

- Receptive language

- The ability to process verbal information

- High functioning status and some words or babbling

- Ability to verbally imitate and do non-verbal imitation

- (Having) five words at age 2.5 would be our answer

- A desire to please!

- The ability for him to pay attention to us even if just for short periods of time.

- The ability to speak and process language.

- Exceptional verbal skills

- Good eye contact, outgoing personality, early intervention

- Some social skills and compliance and/or willingness to learn

- Normal brainwave activity, very good receptive language and no severe sensory impairments, they also need dedicated parents and therapists and someone in the family that has a very large disposable income...

- Eye contact, less tantrums, more language

- A child who is more easily reinforced

- Intact intellectual ability was apparent to me despite low IQ scores in some areas.

- Speech

- Some echolalia, no sensory issues.

- The ability to speak 


\section{Appendix F: \\ Content Analysis of Question 46}


Responses to question 46: "If you were counseling a parent whose child was recently diagnosed with autism, what would be the most important information you could give them?"

\begin{tabular}{|l|}
\hline Key: \\
\hline ABA/discrete trial--yellow \\
\hline Waiver--red \\
\hline Get started as soon as possible-- grey \\
\hline Read/learn--dark green \\
\hline Find a DAN doctor--light blue \\
\hline Join a support group--olive \\
\hline Speech/language--green \\
\hline GFCG diet--purple \\
\hline Preschool--brown \\
\hline Suggested books---underlined \\
\hline \hline Trust your instincts--italics \\
\hline
\end{tabular}

- There is now a medical waiver you can get to help pay for treatment. Get intensive discrete trial training as soon as possible. Get IVIG as soon as possible.

- Tell them about ABA and vitamin therapy.

- To get help right away. Start a home program, even if you have to do all the therapy yourself! Read everything you can find, especially "Let Me Hear Your Voice" by Catherine Maurice.

- They must do discrete trial. Don't give up hope, there is light at the end of the tunnel.

- Get into an ABA program ASAP

- Get an ABA program going as soon as possible. 2. Try the gluten/casein free diet. 3. Find a DAN doctor who can run tests to find out if there are any biological problems.

- Good evaluation. Immediate intensive intervention (25-40 hours of ABA, 4-5 hours of Sensory Integration, 4-5 hours of speech, physical therapy if necessary. Try diet/secretin if health permits. Be a constant advocate; go online to learn all you can. Go with your instincts!!!!

- Contact and join the ASA, join autism Email lists, read the autism books by Powers, Gerlach, and read "Let Me Hear Your Voice" and "The Me Book."

- Get early intervention as soon as possible. I would recommend behavioral therapy and preschool, with an IEP in place.

- To get help from the local region agency (Easter Seals), and then to investigate the possibility of ABA therapy. My son was helped initially by Easter Seals, but the most progress has been while having a daily ABA program. Also preschool is important for the socialization, but ABA should first be introduced to give the child coping skills to actually tolerate attending preschool with other peers.

- Get respite, speech, and DTT services immediately. The child won't like any of it but they are all needed to help the child succeed. Don't let anyone sideline you by saying your child doesn't qualify, won't be helped, or will grow out of it. Trust your instincts. You know your child better than anyone else.

- $\mathrm{ABA}$ and specifically Verbal Behavior have been the most important aspects of treating our son's autism (along with the GFCF diet). 
- Start ABA now. Have a Certified Behavior Analyst to ensure quality, Also include a naturalistic environment teaching as described by Sundberg and Partington as a piece of the program.

- Use visual supports and augmentative communication supports from Day One!

- There is hope, and demand the same degree of empiric evidence behind your child's autism treatment as you would for cancer treatment.

- Start an ABA program as soon as possible. Starting early is very important.

- Start ABA from Day One and intensively and have good therapists. Apply ABA principles at all times. School should be ABA, too.

- I would tell them to try to keep their child engaged in appropriate behavior and life. I would encourage them to have their child assessed by a behavior analyst and definitely consider discrete trial therapy techniques. I would encourage them to seek support and not try to handle it alone.

- Don't waste precious energy on "why?" Just set small reachable goals for your child so they will succeed and build upon them- "one day at a time"

- Information about DTT: how a program is run and service providers.

- There is hope for a bright future for their child. The I would tell them about the GCFC diet, to get an EEG, to consider the DAN Protocol to get the chemistry in their child straightened out, to get signed up for Title 19, to get attached to a support group, to consider DTT of they feel it is right for their child, and to remember that they will get overwhelmed, but to take all the information they get and try to prioritize it to what their child seems to need, and start with first things first.

- Try ABA first. Don't be afraid of treatments because they seem "alternative," but do be careful not to be taken - we are a vulnerable group!

- Begin ABA ASAP and do it for at least 30 hours a per week.

- I would advise them to do a proper, intensive ABA program with expert supervision.

- Read Catherine Maurice's “Let Me Hear Your Voice.” Research the Internet, but don't feel you have to try everything at once.

- Start an ABA program as early as possible.

- Obtain good support services and intensive early intervention. If not available in your area, then relocate for the good of the child. ABA (if the child does well with it), speech therapy, OT (if applicable), and respite (for the parent's sake), involvement in the community, and address self-help skills.

- Educate yourself, to the extent possible, on what this disorder is and what your options and resources are in your area. You must find a way to provide the best services possible for your child. These services are not advertised. Be skeptical of the latest "cure of the month" stories. But, the single most important thing is to start providing your child services NOW!

- Find a good school. Get a good nanny (this is important for middle-class Filipino families, obviously). For poor families, apply for a scholarship to a good school.

- Do behavioral therapy.

- Diet first, ABA second, but do both NOW!

- Referral to DTT consultant. Let them know that the child can improve with intensive treatment and although it is a lot of work, the whole family benefits.

- Start the diet and ABA and be patient. Also, be creative! (Not to mention persistent!) A good ABA program requires constant re-evolution and problem solving. Don't allow much time to 
go by without some sort of progress, All children can improve if you find the way they learn best.

- Research all treatment options and select the one that they feel would benefit their child the most. Most importantly, follow their child's lead.

- Start a discrete trial training program immediately!

- Get started with an ABA program immediately — preferably a verbal behavior program using the ABLLS assessment tool to determine objectives.

- To find a DAN certified doctor and begin biomedical treatment as soon as possible, begin an intensive 1:1 program and see a developmental pediatrician that can lead you in the right direction for other treatments such as Occupational Therapy that may be needed.

- Start an ABA program! Get started as soon as possible and be as persistent and consistent as you can be.

- Read "Let Me Hear your Voice," call UCLA/or an authorized provider with ABA/DTTUCLA model.

- Check all the options: diet, vitamins, meds

- Start ABA now!

- Start Lovaas'-based ABA as soon as possible and once the child is under instructional control, echoic and imitative, switch to Verbal Behavior.

- Start ABA as soon as possible and be HIGHLY involved in the program. Always know what's going on in the program and help the child generalize at all times. Make sure everyone around the child is exercising good behavior modification principles.

- Start ABA as soon as possible and be patient, it does work but it is not easy.

- Location of replication sites/consultants, 2. Phone number of Great Plains Laboratory for yeast/food allergy testing, 3 . Constantly engage your child, 4 . Don't blame yourself.

- Get the child communicating his needs and wants. Work on receptive language all day every day. Work on literacy ASAP.

- Start ABA early. Read and read and don't count on medical or educational professionals to know what your child needs. Get on the Internet. Keep yourself healthy and your family together.

- Start an intensive home based ABA program right away.

- Start ABA as quickly as possible. We waited way too long.

- Get all the information you can. Make connections with professionals and parents.

- Early intervention, get over your own hang ups about the diagnosis, don't dwell on yourself, work on making this child function in this world!

- Get ABA treatment immediately, then look at medical conditions such as allergies, vaccinations, etc.

- To start Sensory Integration therapy immediately; have auditory training if ears are sensitive. Add speech and or a picture communication system. Make sure the program you choose does not include "aversives." Drop by the program frequently and at different times. Remove your child if you see any child being "manhandled."

- Get help immediately. The sooner the better-I have living proof!

- Join FEAT (Families for Early Autism Treatment) - buy a computer or gain access to one immediately. Move to a state where you can have access to a 30 hour+ week professionallyadministered intervention like ABA. Sue if you have to (we did) but try to avoid it by sharing the research and the Surgeon General's Report. Try low cost/low impact additional things on 
your own like a rich sensory diet daily, an elimination diet (read "Is This your child?" by

Doris Rapp), network with other parents and professionals, avoid fads like Secretin until you've read the original research, go to a support group. Find out who's good, professionally, and who to avoid. Read Maurice, Sean Barron, Williams and Grandin to stay inspire. Advocate for and find a family therapist for support. Bug your pediatrician to READ, and if they don't, find one who will. Trust your parenting instincts. Take care of yourself and find a really good babysitter your child likes for time off for you.

- All my internet resources, and to realize that there is a lot of hope for your child, and that you don't need to embark on a 40 hour per week ABA program to save your child. The key is to develop an individualized program with a typical peer setting and to do as much as you can possibly do-but there is no one cure all.

- Get ABA training, and push for as much therapy time as your child can handle. Get on GFCF diet. Get a good speech and OT. Keep copies of everything and a phone log, reports, and correspondence in three-ring binders for easy access. Also keep representative samples of school projects, wiring samples. Take periodic videotape. You want to be able to pull together records quickly. You'll need to do that for every medical appointment, PET meeting, and to appeal adverse decisions. A computer with Internet hookup and a good printer are a must. A cell phone is nice-allows sitters, schools, therapists instant contact. Helps with the insanity of maintaining the hectic life and therapy schedule.

- Read "Let Me Hear your voice" and get as many hours of intervention as possible. Do not believe most school professionals know the best treatment for autism and don't trust them to implement what is most effective (rather than what is most economical for them).

- Applied Behavior Analysis works!!! Get your child into an ABA program ASAP. Be sure to include social skills and playgroups as quickly as possible (our entire program the second year was playgroup oriented). Practice ABA skills at home - don't be afraid to have structure and enforce rules and reward positive behavior. IT WORKS. If you don't maintain ABA at home, you undermine the program.

- Start NOT, which includes dietary intervention, and everything else will fall into place. If the child is older ABA may be needed but I would leave that decision to the NOT provider. If the child is younger, NOT, including dietary intervention, would probably be all the child would need.

- I think consultants should tell parents about the different types of ABA.

- Fight hard to learn about all available treatments, and quickly. Time is very important. Find out which method works for you and your child. Push speech. Take good notes, archive everything. Hire an advocate.

- Don't expect your child to be "fixed." Discrete trial training is valuable and effective for certain skills, behaviors, and children, but it is not a "magic pill." Autism is OKAY!

- Get a diagnosis from a knowledgeable practitioner. Join a support group. Learn as much as you can. Become involved with your child's school. Let the team members of your CPSE and CSE know you are with them, not against them, and let them think the supports you need for your child are their great ideas.

- Start ABA NOW!

- Run, don't walk to see Dr. Goldberg, or another physician using the NIDS protocol. By treating the cause of the problem (a dysfunctional immune system), our son was able to focus, became a bright, happy and alert child and was then able to learn very quickly from his ABA program. As a result of the medical treatment, all of our son's sensory and self-stim 
behaviors are resolved and appropriate play emerged without targeting them in his ABA program. Also, find a very well qualified consultant to supervise your program who will change your home program as your child's needs change (go beyond discrete trial methods once your child is capable and help you generalize his learning.)

- Discrete trial training. Exposure to "normal" children. High expectations of the child. Don't buy into "he has autism he can never..."

- Test them for allergies and remove from diet, secretin infusion (especially if history of gastrointestinal problems) and $\mathrm{ABA} /$ discrete trial therapy for 20-40 hours.

- Information on ABA, PECs, and Positive Behavior Support. Start program as soon as possible. Apply for waiver.

- Start ABA/DTT immediately - the more hours a week the better (30-40+/week)

- To begin ABA as soon as possible. Also start the GFCF diet.

- Focus on teaching the child to initiate - speech, play, etc. Focus on social and emotional development by making the child interact with others, done best with "Floor Time" by Greenspan. Find a friend/peer the child can become close to and learn from (imitate).

- Start ABA therapy as soon as possible. Even if the child doesn't recover, ABA will help substantially in many cases.

- Start ABA now.

- I recommend to everyone ABA, whether your child is high or low functioning. It doesn't matter. And a classroom of typical peers for preschool. Life was passing my son by. I knew he was capable or learning a lot more, he just needed the ABA approach. It worked. He has made great gains this year. 